\title{
Mechanism by which dietary polyunsaturated fat regulates lipogenic gene expression
}

\author{
Alison Bloom Kohan \\ West Virginia University
}

Follow this and additional works at: https://researchrepository.wvu.edu/etd

\section{Recommended Citation}

Kohan, Alison Bloom, "Mechanism by which dietary polyunsaturated fat regulates lipogenic gene expression" (2009). Graduate Theses, Dissertations, and Problem Reports. 2889.

This Dissertation is protected by copyright and/or related rights. It has been brought to you by the The Research Repository @ WVU with permission from the rights-holder(s). You are free to use this Dissertation in any way that is permitted by the copyright and related rights legislation that applies to your use. For other uses you must obtain permission from the rights-holder(s) directly, unless additional rights are indicated by a Creative Commons license in the record and/ or on the work itself. This Dissertation has been accepted for inclusion in WVU Graduate Theses, Dissertations, and Problem Reports collection by an authorized administrator of The Research Repository @ WVU.

For more information, please contact researchrepository@mail.wvu.edu. 
Mechanism by which Dietary Polyunsaturated Fat Regulates Lipogenic Gene Expression

\author{
Alison Bloom Kohan \\ Dissertation submitted to the \\ School of Medicine \\ at West Virginia University \\ in partial fulfillment of the requirements \\ for the degree of
}

Doctor of Philosophy

in

Biochemistry and Molecular Biology

Lisa Salati, Ph.D., Chair

Michael Miller, Ph.D.

Yehenew Agazie, Ph.D.

Steven Frisch, Ph.D.

Fred Minnear, Ph.D.

Department of Biochemistry

Morgantown, West Virginia

2009

Keywords: polyunsaturated fatty acids, non-esterified fatty acids, lipogenesis, dietary fat, nutritional regulation of gene expression, primary hepatocytes, chylomicron remnants, dietary triacylglycerol 


\section{ABSTRACT \\ Mechanism by which Dietary Polyunsaturated Fat Regulates Lipogenic Gene Expression Alison Bloom Kohan}

Primary hepatocytes treated with non-esterified polyunsaturated fatty acids have been used as a model for describing the inhibitory effects of dietary polyunsaturated fats on lipogenic gene expression. This model resembles starvation or uncontrolled diabetes but not dietary fat ingestion, which is delivered to liver via chylomicron remnants. Chylomicron remnants enriched with polyunsaturated fatty acids stimulate a unique pattern of intracellular signaling. These remnants enhance p38 mitogen activated protein kinase (MAPK) activity but do not inhibit insulin signaling or induce extracellular-signal related kinase (ERK) or AMP-activated protein kinase (AMPK) activation as do non-esterified polyunsaturated fatty acids. Polyunsaturated fatty acids-enriched remnants and non-esterified polyunsaturated fatty acids both inhibit the rate of fatty acid synthesis and the expression of the lipogenic genes, particularly those regulated by sterol response element binding protein-1c (SREBP-1c). Saturated fatty acid-enriched remnants fail to inhibit the lipogenic genes indicating that the inhibitory action of dietary polyunsaturated fats involves regulatory mechanisms in liver. In contrast, polyunsaturated fatty acids-enriched remnants fail to inhibit malic enzyme, glucokinase, L-pyruvate kinase, and cytochrome P450-7 $\alpha$ (Cyp-7 $\alpha$ ) expression despite their inhibition by non-esterified fatty acids. These genes are regulated independently of SREBP-1c. Therefore, non-esterified polyunsaturated fatty acids do not accurately model all aspects of regulation of hepatic metabolism by dietary fat. 


\section{ACKNOWLEDGEMENTS}

I would like to thank all those people who have supported me throughout my $\mathrm{Ph} . \mathrm{D}$ training. First, I am very thankful for all the help and advice that I have received from my advisor Dr. Lisa Salati in these last 6 years. I have learned how best to teach, learn, and participate in scientific endeavors through her. I appreciate all the time and effort she took to train me from an inexperienced graduate student to the doctoral graduate I am today.

I also want to thank all of my lab mates who have made my work in the lab so much more fulfilling. Callee, Viola, and Sushant have at times been my biggest fan club, my most helpful reviewers, and my best critics. At all times, they have been my friends. Without them, I'm not sure how I could have made it through to my defense. I'll miss our scientific discussions, but also they're daily friendship as I start in a new lab.

Finally, I want to thank my family. Without the continuous support of my parents, my inlaws, and my husband I could not have succeeded at this goal. My husband Mark, especially, has been an incredible source of strength, support, and love throughout this process. He has always reminded me why I chose this path, and he has always helped me to stay on it. Without him, this would not be possible. 
TABLE OF CONTENTS

CHAPTER 1.

I. SIGNIFICANCE OF PUFA IN HUMAN HEALTH

II. POLYUNSATURATED FATTY ACID BIOCHEMISTRY

III. LIPOGENESIS

IV.

V. DIETARY FAT AS A REGULATOR OF LIPOGENESIS

a. TRANSCRIPTIONAL REGULATION BY PUFA 9

i. LIVER X RECEPTORS

ii. PEROXISOMAL PROLIFERATOR-ACTIVATED RECEPTORS

iii. STEROL REGULATORY ELEMENT BINDING PROTEIN-1C

iv. CARBOHYDRATE RESPONSE ELEMENT BINDING PROTEIN

b. POSTTRANSCRIPTIONAL REGULATION OF LIPOGENIC GENES BY PUFA

i. G6PD: REGULATION BY A

POSTTRANSCRIPTIONAL MECHANISM

VI. INSULIN SIGNALING AND ITS REGULATION BY PUFA
a. INSULIN RECEPTOR
b. INSULIN RECEPTOR SUBSTRATES
c. PHOSPHOINOSITIDE 3-KINASE
d. AKT
e. ATYPICAL PROTEIN KINASE C $(\zeta / \lambda)$
f. AMP-ACTIVATED PROTEIN KINASE
g. MITOGEN-ACTIVATED PROTEIN KINASES
h. EXTRACELLULAR SIGNAL-REGULATED KINASE
i. p38 MAPK
j. c-JUN N-TERMINAL PROTEIN KINASE 
VII. PHYSIOLOGY OF LIPID DIGESTION, ABSORPTION, AND UPTAKE BY THE LIVER

a. ANIMAL AND CELL CULTURE MODELS

b. DIETARY LIPID DIGESTION, ABSORPTION, AND HEPATIC UPTAKE

c. FREE FATTY ACID TRAFFICKING ACROSS THE CELL MEMBRANE

VIII. HYPOTHESIS

IX. REFERENCES

X. CHAPTER 2. PAPER IN PRESS - BIOCHEMICAL AND 63 BIOPHYSICAL RESEARCH COMMUNICATIONS

A ROLE FOR AMPK IN THE INHIBITION OF GLUCOSE-6-PHOSPHATE DEHYDROGENASE BY POLYUNSATURATED FATTY ACIDS

XI. CHAPTER 3. PAPER SUBMITTED TO J. LIPID RESEARCH

CHYLOMICRON REMNANTS AND NON-ESTERIFIED FATTY ACIDS EXHIBIT MARKED DIFFERENCES IN THEIR ABILITY TO RECAPITULATE THE INHIBITION OF LIPOGENESIS BY DIETARY POLYUNSATURATED FAT. 


\section{ABBREVIATIONS}

$\mathrm{ACC}$

AICAR

AMP

AMPK

ATP

ATP-CL

bHLH/LZ

cAMP

ChREBP

CPT-1

CREB

CYP7-A1

DAG

DHA

EPA

ER

ESE

ESS

FAS

FXR

G6PD

GK

GLUT 4

GPCR

GS

GSK-3

HDL

HNF4a

HnRNP
Acetyl-CoA carboxylase

5-aminoimidazole-4-carboxamide riboside

Adenosine monophosphate

AMP-activated protein kinase

Adenosine triphosphate

ATP-citrate lyase

Basic helix-loop-helix leucine zipper

Cyclic adenosine monophosphate

Carbohydrate response element binding protein

Carnitine palmitoylacyltransferase-1

cAMP-response element binding protein

Cholesterol-7-alpha hydroxylase

Diacylglycerol

Docosahexaenoic acid

Eicosapentanoic acid

Endoplasmic reticulum

Exonic splicing enhancer

Exonic splicing silencer

Fatty acid synthase

Farnesoid X receptor

Glucose-6-phosphate dehydrogenase

Glucokinase

Glucose transporter 4

$\mathrm{G}$ protein coupled receptor

Glycogen synthase

Glycogen synthase kinase-3

High density lipoprotein

Hepatic nuclear factor-4-alpha

Heterogeneous nuclear ribonucleoprotein 
IR

IRS

JNK

LDL

LOX

LXR

LXRE

MAPK

ME

MEK

MEKK

NADPH

PDH

PDK-1

PDK-4

PEPCK

PFK

$\mathrm{PH}$

PI3K

$\mathrm{PIP}_{2}$

PIP3

PK

PKA

PKB

aPKC

PP2A

PPAR

PPP

PTB

PUFA

RXR
Insulin receptor

Insulin receptor substrate

Jun N-terminal kinase

Low density lipoprotein

Lipoxygenase

Liver X receptor

LXR response element

Mitogen-activated protein kinase

Malic enzyme

MAPK kinase

MEK kinase

Nicotinamide adenine dinucleotide phosphate

Pyruvate dehydrogenase

Phosphoinositide-dependent protein kinase-1

Pyruvate dehydrogenase kinase- 4

Phosphoenolpyruvate carboxykinase

Phosphofructokinase

Pleckstrin-Homology domain

Phosphatidylinositol-3-kinase

Phosphatidylinositol 4,5-bisphosphate

Phosphatidylinositol-3-phosphate

Pyruvate kinase

Protein kinase A

Protein kinase B

Atypical PKC

Protein phosphatase 2A

Peroxisome proliferator-activated receptor

Phosphate pentose pathway

Phosphotyrosine-binding domains

Polyunsaturated fatty acid

Retinoid X receptors 
S-14

S1P

S2P

S6K-1

SCAP

SCD-1

SR proteins

SRE

SREBP-1c

TNF- $\alpha$

TOR

TORC1

TORC2

TSC

UTR

VLDL

$\mathrm{X} 5 \mathrm{P}$
Spot-14

Site-1-protease

Site-2-protease

p70 S6 kinase-1

SREBP cleavage-activating protein

Stearoyl-CoA desaturase-1

Serine and arginine rich domain-containing proteins

SREBP-1c response element

Sterol response element binding protein-1c

Tumor necrosis factor alpha

Target of rapamycin

TOR complex 1

TOR complex 2

Tuberous sclerosis protein

Untranslated region

Very low density lipoprotein

Xylulose-5-phosphate 


\section{CHAPTER I.}

\section{SIGNIFICANCE OF POLYUNSATURATED FATTY ACIDS IN HUMAN}

HEALTH

As the incidence of heart disease, obesity, and type 2 diabetes increases in the United States, diet as a causative and preventative factor has gained attention. Just as it was once necessary to elucidate the obligatory vitamins and macronutrients needed for the body, it is now necessary to determine the proportions and types of fat, cholesterol, and carbohydrates necessary for proper health. Specifically, insight into nutritional control of metabolism and gene expression is quite important if these diseases are to be better understood and for clinical interventions to be improved.

Where these diseases intersect is in the disregulation of metabolism such that insulin signaling and lipid homeostasis are disrupted. It is known that dietary polyunsaturated fatty acids are able to regulate both insulin signaling and their own metabolism (1-3). Therefore it is increasingly important to understand the action of dietary polyunsaturated fatty acids on metabolic processes.

\section{POLYUNSATURATED FATTY ACID BIOCHEMISTRY}

Fatty acids with two or more double bonds are known as polyunsaturated fatty acids. There are two main families of polyunsaturated fatty acids, the $n-3$ and $n-6$ polyunsaturated fatty acids, which are named by the position of the distal double bond relative to the terminal methyl end of the fatty acid (these fatty acids are sometimes also classified in popular literature as omega-3 and omega-6 polyunsaturated fatty acids). Mammals are unable to synthesize the 18carbon precursors of all the necessary $n-3$ and $n-6$ polyunsaturated fatty acids, and $n-3$ and $n-6$ polyunsaturated fatty acids cannot be inter-converted within the cell. Therefore, the 18-carbon $n$ 3 and $n-6$ fatty acids are termed "essential fatty acids" that must be obtained from the diet to support normal metabolism. Linoleic acid (n-6) and linolenic acid (n-3) are the dietary sources of essential polyunsaturated fatty acids. The loss of these fatty acids in the diet results in essential fatty acid deficiency, which results in a loss of integrity of the skin and cell membranes, and an 
inability to synthesize eicosanoids (4). In western diets, the most abundant sources of $n-6$ polyunsaturated fatty acid are safflower, sunflower, and soybean oils. The most abundant sources of $n-3$ polyunsaturated fatty acid are canola and linseed oil, and salmon $(5,6)$. However, both $n-3$ and $n-6$ polyunsaturated fatty acids are present in a variety of foods, including other fish, nuts, and some meat $(7,8)$.

In the endoplasmic reticulum, linoleic and linolenic acid are further metabolized into long-chain highly unsaturated fatty acids to provide substrate fatty acids for the formation eicosanoids, intracellular signaling molecules, structural components of the cell membrane, and for $\beta$-oxidation. Linoleic and linolenic acids undergo sequential desaturation and elongation reactions to form arachidonic and eicosapentaenoic acid, respectively. The conversion of linoleic and linolenic acids to their long-chain highly unsaturated fatty acids involves the fatty acid elongases (ELOVL5 and ELOVL2) and desaturases (delta-6- and delta-5-desaturases)(9). Delta6-desaturase is the rate-limiting enzyme in the metabolism of $n-3$ and $n-6$ polyunsaturated fatty acids to their highly unsaturated fatty acid products (Figure 1)(10).

\section{FIGURE 1.}

\section{METABOLISM OF ESSENTIAL FATTY ACIDS}

n-6 POLYUNSATURATED FATTY ACIDS

LINOLEIC (C18:2n6)

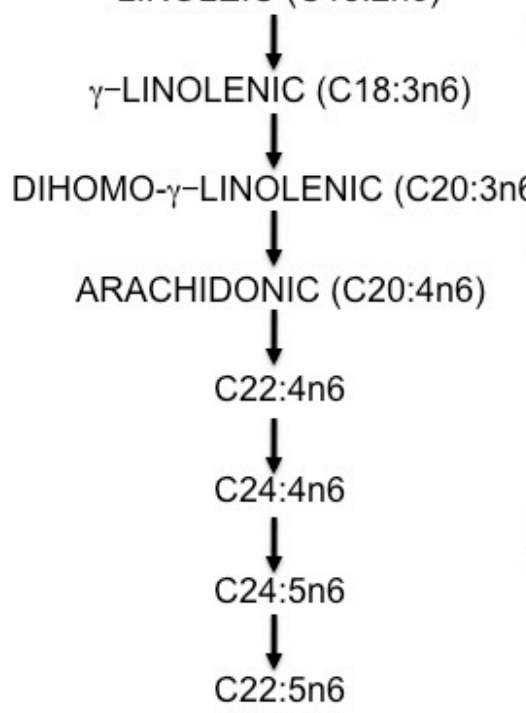

n-3 POLYUNSATURATED FATTY ACIDS

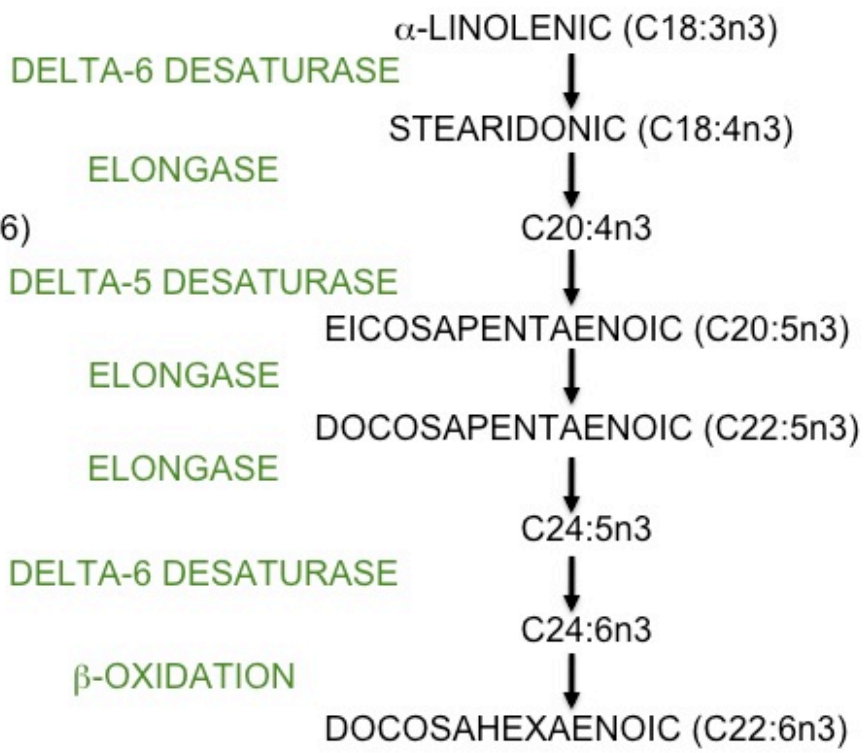


Arachidonic and eicosapentaenoic acids are the 20-carbon precursors of eicosanoids, which are signaling molecules derived through the oxidation of 20-carbon precursor fatty acids. Eicosanoids mediate inflammation in response to cell stress, cytokines, or growth factors. Biosynthesis begins when arachidonic and eicosapentaenoic acids, which are stored in the cytosolic leaflet through their esterification to membrane phospholipids and glycerides, are mobilized by the action of phospholipase A2 to form free arachidonic and eicosapentaenoic acids (11). Arachidonic acid is converted to prostaglandins and thromboxanes by cyclooxygenases, and to leukotrienes by lipoxygenases; these enzymes form the pro-inflammatory eicosanoids. Eicosapentaenoic acid will be converted by cyclooxygenases to anti-inflammatory eicosanoids (9). This is a major difference in the downstream action of the $n-3$ and $n-6$ polyunsaturated fatty acids.

Aside from their roles in eicosanoid metabolism, polyunsaturated fatty acids also mediate cell membrane signaling pathways. When they are esterified to the two-carbon of phospholipids within the cell membrane, they participate in signal transduction pathways involving diacylglycerol. Docosahexaenoic acid, an $n-3$ derivative of linolenic acid, binds to the $\mathrm{G}$ protein-coupled receptor (GPCR) rhodopsion in the retina. There, it is necessary for maintaining the responsiveness of the GPCR to light $(12,13)$. Eicosanoid derivatives of arachidonic acid have also been shown to modulate other GPCRs involved in host defense and inflammatory responses (14).

$n-3$ and $n-6$ polyunsaturated fatty acids are also necessary for maintaining cell membrane function. As the polyunsaturated fatty acid content of the cell membrane increases, so does its fluidity (due to the increase in "kinks" formed by the multiple double bonds of $n-3$ and $n-6$ polyunsaturated fatty acids). In skin, linoleic acid (n-3) is necessary for skin structure and function because it is a component of ceramides (15). In neurons, DHA (n-6) is necessary for supporting cell survival through its binding to membrane phosphotidylserine (16).

\section{LIPOGENESIS}

Lipogenesis is the process by which simple sugars such as glucose are converted to fatty acids, which are subsequently esterified with glycerol to form triacylglycerols. When excess energy is ingested beyond the body's immediate energy needs, the excess energy is converted 
into triacylglycerol through the process of lipogenesis. Conversely, when insufficient calories are ingested, this triacylglycerol is oxidized to make up for the energy deficit. Lipogenesis occurs primarily in liver (where the triacylglycerol is exported to peripheral tissues in VLDL particles), adipose (the major storage site of triacylglycerol), and lactating mammary glands (where triacylglycerol is secreted in milk)(reviewed in 17, 18).

The formation of triacylglycerol requires long-chain fatty acids either obtained from the diet, or synthesized from acetyl-coenzyme A (acetyl-CoA) through a concerted set of reactions that include glycolysis, the citric acid cycle, the pentose phosphate pathway, and fatty acid synthesis. These reactions collectively provide the carbon and reducing equivalents necessary to produce fatty acids that will be esterified to glycerol to form triacylglycerol (Figure 2)(19).

The synthesis of fatty acids by fatty acid synthase (FAS) requires acetyl-CoA, malonyl$\mathrm{CoA}$, and NADPH. Acetyl-CoA is provided from the reactions of glycolysis (which provides pyruvate for the citric acid cycle) and the citric acid cycle (which exports citrate from the mitochondria to the cytoplasm). ATP-citrate lyase (ATP-CL) then catalyzes the conversion of citrate to acetyl-coA and oxaloacetate. The reactions of the pentose phosphate pathway provide NADPH reducing equivalents for the subsequent reactions of fatty acid synthesis. Since the enzymes in these pathways work in concert to provide either substrate or reducing equivalents, these enzymes are termed the lipogenic family of enzymes. Members of the lipogenic enzyme family include malic enzyme (ME), glucose-6-phosphate dehydrogenase (G6PD), acetyl-CoA carboxylase (ACC), ATP-citrate lyase (ATP-CL), and fatty acid synthase (FAS)(10).

Acetyl-CoA carboxylase (ACC) is the rate-limiting enzyme in fatty acid synthesis, and it catalyzes the synthesis of malonyl-coA from acetyl-CoA. ACC is allosterically inhibited by long-chain fatty acids and by AMPK-mediated phosphorylation when cellular AMP levels are high. Malonyl-CoA is the $\mathrm{C} 2$ donor in the de novo synthesis of fatty acids, and it is also an inhibitor of the carnitine-palmitoyl shuttle system for fatty acid oxidation in the mitochondria $(20,21)$.

All subsequent reactions of fatty acid synthesis are carried out by the 4 enzymatic activities of FAS. These include: $\beta$-keto-ACP synthase, $\beta$-keto-ACP reductase, $3-\mathrm{OH}$ acyl-ACP dehydratase and enoyl-CoA reductase. The reduction reactions require the NADPH (20). The primary fatty acid synthesized by FAS is palmitate, which is released from the enzyme to undergo additional elongation and/or desaturation reaction to provide other fatty acids. 
Alternatively, palmitate can become the substrate for triacylglycerol synthesis.

\section{FIGURE 2.}

\section{LIPOGENESIS}

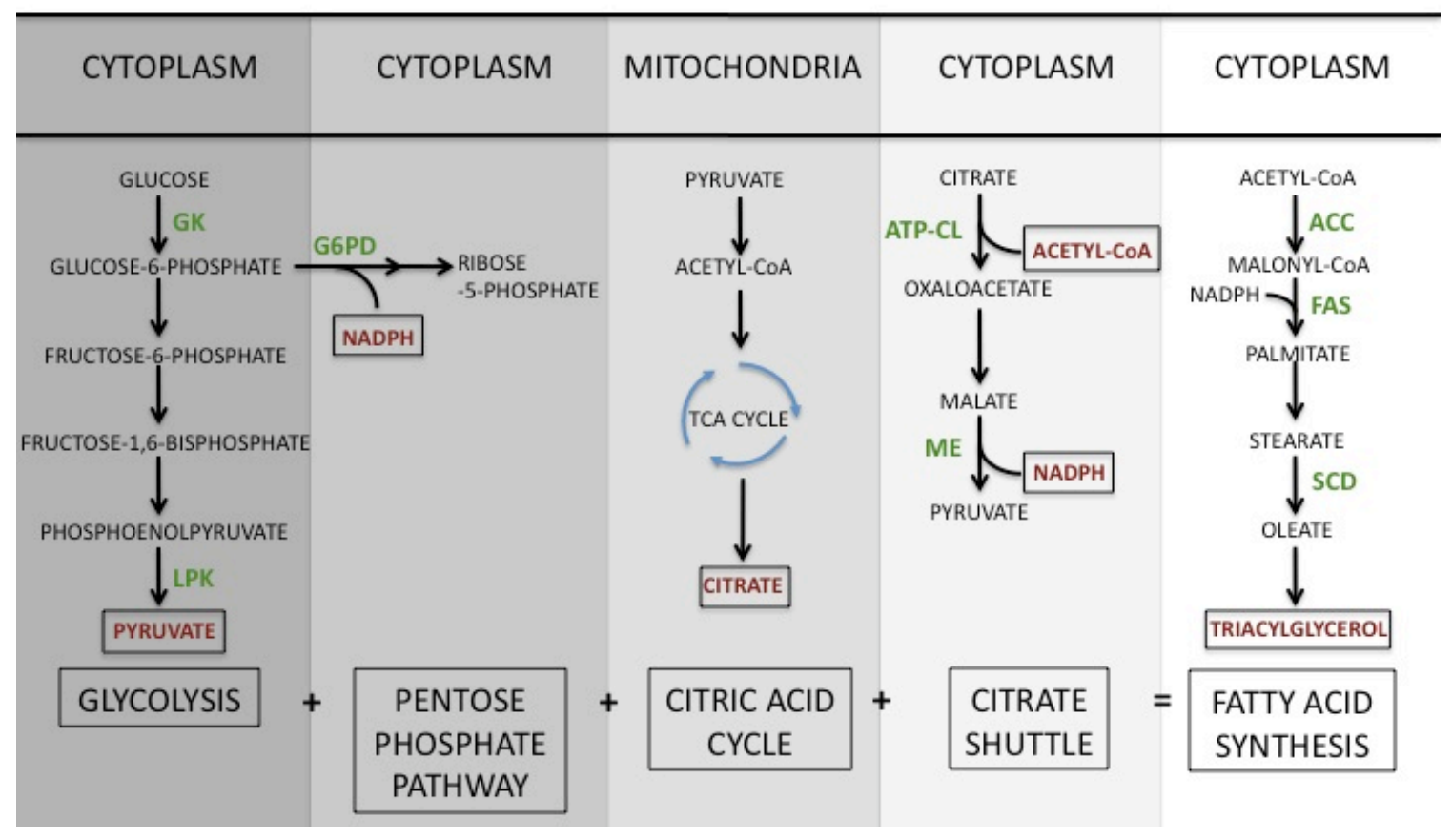

\section{IV.}

Dietary fat is predominantly triacylglycerol. The fatty acids comprising the triacylglycerol molecule are saturated, monounsaturated, and polyunsaturated. These fatty acids provide a major source of energy through their own $\beta$-oxidation. Fatty acids stored as triacylglycerols (primarily within adipose tissue) are also substrates for $\beta$-oxidation. In response to energy deprivation, the fatty acids of stored triacylglycerols are mobilized for use by the peripheral tissues.

In adipose tissue, a stimulus for the mobilization of stored triacylglycerol is glucagon or epinephrine. Upon binding to cell-surface receptors, these hormones stimulate the activation of adenylate cyclase, resulting in an increase intracellular cAMP and the activation of PKA (22). PKA then phosphorylates and activates hormone sensitive lipase (HSL), which will then hydrolyze fatty acids from triacylglycerols. This stimulation is inhibited by insulin, which alerts 
the body that energy in the form of glucose is available for peripheral tissues to use rather than stored fatty acids. The complete hydrolysis of fatty acids from the glycerol backbone also requires the non-inducible enzymes diacylglycerol lipase and monoacylglycerol lipase (23-26). Once free fatty acids are hydrolyzed from the glycerol backbone, they are able to diffuse out of adipocytes into the blood, where they become bound to albumin. Fatty acids bound to albumin are then transported to tissues for uptake and $\beta$-oxidation (23-26).

For $\beta$-oxidation in peripheral tissues, these free fatty acids enter the cell and must be activated in the cytoplasm to form a fatty acyl-CoA thioesters, catalyzed by acyl-CoA synthetase (27). The transport of fatty acyl-CoA into the mitochondria is accomplished by an acyl-carnitine intermediate that is generated by carnitine palmitoyltransferase I (CPT I) on the outer mitochondrial membrane (28). This acyl-carnitine is then transported into the mitochondria where CPT II catalyzes the regeneration of the fatty acyl-CoA molecule. The fatty acyl-CoA molecule is the substrate for $\beta$-oxidation (Figure $3 A)(23-26)$.

\section{FIGURE 3A.}

\section{TRANSPORT OF ACETYL-COA INTO THE MITOCHONDRIA FOR $\beta$-OXIDATION}

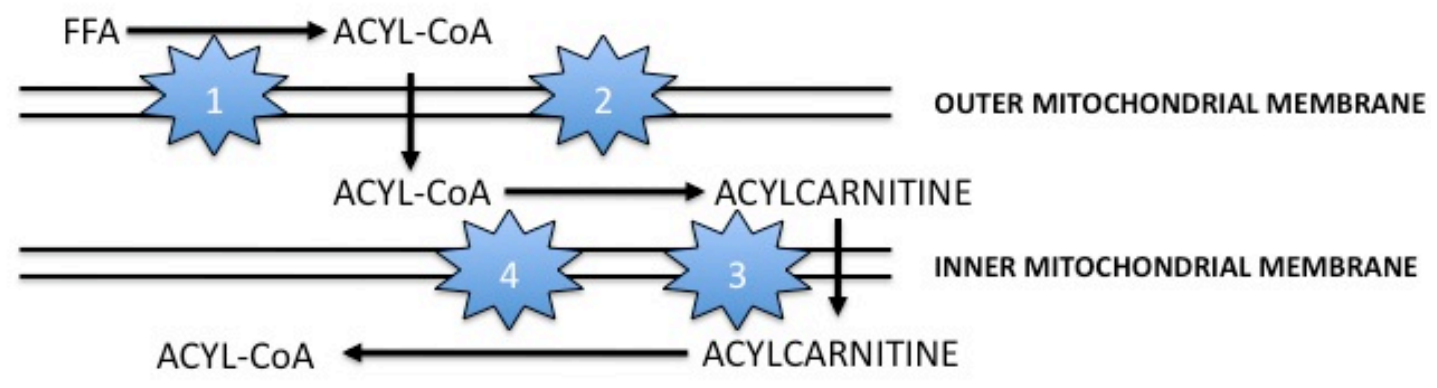

1. ACYL-COA SYNTHETASE

2. CARNITINE PALMITOYL TRANSFERASE I

3. CARNITINE ACYLCARNITINE TRANSLOCASE

4. CARNITINE PALMITOYL TRANSFERASE II 
$\beta$-oxidation occurs through the sequential removal of 2 -carbon units through oxidation at the $\beta$-carbon position of the fatty acyl-CoA. $\beta$-oxidation reactions proceed through the actions of acyl-coA dehdyrogenase, enoyl-CoA hydratases, L-3-hydroxyacyl-CoA dehydrogenases, and thiolases $(25,29)$. Each round of $\beta$-oxidation produces one mole of $\mathrm{NADH}$, one mole of FADH2 and one mole of acetyl-CoA. The acetyl-CoA is further metabolized by the citric acid cycle. Acetyl-CoA can also be diverted to synthesize ketone bodies ( $\beta$-hydroxybutyrate and acetoacetate), which are exported to tissues such as brain where $\beta$-oxidation does not occur. The $\mathrm{NADH}$ and FADH 2 generated during $\beta$-oxidation and by the citric acid cycle then enter the respiratory pathway for the production of ATP (Figure 3B)(23-25).

\section{FIGURE 3B.}

\section{B-OXIDATION}

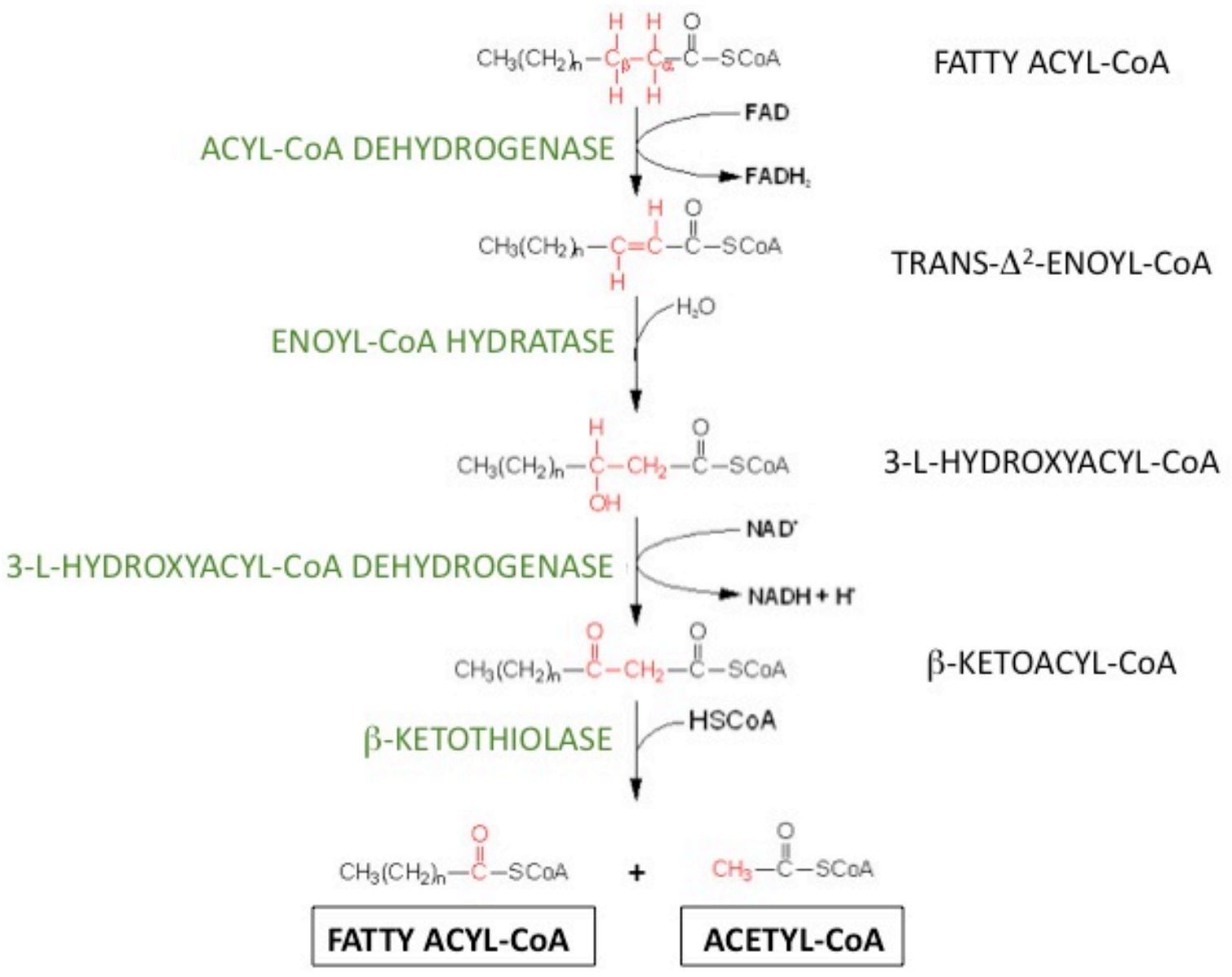




\section{DIETARY POLYUNSATURATED FAT AS A REGULATOR OF LIPOGENESIS}

The discovery that fatty acids can inhibit lipogenesis and lipogenic enzyme activity (and therefore modulate energy homeostasis) is essential to understanding how changes in dietary fat consumption may mediate a decrease in cardiovascular disease. It is well established that in contrast to the stimulatory effect of dietary carbohydrate, the inhibitory effect of polyunsaturated fat on lipogenesis and lipogenic enzyme activity is due specifically to the inclusion of polyunsaturated fat to the diet (30-32).

When rats are switched from a high-carbohydrate fat-free diet to a diet containing polyunsaturated fat, hepatic lipogenesis and the lipogenic enzyme activity are inhibited (33). Regardless of whether the rats have been starved and then re-fed a high-carbohydrate diet supplemented with polyunsaturated fat, or whether the rats receive a single gavage of polyunsaturated fat, lipogenesis and lipogenic enzyme activity are inhibited $(34,35)$. In support of this data, when the carbohydrate content of a diet is held constant, but either polyunsaturated or saturated fat is added to the diet only the polyunsaturated fat inhibits lipogenesis and lipogenic enzyme activity $(33,36)$. Neither monounsaturated nor saturated fatty acids inhibit lipogenic enzyme activity in these diets $(33,34,36)$. The specific inhibitory effects of dietary polyunsaturated fat are not due to essential fatty acid deficiency; in rats fed a diet adequate in essential fatty acids but supplemented with polyunsaturated fat, lipogenesis and lipogenic enzyme activity in further inhibited (33).

The specific inhibition of lipogenesis by polyunsaturated fatty acids but not saturated fats suggest that prostanoids may mediate this effect. However, both n-3 and n-6 polyunsaturated fatty acids inhibit lipogenesis (but give rise to different prostanoid products), and inhibiting the metabolism of dietary linoleic acid does not abolish the effect of polyunsaturated fatty acid on lipogenesis $(37,38)$. Therefore, the mechanism by which polyunsaturated fatty acids inhibit lipogenesis does not involve their metabolism to prostanoid products.

The molecular basis for the inhibitory effects of polyunsaturated fatty acids on lipogenesis and lipogenic enzyme activity is still incomplete. In order to address this molecular mechanism, isolated hepatocytes in culture have been used to study the inhibitory effects of fatty acids on lipogenesis and lipogenic enzyme activity. In primary rat hepatocytes, the addition of non-esterified fatty acids inhibits lipogenesis and the activity of ACC, FAS, ATP-CL, G6PD, 
and ME (28, 39-41). Adding polyunsaturated fatty acids in primary hepatocytes mimics the effects of adding polyunsaturated fat to the diet of rats; $n-3$ and $n-6$ polyunsaturated fatty acids inhibit lipogenesis and lipogenic enzyme activity; saturated fatty acids do not accomplish this inhibition (with the exception of ACC, which is inhibited at low concentrations by palmitate; however, palmitate become cytotoxic at concentrations above $250 \mathrm{mM}$, suggesting that its effect may be due to this toxicity rather than a specific effect of fatty acid on enzyme activity)(33, 42).

Due to this strong correlation between experiments in intact rat and primary hepatocytes, primary hepatocytes have been utilized to address a central question in this field: primarily, what are the specific intracellular mechanisms that mediate the inhibitory effect of polyunsaturated fat on lipogenesis and lipogenic enzyme activity.

\section{a. TRANSCRIPTIONAL REGULATION BY POLYUNSATURATED FAT}

As described above, polyunsaturated fatty acid, added to either hepatocytes in culture or to the diet of rats, is inhibitory to hepatic lipogenesis and lipogenic enzyme activity. The activities of ACC, FAS, ATP-CL, ME, and G6PD are coordinately regulated so that glucose is converted to palmitate only when dietary energy is high, and conversely, that fatty acids are funneled towards $\beta$-oxidation when dietary energy is low. This coordinate regulation of substrate (glucose) to product (fatty acid) is accomplished by changing the capacity of the lipogenic suite of enzymes. This occurs through two mechanisms: 1) short-term changes in flux are accomplished in minutes through the inhibition of enzyme catalytic activity through phosphorylation and dephosphorylation or through the binding of allosteric inhibitors, and 2) long-term changes in flux are accomplished in hours by changing mRNA and protein synthesis of the key lipogenic enzymes.

Short-term regulation is only observed in ACC; this enzyme is inhibited by phosphorylation and also by the presence of long-chain fatty acyl-CoA. ACC is stimulated by the presence of citrate. These short-term controls enable flux through the fatty acid synthetic pathway (the pace of which is controlled by ACC) to change immediately upon the availability of acetyl-CoA substrate, or to be inhibited by product feedback (long-chain fatty acyl-CoA). For the rest of the lipogenic enzymes, long-term changes in enzyme activity correspond to changes in the amount of the enzyme present in the cell. 
Polyunsaturated fatty acids cause large inhibitions in the rate of transcription of the lipogenic enzymes, thereby inhibiting both the amount of mRNA and protein synthesis in the liver, intestine, pancreas, and adipose tissue $(43,44)$. These nuclear effects occur within hours of feeding a diet rich in polyunsaturated fatty acid $(43,44)$. These transcriptional changes affect the amount of ATP-CL, FAS, ACC, and ME (45). These transcriptional mechanisms involve either the nuclear receptors LXR and PPAR- $\alpha$, or the transcription factors SREBP- $1 \mathrm{c}$ and ChREBP (46). The transcriptional mechanisms by which polyunsaturated fatty acids inhibit flux through the lipogenic pathway will be the focus of the rest of section.

In contrast to the transcriptional changes in other lipogenic genes, polyunsaturated fat does not inhibit G6PD at the transcriptional level. Instead, the level of G6PD mRNA is inhibited by changes in the processing of the pre-mRNA transcript (47). This posttranscriptional regulation will be discussed below.

\section{i. LIVER X RECEPTORS}

Liver X receptor (LXR) is a ligand-regulated member of the nuclear receptor superfamily of transcription factors. LXR functions as an intracellular sensor of excess cholesterol and as such, upregulates genes involved in intestinal cholesterol absorption, the conversion of cholesterol to bile acids, reverse cholesterol transport, lipogenesis, and inflammation. These genes include: CYP7a1, ABCA1, ABCG5, ABCG8, SREBP-1c, FAS, LPL, CETP, PLTP, ApoE, ApoCI, ApoCII, and ApoCIV (48).

LXR- $\alpha$ is expressed in liver, intestine, adipose tissue, kidney, and macrophages, whereas LXR- $\beta$ is expressed ubiquitously. Structurally, LXR contains a DNA-binding domain and a ligand-binding domain. To function, LXRs form obligate heterodimers with retinoic X receptors (RXRs) in order to bind to liver X receptor response elements (LXRE) in the promoter regions of target genes. The DNA binding domain of LXR is comprised of two zinc-fingers, while its ligand-binding domain lies within the C-terminal terminal region; this domain binds to oxysterols and cholesterol derivatives such as 24(S)-hydroxycholesterol and 24(S), 25epoxycholesterol. Binding of these endogenous ligands increases the transcriptional activity of LXR $(49,50)$. 
Evidence that LXR also plays a major role in regulating lipogenesis comes from LXRdeficient mice, which show a clear deficiency in hepatic expression of SREBP-1c, SCD-1, and FAS (51). Promoter analysis of ACC1, CYP7A1, SREBP-1c, FAS, ABCA1, GLUT4, PEPCK, and G6Pase indicate that these are direct targets of $\operatorname{LXR}(50,52)$.

A role for polyunsaturated fatty acids in mediating these actions of LXR has been determined. Polyunsaturated fatty acids bind directly to LXR- $\alpha$ and they repress the activation of LXR- $\alpha$ by oxysterols (53). Polyunsaturated fatty acids also interfere with the DNA-binding of LXR- $\alpha$ to target gene LXREs (54). Therefore, part of the inhibitory effect of polyunsaturated fatty acids on lipogenesis is to antagonize this nuclear receptor.

\section{ii. PEROXISOMAL PROLIFERATOR-ACTIVATED RECEPTORS}

Another action of dietary polyunsaturated fatty acid is to increase the capacity for hepatic $\beta$-oxidation through the activation of peroxisome proliferator-activated receptors (PPARs); transcription factors that induce genes for $\beta$-oxidation, lipid transport, and thermogenesis (55, 56). The most important gene targets of PPARs include carnitine palmitoyltransferase, peroxisomal acyl-CoA oxidase, uncoupling protein-3, fatty acid transport proteins, long-chain acyl-CoA synthetase, and pyruvate dehydrogenase kinase $(57,58)$.

There are three isoforms of PPARs $(\alpha, \delta, \gamma)$ encoded by separate genes and activated by specific compounds; PPAR- $\alpha$ is expressed in liver, heart, kidney, and intestine. PPAR- $\delta$ is widely expressed, including in brain, adipose, and skin. The PPAR- $\gamma$ gene is alternatively spliced to produce three PPAR- $\gamma$ isoforms $(\gamma 1, \gamma 2, \gamma 3)$ that are expressed in adipose, colon, retina, and mammary gland (44).

PPARs are members of the nuclear hormone receptor superfamily; as such, they are transcription factors that act upon DNA response elements as heterodimers with retinoic $\mathrm{X}$ receptors (RXRs) $(59,60)$. Like other nuclear hormone receptors, they contain a ligand-binding domain and two zinc finger motifs for binding to its cognate DNA sequences, which are comprised of a direct repeat with a single nucleotide space (DR1 elements)(60).

Endogenous PPAR ligands include non-esterified unsaturated fatty acids, and binding of intracellular non-esterified polyunsaturated fatty acids and their metabolites activate this transcription factor; therefore, PPARs act as intracellular non-esterified fatty acid sensors (61). 
Additionally, PPAR- $\alpha$ is activated by fibrates, PPAR- $\gamma$ is activated by eicosanoids, and PPAR- $\delta$ is activated by prostanoids (44). PPARs were first described in rodents as transcription factors that bind fibrates and subsequently upregulate peroxisomal proliferation and fatty acid oxidation $(59,62)$. While PPARs in humans are also responsive to fibrates, they do not induce peroxisomal proliferation. Instead, they induce peroxisomal fatty acid oxidation, a process that metabolizes very long chain fatty acids for mitochondrial $\beta$-oxidation. This action of PPARs has been manipulated in humans by the administration of fibrate drugs to lower cholesterol and serum lipid concentrations. In humans, the main role of PPARs is to induce the expression of oxidative genes during starvation and gluconeogenesis.

The direct role of polyunsaturated fatty acids in mediating the activity of PPAR- $\alpha$ is still unclear, in that different sources of polyunsaturated fatty acids may have drastically different effects on its activity. Specifically, it has recently been observed that fatty acids derived from hepatic triacylglycerol hydrolysis, but not as greatly from $\beta$-oxidation, serve to activate PPAR- $\alpha$ (63). This is a novel finding pointing towards a possible intracellular partitioning mechanism for fatty acids derived from exogenous sources versus lipogenesis, triacylglycerol hydrolysis or $\beta$ oxidation.

\section{iii. STEROL REGULATORY ELEMENT BINDING PROTEIN-1C}

Sterol regulatory element binding proteins (SREBPs) are major regulators of lipogenesis and cholesterol metabolism $(64,65)$. There are three SREBP isoforms, SREBP-1a, $-1 \mathrm{c}$, and -2 . SREBP-1a and -1c are encoded by the same gene, but differ in their inclusion of the first exon after an alternative transcription start site (66). SREBP-2 is encoded by a different gene $(66,67)$. Both SREBP-1a and -1c regulate lipogenic genes, but the expression of SREBP-1c predominates in the liver of experimental animals in the fed state, whereas SREBP-1a and SREBP-2 are expressed in all tissues and in actively dividing cell lines (68). Although there is an overlap in the functions of SREBP-1 and -2, SREBP-2 is primarily involved in the transcriptional activation of genes involved in cholesterol uptake and synthesis $(69,70)$. The regulation of SREBP-1c will be the focus of the rest of this section.

The transactivation domain of SREBP-1c is composed of a stretch of acidic residues, a proline-rich domain, and a basic/helix-loop-helix/leucine zipper (bHLH-LZ) that facilitates 
SREBP-1c dimerization, transport into the nucleus, and DNA-binding activity. This bHLH-LZ domain contains a specific tyrosine residue for binding to sterol response elements (SRE) in the promoter of its target genes. Lipogenic genes regulated by SREBP-1c include ACC, FAS, GPAT, SCD, and delta5-and delta-6-desaturases (71-74). Cholesterol metabolism genes regulated by SREBP-1c include the LDL receptor, HMG-CoA reductase, and HMG-CoA synthase, and SREBP itself (69).

SREBP-1c is synthesized as a precursor protein, which is inserted in the ER membrane. A membrane-spanning domain anchors it to the ER membrane. All three isoforms contain an Nterminal 480 amino acids which function as the bHLH-LZ transcription factor, a region of 80 amino acids which contain the transmembrane spanning domains across the ER membrane, and a regulatory C-terminal domain containing 590 amino acids (75). In order for SREBPs to become active, the membrane-bound SREBP must be transported from the ER to the Golgi, where the Nterminal fragment is cleaved and can enter the nucleus. SREBPs are escorted from the ER to the Golgi by Scap (76). Scap itself is regulated by the binding of another protein, Insig-1; when Scap binds to Insig-1, Scap is unable to transport SREBP to the Golgi, and SREBP target gene expression declines (76-78).

Both insulin and carbohydrate-rich diets are strong regulators of SREBP-1c. Re-feeding mice a high carbohydrate diet increases the expression of SREBP-1c in liver, whereas starvation decreases SREBP-1c mRNA expression $(75,79,80)$. Importantly, this dietary paradigm does not effect the expression of the other SREBP isoforms. The effect of insulin on SREBP-1c gene expression is blocked by the actions of glucagon and an increase in cAMP $(81,82)$. The transcriptional regulation of SREBP-1c is due to the presence of both an SRE and an LXRE within the SREBP-1 promoter region (83). LXR agonists promote LXR heterodimer formation with RXR, which potently activate SREBP-1c expression $(52,84)$.The transcriptional activation of SREBP-1c by insulin requires the LXRE (85). The basal expression of SREBP-1c is due to the SRE within its promoter that binds to mature SREBP-1c in a feed-forward mechanism (85).

Regulation of SREBP-1c by insulin occurs at a posttranscriptional level by increasing the processing of inactive membrane-bound SREBP-1c to the active nuclear form (86). This stimulation occurs within the first two hours of insulin treatment in primary rat hepatocytes (87). In mouse liver and primary rat hepatocytes, insulin inhibits the expression of Insig-2a, another isoform of Insig-1, but insulin does not inhibit the expression of Insig-1 (which is mainly 
affected by changes in intracellular sterol levels) $(88,89)$. Therefore, one mechanism by which insulin can stimulate hepatic lipogenesis is through in promotion of SREBP-1c transport to the Golgi for maturation. The responsiveness of SREBP-1c to insulin allows active SREBP-1c to bind and activate the transcription of lipogenic genes, which are also responsive to insulin stimulation and carbohydrate feeding.

Insulin requires the activities of $\mathrm{PI} 3 \mathrm{~K}$ and $\mathrm{AKT}$ to mediate its effects on SREBP-1c. Over-expression of constitutively active AKT in primary hepatocytes stimulates the posttranslational processing of SREBP-1 (90). This regulation requires ERK activity. Loss of PI3K activity corresponds to a loss in the insulin induction of SREBP-1c $(91,92)$. Additional regulation of SREBP-1c may be mediated by the insulin activation of atypical protein kinase $\mathrm{C}$ $(93,94)$.

Diets rich in polyunsaturated fatty acids inhibit SREBP-1, but not SREBP-2, through several mechanisms, including an inhibition of its rate of transcription, and through a decrease in the processing of the mature protein (46). In liver, polyunsaturated fatty acids inhibit SREBP-1a and -1c mRNA expression through an LXR-dependent mechanism (95). Polyunsaturated fatty acids inhibit SREBP-1c processing by inhibiting the degradation of Insig-1, which leads to an increase in its availability and the retention of SREBP-1c at the ER membrane (96). Therefore, when polyunsaturated fatty acids are high, or when cholesterol is abundant, mature SREBP-1c cannot induce the expression of lipogenic or cholesterol synthesis genes $(76,78)$.

It remains to be determined whether SREBP-1c plays any role in the regulation of genes that are not regulated at a transcriptional level but whose mRNA accumulation is inhibited by polyunsaturated fatty acids, such as G6PD and ME. It is possible that SREs may still be found in the promoters of genes encoding splicing factors and other genes involved in posttranscriptional regulation.

Interestingly overexpression of SREBP-1c in primary hepatocytes is not sufficient to induce the mRNA expression of lipogenic genes to the extent that is seen with treatment with high glucose and insulin in wild-type hepatocytes (97). Additionally, SREBP-1c-deficient mice are unable to fully induce fatty acid synthesis in response to a high carbohydrate feeding (98). These findings suggested that another transcription factor must function to induce lipogenic and glycolytic mRNA expression when animals are red a high-carbohydrate diet, or when 
hepatocytes are treated with glucose. This transcription factor (ChREBP) will be discussed in the next section.

\section{iv. CARBOHYDRATE RESPONSE ELEMENT BINDING PROTEIN}

Carbohydrate response element binding protein (ChREBP) was first identified by affinity chromatography as the transcription factor responsible for mediating the increase in expression of both lipogenic and glycolytic genes in response to a high carbohydrate diet (99). ChREBP is found in almost all tissues, but is most abundant in tissues with increased lipogenic capacity, such as liver and adipose tissues $(99,100)$. ChREBP is composed of a bHLH-LZ domain, and LZ-like domain, and a nuclear localization signal, and a polyproline domain. ChREBP binds to carbohydrate response elements (ChOREs) within the promoter regions of target genes. These ChORE elements are composed of two E boxes (with the canonical CACGTG DNA sequence) that form cognate sequences for bHLH-LZ transcription factors $(101,102)$.

Through ChIP assays and through overexpression studies, the direct binding of ChREBP to the promoters of lipogenic and glycolytic genes was observed and characterized. When ChREBP is deficient, the induction of FAS, ACC, and LPK in response to high glucose is no longer observed $(103,104)$. ChREBP must bind its obligate heterodimer partner Mlx, Max-like protein $\mathrm{X}$, in order to function as a transcription factor. Two of these ChREBP heterodimers are then able to bind the E boxes within promoter (105-107).

The regulation of ChREBP is still undefined. ChREBP mRNA expression is induced by glucose and high carbohydrate re-feeding in hepatocytes or intact animals (103). The cellular localization of ChREBP changes in response to glucose, and this appears to occur coincident with a change in phosphorylation status. This mechanism appears to be the primary regulator of ChREBP, and it involves at least one dephosphorylation of ChREBP near its nuclear localization signal by protein phosphatase 2A (PP2A) that is responsive to the glucose status of the cell. This dephosphorylation event allows ChREBP to translocate to the nucleus to bind to target gene promoter elements. In contrast, during low-glucose conditions, this same site is phosphorylated in response to PKA and is unable to transcriptionally activate its target genes in the nucleus (108110). 
AMP-activated protein kinase (AMPK) is also responsible for phosphorylating ChREBP when intracellular AMP levels are high. AMPK activation keeps ChREBP out of the nucleus in order to maintain intracellular energy catabolism (111). The regulation of ChREBP phosphorylation and dephosphorylation, and the potential role for this as a signal for nuclear translocation is still very unclear, however, because a phosphorylation-defective mutant ChREBP is still responsive to glucose. Additionally, it has been shown that the phosphorylation status does not correlate with a change is glucose status in primary hepatocytes (although the expression of ChREBP target genes does reflect glucose status in these cells)(112).

The mechanism by which carbohydrate regulates both the expression and activity of ChREBP is unknown. In addition, the corresponding regulation of its obligate heterodimer Mlx is also unknown. However, a role for ChREBP regulation by polyunsaturated fatty acids is clear. Just as polyunsaturated fatty acids are potent inhibitors of hepatic lipogenesis (in large part due to their inhibition of SREBP-1c), polyunsaturated fatty acids are also effective at inducing ChREBP mRNA degradation and inhibiting its nuclear translocation. This effect may stem from the inhibitory role of polyunsaturated fatty acids on the glycolytic pathway $(103,108)$. Just as polyunsaturated fatty acids inhibit SREBP-1c through a transcriptional mechanism involving LXR, a similar mechanism may function in the regulation of ChREBP by polyunsaturated fatty acids $(53,113)$.

\section{b. POSTTRANSCRIPTIONAL REGULATION OF LIPOGENIC GENES BY POLYUNSATURATED FATTY ACIDS}

Posttranscriptional regulation can occur at several points during the life span of an mRNA. These include pre-mRNA processing in the nucleus (capping, splicing, and polyadenylation), export from the nucleus, stability of the mature RNA in the cytoplasm, and regulation of the proteins that control these events. Dietary nutrients including carbohydrate, cholesterol, iron, and polyunsaturated fatty acids have been shown to regulate the expression of several genes through control of these molecular events. In response to a polyunsaturated fatty acid-enriched diet, both the rate of transcription and processing of the nuclear precursor mRNA of tricarboxylate carrier protein was inhibited (114). Treatment of hepatocytes with insulin significantly enhances the efficiency of processing of Spot-14 nuclear precursor mRNA to 
mature mRNA $(115,116)$. SREBP-1c is also regulated at a posttranscriptional mechanism, in response to polyunsaturated fatty acids; this mechanism involves the inhibition of processing of the membrane-bound precursor SREBP-1c to its active nuclear form (117).

The most well defined gene that is regulated at a posttranscriptional step in response to changes in diet is G6PD. For G6PD, treatment of hepatocytes with polyunsaturated fatty acid results in a decrease in the splicing efficiency of the pre-mRNA in the nucleus. This regulation of G6PD by dietary polyunsaturated fatty acids will be the focus of the rest of this section.

\section{i. G6PD: REGULATION BY A POSTTRANSCRIPTIONAL MECHANISM}

G6PD is the rate-limiting enzyme in the pentose phosphate pathway. G6PD catalyzes the first reaction in this pathway by converting glucose-6-phosphate to 6-phosphogluconolactone (118-120). NADPH is concomitantly produced during this reaction, and serves as a source of reducing equivalents for fatty acid biosynthesis and for cellular detoxification (121). This pathway provides $50-75 \%$ of the NADPH used in lipid biosynthesis, as well as the sugarphosphate moieties that are necessary for nucleotide biosynthesis and nucleotide coenzyme formation (Figure 4)(119).

\section{FIGURE 4.}

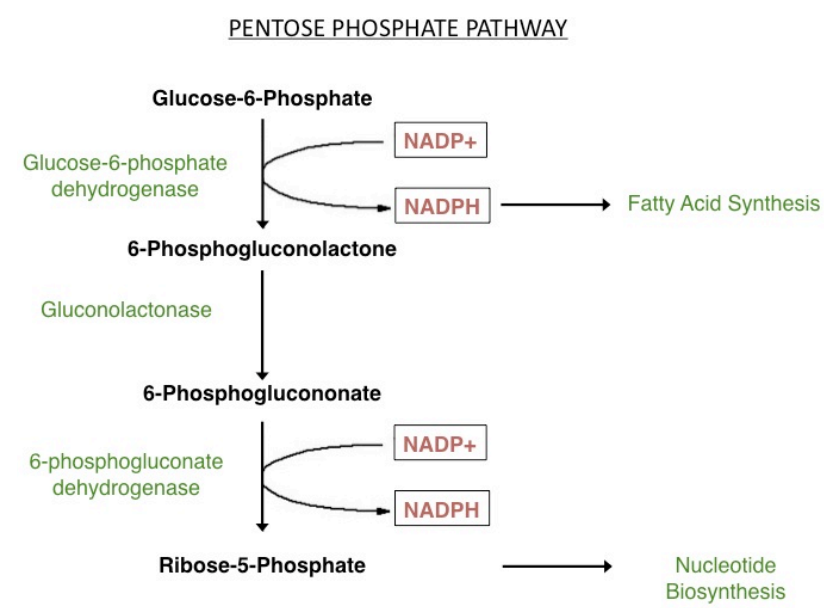

G6PD is found in all cells (122). Mutations in the gene result in an increased susceptibility to oxidative stress due to the loss of NADPH and its ability to reduce free radicals and peroxides. In humans, the disease associated with a partial loss of G6PD activity is known as 
Favism $(123,124)$. The disease is caused by point mutations in the G6PD gene, and diminishes (but does not abolish) the activity of the enzyme. G6PD-deficiency results in reduced serum lipoprotein levels, demonstrating the importance of G6PD in generating NADPH for fatty acid synthesis (123). Chronic non-spherocytic hemolytic anemia can also occur in individuals with more severe mutations, again emphasizing the important role of NADPH in defending against oxidative stress (125). There is no known complete deletion of G6PD in humans; knock-out mutations are embryonic lethal in mice, and it is hypothesized that a complete loss of G6PD would be fatal in humans as well (126).

While G6PD is expressed constitutively in all tissues, it is regulated both nutritionally and hormonally in liver, adipose tissue, and lactating mammary glands, all of which are tissues that undergo high rates of lipogenesis (120). It has been shown that insulin increases the expression of G6PD, whereas polyunsaturated fat inhibits its expression $(28,127)$. This regulation by polyunsaturated fat is expected, as polyunsaturated fat has been shown to inhibit other lipogenic enzymes in the same manner.

Over a normal diurnal cycle, G6PD mRNA accumulation in mouse liver changes up to 7fold with the consumption of food $(128,129)$. When mice are starved, G6PD mRNA accumulation is decreased; it takes $30 \mathrm{~h}$ for G6PD mRNA levels to maximally increase by 17 fold upon re-feeding $(130,131)$. Inclusion of polyunsaturated fat in the re-fed diet, however, causes a decrease in G6PD activity and mRNA accumulation. Within $4 \mathrm{~h}$ of re-feeding accumulation of G6PD mRNA is decreased by $80 \%$, and a maximal inhibition occurs after $9 \mathrm{~h}$ $(129,130)$. Arachidonic acid treatment of primary rat hepatocytes also causes a decrease in G6PD mRNA accumulation over a similar time course (with a maximal inhibition of G6PD mRNA at $8 \mathrm{~h})(130)$.

The rate of transcription of the G6PD gene does not change after dietary manipulations, including starvation, re-feeding, and the inclusion of polyunsaturated fat in the diet both in the intact mouse liver and in primary hepatocytes $(127,130)$. The accumulation of G6PD mRNA does change by up to 30-fold after these manipulations. By isolating total RNA from both the nucleus and the cytoplasm of mouse livers after both starvation/re-feeding and the inclusion of polyunsaturated fat in the diet, it was determined that a change in accumulation of G6PD nuclear precursor mRNA precedes a change in the accumulation of mature G6PD mRNA in the cytoplasm (130). Therefore, G6PD is exclusively regulated by polyunsaturated fatty acid at a 
nuclear posttranscriptional step (127).

Within the nucleus, a pre-mRNA must be capped, spliced, and polyadenylated in order to be competent for translation in the cytoplasm. All of these events present an opportunity for regulation. For G6PD, the addition of the 7-methylguanine cap and polyA tail is not regulated in response to polyunsaturated fatty acid (127). G6PD is regulated by a change in the efficiency of splicing. There is an accumulation of partially and fully spliced G6PD mRNA in the nucleus of re-fed mouse liver, whereas there is less accumulation of these mRNA species in the starved animal livers (132). This same nuclear posttranscriptional mechanism occurs when mice are refed a diet enriched in polyunsaturated fat. Animals re-fed this diet have a decreased accumulation of the partially and fully spliced G6PD mRNA, in comparison to animals re-fed a diet low in polyunsaturated fat (129). The decreased accumulation of fully spliced G6PD mRNA corresponds to a decrease in G6PD protein expression, because less efficiently spliced mRNA species (those that are unspliced or only partially spliced) are degraded through one of two pathways, either by the nuclear exosome or nonsense mediated decay $(133,134)$. As the premRNA is degraded, there is less corresponding G6PD mRNA in the cytoplasm to be translated.

The mechanism for splicing requires RNA sequence elements within both the intron and exon, though these elements do not have strong consensus sequences. Exons also contain sequence elements that regulate splicing, including exon splicing enhancers (ESE) and exon splicing silencers (ESS). In order for splicing to occur, the exons must be correctly defined, the introns must be excised, and the surrounding exons joined. This process requires five small nuclear RNAs (U1, U2, U4, U5, U6 snRNAs).

RNA splicing also requires trans-acting factors, such as the serine-arginine rich (SR) proteins and the heterogeneous nuclear ribonucleoproteins (hnRNPs). SR proteins bind ESEs in order to enhance splicing, while hnRNPS bind to ESSs to inhibit splicing (135-139). However, there are some examples of SR proteins inhibiting splicing and hnRNPs stimulating splicing $(140,141)$. These cofactors can be regulated by changes in their subcellular localization (they reside inactively in nuclear speckles), and by changes in their phosphorylation state (142-144). Therefore, existing questions in this field include, 1) understanding the specific trans-acting factors that bind to and regulate each gene, 2) how specific trans-acting factors bind to cis-acting RNA elements, and finally 3 ) how this binding regulates splicing. 
The sequence elements within G6PD that are essential to its regulation by polyunsaturated fat have been determined. A cis-acting element resides within exon 12 of G6PD and is responsible for directing less-efficient splicing of the G6PD pre-mRNA (47). The binding of hnRNP A2/B1, hnRNP K, and hnRNP L to this element correlates with splicing inhibition (145). Additionally, the specific SR protein involved in stimulating G6PD splicing has been identified as SRp20 (Walsh, C.M., manuscript in preparation). The interaction of this SR protein within the G6PD regulatory region is thought to stimulate G6PD splicing (Walsh, et al unpublished). The identification of the specific trans-acting factors, and the subsequent regulation of those factors in response to diet is quite novel. It is also necessary in elucidating the intracellular mechanisms that mediate changes in gene expression in response to diet.

While it has been determined that G6PD is inhibited by polyunsaturated fat through changes in splicing efficiency of the pre-mRNA, the molecular signaling pathway by which this occurs has also been characterized. In primary rat hepatocytes, insulin stimulates G6PD expression through activation of the PI3K, resulting in the accumulation of G6PD mRNA (146). Polyunsaturated fatty acids, specifically arachidonic acid, inhibit this accumulation of G6PD mRNA in response to insulin. Polyunsaturated fat mediates this effect through the activation of p38 MAPK and the subsequent serine phosphorylation of IRS-1. Additionally, arachidonic acid treatment results in a decrease in AKT activation (146).

A role for AMP-activated protein kinase (AMPK) has also been described for the regulation of G6PD by polyunsaturated fatty acid (147). AMPK activity is increased when hepatocytes are treated with arachidonic acid, and this activation coincides with a decrease in G6PD mRNA. Activation of AMPK by pharmacological activators mimics the effect of arachidonic acid on G6PD mRNA. Finally, when hepatocytes express a nonfunctioning AMPK, arachidonic acid is unable to inhibit G6PD mRNA (147). Whether AMPK works solely through its activation of $\mathrm{p} 38 \mathrm{MAPK}$, or through the activation of another signaling molecule to regulate G6PD is unclear. 


\section{INSULIN SIGNALING AND ITS REGULATION BY POLYUNSATURATED FATTY ACID}

Insulin is arguably the most important hormone in the body for maintenance of whole body energy homeostasis. No other hormone is as potent a regulator of metabolic events throughout so many different target tissues. Insulin is secreted from $\beta$-cells in the pancreatic islets of Langerhans in response to increases in circulating blood glucose. The main function of insulin is to maintain plasma glucose concentrations of $4-7 \mathrm{mM}$; these concentrations are maintained during the re-fed condition due to the coordinated actions of insulin on tissues such as muscle, adipose, liver, and pancreas. Insulin stimulates glucose uptake in muscle and adipose after the ingestion of carbohydrate, and conversely inhibits glucose production and secretion from liver during this same period. Therefore, insulin tightly controls the source of glucose for energy use during both starvation and re-feeding by controlling whether or not the liver or a carbohydrate-rich meal is the major source of glucose in the blood.

Insulin stimulates GLUT4 translocation to the cell surface in adipose and muscle for glucose uptake into those tissues. Up to $75 \%$ of insulin-dependent glucose uptake occurs in skeletal muscle, where that glucose is primarily used to provide energy (ATP) to working muscles. In adipose tissue insulin stimulates glucose uptake and its conversion to triacylglycerol for energy storage.

Beyond maintaining blood glucose levels of 4-7 mM, insulin also functions in the liver to maintain whole body energy homeostasis. While insulin does not stimulate glucose uptake by the liver, it coordinately inhibits hepatic glycogenolysis and gluconeogenesis, and stimulates hepatic glycolysis and lipogenesis (148). Therefore, insulin acts to coordinate energy consuming versus energy storage pathways, which are essential for providing energy (in the form of fatty acids and glucose) to the rest of the body during postprandial period. The effects on lipogenesis occur primarily through the insulin regulation of lipogenic gene expression, as described above.

Disruption in insulin signaling has serious effects on energy homeostasis, leading to pathological concentrations of glucose and fatty acids circulating in the blood. From a clinical perspective, this is evidenced by the poor health of people with diabetes and obesity-related insulin resistance, in which insulin signaling is extremely disturbed (149). Insulin resistance is defined by defects in the ability of insulin-sensitive tissues to respond appropriately to the 
presence of insulin; these defects include an increase in serine phosphorylation of the insulin receptor substrates (especially IRS-1 and IRS-2), and a prolonged activation by insulin of the down-stream signaling kinases. In skeletal muscle and liver, increased intracellular triacylglycerol and high circulating non-esterified fatty acids is associated with insulin resistance, and makes these tissues insensitive to increases in circulating insulin (149). This appears to be due to disregulation of intermediate proteins and kinases, which will be discussed in the preceding sections.

\section{a. INSULIN RECEPTOR}

Insulin exerts its metabolic effects on target tissues through its interaction with the insulin receptor. The insulin receptor is made up of two extracellular $\alpha$-subunits that transduce the insulin signal to cytosolic $\beta$-subunit kinase domains. The $\beta$-subunits then trans-autophosphorylate each other at specific tyrosine residues. These phosphorylated tyrosine residues function in two distinct capacities: either as part of the catalytic portion of the $\beta$-subunits or as docking sites for proteins that interact with the phosphorylated insulin receptor (150).

\section{b. INSULIN RECEPTOR SUBSTRATES}

Of at least ten intracellular substrates that can bind the insulin receptor, the insulin receptor substrates (IRS) are the major adaptor proteins that bind to the phosphorylated tyrosine residues of the activated insulin receptor (151). There are four isoforms of IRS (IRS-1, -2, -3, 4), all of which contain a pleckstrin homology $(\mathrm{PH})$ domain and a phospho-tyrosine-binding domain (PTB) (151). IRS proteins also contain several tyrosine phosphorylation motifs (YXXM), which become tyrosine phosphorylated by the activated insulin receptor (152). It is through these domains that IRS proteins recruit other adaptor proteins with Src homology 2 (SH2) domains. The two major SH2-containing proteins that bind to IRS proteins are Grb2 and PI3K $(1,149,150)$. Grb2 transmits the insulin signal to the Ras-MAP kinase pathway, stimulating growth and differentiation (153), while PI3K promotes the metabolic actions of insulin within the cell (154). 
The isoforms of IRS vary in their tissue distribution as well as their precise role in mediating the insulin signal. IRS-1 and IRS-2 are widely expressed in mammalian tissues; IRS-3 is expressed predominantly in adipose tissue, while IRS-4 is mainly expressed in embryonic kidney. IRS-1 and IRS-2 appear to play overlapping functions in activating PI3K; in fibroblasts, the knockout of IRS-1 (and the subsequent loss of insulin signaling) can be reversed with overexpression of either IRS-1 or IRS-2. Whole body IRS-1 knockout demonstrates a role for IRS-1 in mediating growth, because these animals are growth retarded, whereas IRS-2, -3 , and -4 knockout mice are of normal size (155-159). Additionally, IRS-1 knockout mice only become mildly insulin resistant, likely because IRS-2 (or the other IRS isoforms) can substitute for the IRS-1 in these cells (160). However, IRS-2 knockout mice become overtly diabetic (157). Loss of IRS-3 and -4 does not lead to a disruption in insulin sensitivity (161).

While the exact function of each IRS protein has not been clearly defined in all tissues, much is known about the regulation and importance of IRS-1 to insulin signaling in liver. The phosphorylation of IRS-1 is integral to maintenance of insulin responsiveness (162), and the serine phosphorylation of IRS-1 leads to a desensitization of the insulin response $(1,163)$. Phosphorylation of IRS-1 at $\operatorname{ser}^{307}$, $\operatorname{ser}^{612}$, and $\operatorname{ser}^{632}$ uncouples IRS-1 from the insulin receptor and occludes PI3K binding sites $(1,164,165)$. This negative regulatory phosphorylation is mediated by a variety of kinases, including MAP kinases, PKC, mTOR, S6K, and IKK, and in response to various stimuli, including excess free fatty acids (1, 166-169). In both muscle and liver, the accumulation of intracellular triacylglycerol results in a decrease in IRS-associated PI3K activity (170).

\section{c. PHOSPHOINOSITIDE 3-KINASE}

PI3K plays a major role in propagating the insulin signal for the regulation of metabolic events (171). In fact, both pharmacological inhibitors and dominant negative forms of the kinase completely block the effects of insulin on lipogenic gene expression. PI3K is a heterodimeric protein that contains a catalytic and regulatory domain (p110 and p85 subunits, respectively). The $\mathrm{p} 85$ regulatory domain interacts with tyrosine-phosphorylated IRS-1 and IRS-2 through their SH2 domains $(1,171,172)$. There are 3 catalytic domain isoforms and at least eight different 
regulatory domain isoforms that differ in their tissue distribution. The combination of these subunits provides different tissue specificity and insulin responsiveness to PI3K.

$\mathrm{PI} 3 \mathrm{~K}$ is responsible for the phosphorylation of membrane phosphoinositides, which recruit signaling molecules to the membrane including serine/threonine kinases, Rho GTP-ases, and the TEC-family of tyrosine kinases (173). When PI3K is associated with IRS-1, the p85 regulatory subunit can no longer bind to the p110 catalytic subunit. The relief of this allosteric inhibition allows the p110 domain of PI3K to phosphorylate membrane phosphoinositides to form the second messenger phosphatidylinositol (3,4,5)-triphosphate (PIP3), which can then bind to proteins containing PH-domains. The presence of PIP3 then recruits 3-phosphoinositidedependent protein kinase1 (PDK1), a serine/threonine kinase, to the membrane. PDK1 then phosphorylates and activates AKT and also the atypical protein kinase $\mathrm{C}$ family members (1, 174).

\section{d. $\quad \underline{\mathbf{A K T}}$}

AKT is a PH-domain containing serine/threonine kinase, which lies directly downstream of PI3K. AKT mediates the actions of insulin on intracellular metabolism, and is absolutely required to transduce the insulin signal. The three isoforms of $\operatorname{AKT}(\alpha, \beta$, and $\gamma)$ vary in their tissue distribution; AKT- $\alpha$ is the active isoform expressed in muscle and liver, AKT- $\beta$ is the predominant isoform activated in adipose, while AKT- $\gamma$ is only insulin-responsive in cell culture models (175). All the isoforms of AKT require activation by PI3K (176).

AKT becomes activated after the formation of PIP3 at the membrane by active PI3K. The formation of PIP3 recruits both AKT and its upstream kinase phosphoinositide-dependent protein kinase-1 (PDK1) to the membrane. There, AKT is phosphorylated at $\mathrm{thr}^{308}$ by PDK1 $(174,177)$. AKT also becomes phosphorylated at $\operatorname{ser}^{473}$ by the mammalian target of rapamycin (mTOR)-rictor complex (178). Both phosphorylations are required for the full activity of AKT. Through these phosphorylations, AKT is able to mediate insulin actions on glycogen synthesis, glucose transport, lipogenesis, and gluconeogenesis.

Activated AKT phosphorylates target proteins at serine residues. These target proteins include glycogen synthase kinase 3 (GSK 3), 6-phosphofructo-2-kinase, the Forkhead family of transcription factors (including FOXO-1), mTOR, Raf, and pro-apoptotic BAD (179). Through 
these phosphorylations, AKT is able to mediate insulin actions on glycogen synthesis, glucose transport, lipogenesis, and gluconeogenesis. AKT phosphorylates GSK3 at $\operatorname{ser}^{21}$ and $\operatorname{ser}^{9}$, thereby inactivating it. This action of AKT results in increased glycogen synthase activity and therefore glycogen synthesis when glucose is abundant (180). AKT phosphorylation of FOXO-1, which occurs during insulin treatment or re-feeding, activates FOXO-1 and the expression of its target lipogenic and gluconeogenic genes (181-184). AKT mediates the effects of insulin on protein translation through its activation of mTOR and thereby its downstream target S6K. Cell survival is promoted through the AKT inactivation of BAD and apoptosis. Finally, AKT promotes crosstalk between PI3K and MAPK through its phosphorylation of Raf (185). Insulin activates the Ras-Raf-MAPK pathway through the activation of the small GTPase Ras. Ras activated Raf, which phosphorylates and activates MEK1 and MEK2. MEK1/2 are the upstream activators of ERK1/2 (186). AKT is also important to many of the downstream effects of insulin on cell survival and lipogenesis. Overexpression of active AKT can recapitulate the effects of insulin on G6PD and several other lipogenic genes (187-190)(Kohan, A.B., unpublished data).

\section{e. ATYPICAL PROTEIN KINASE C $(\zeta / \lambda)$}

Atypical protein kinase $\mathrm{C}$ is a downstream target of $\mathrm{PI} 3 \mathrm{~K}$ and the insulin receptor. There are two isoforms of atypical protein kinase C, PKC $\zeta$ and PKC (191). They are homologous in their catalytic domain, but play different roles during development. Based on knockout studies, $\operatorname{PKC} \lambda$ is necessary for embryonic development, and is embryonic lethal (192). However, PKC $\zeta$ knockout has not been demonstrated to have phenotyptic differences (192). PKC $\zeta / \lambda$ are serine/threonine kinases, containing a conserved catalytic domain and a regulatory domain. Unlike the novel and conventional PKCs, PKC $\zeta / \lambda$ is not sensitive to changes in intracellular calcium $(193,194)$.

Insulin stimulates the phosphorylation and activation of $\mathrm{PKC} \zeta / \lambda$ through the formation of PIP3 and the recruitment of PDK- 1 to the cell membrane. PDK-1 phosphorylates PKC $\zeta / \lambda$ at serine/threonine residues within its activation loop. Complete activation of $\mathrm{PKC} \zeta / \lambda$ also requires PIP3-dependent auto-phosphorylation (195-197). PKC $\zeta / \lambda$ is activated by insulin, but this activation differs from other major PI3K targets (such as AKT) in that it requires IRS-2, but not IRS-1; this demonstrates a separate role for PKC $\zeta / \lambda$ activation along with PI3K in mediating 
intracellular metabolism (198).

Although $\mathrm{PKC} \zeta / \lambda$ has been shown to be an important regulator of cell growth, survival, and inflammation through its interaction with nuclear-factor $-\kappa \mathrm{B}, \mathrm{PKC} \zeta / \lambda$ has recently been shown to play an important role in the insulin induction of SREBP-1c in liver (199-201). In hepatocytes, the loss of PI3K results in a loss of SREBP-1c induction by insulin. However, this effect can be rescued by reconstitution with $\mathrm{PKC} \zeta / \lambda$, rather than $\mathrm{AKT}$, indicating that $\mathrm{PKC} \zeta / \lambda$ is the major downstream target of PI3K responsible for SREBP-1c regulation $(186,202)$. This suggests that PKC $\zeta / \lambda$ activation may regulate many lipogenic genes, whereas AKT may be more important for the regulation of glucose metabolism. However, the full library of PKC substrates has not been determined.

Elevated free fatty acids have also been shown to activate PKC isoforms, including PKC $\zeta / \lambda(203,204)$. This activation contributes to insulin resistance, since PKC $\zeta / \lambda$ can then phosphorylate and inactivate the IRS proteins (205-207). The extent to which free fatty acids or dietary polyunsaturated fatty acids activate $\mathrm{PKC} \zeta / \lambda$ in the liver is still unknown.

\section{f. AMP-ACTIVATED PROTEIN KINASE}

AMP-activated protein kinase (AMPK) is involved in the cellular response to metabolic stresses and the maintenance of energy homeostasis. AMPK is a master metabolic sensor, and it acts as an upstream mediator of signaling pathways that respond to diet, hormones, and other cellular stresses. AMPK is a sensor of cellular energy because it is activated by an increase in the AMP/ATP ratio (208). Overall, this leads cells to abandon energy-consuming pathways (such as glycogen and fatty acid synthesis) and to stimulate energy-producing pathways (such as fatty acid oxidation and glycolysis). These actions of AMPK are required to replenish and stabilize cellular ATP levels.

AMPK is expressed ubiquitously among all mammalian cells, and it is highly conserved in all eukaryotes. AMPK is a heterotrimeric protein composed of a catalytic $\alpha$-subunit and two regulatory $\beta$ - and $\gamma$-subunits. AMPK is allosterically activated by AMP, which binds cooperatively to its $\gamma$-subunits. Upon binding of AMP, AMPK becomes a better target for its upstream kinase LKB1, which promotes full activation of AMPK through the phosphorylation of $\operatorname{thr}^{172}$ within the kinase domain of the $\alpha$-subunit. LKB1 forms a heterotrimer with the proteins 
MO25 and STRAD, which is required for the catalytic activity of the kinase. LKB1 appears to be constitutively active, because activators of AMPK do not activate the kinase activity of LKB1 $(209,210)$. AMP binding also inhibits dephosphorylation at $\operatorname{thr}^{172}$ by protein phosphatase $2 \mathrm{C}$ (208).

AMPK plays a regulatory role in numerous cellular processes both catabolic and anabolic in nature. Perhaps the most well understood result of AMPK activation is the phosphorylation and inactivation of acetyl-coA carboxylase (ACC) at $\operatorname{ser}^{79}, \operatorname{ser}^{1200}$ and $\operatorname{ser}^{1215}(211,212)$. ACC catalyzes the conversion of acetyl $\mathrm{CoA}$ to malonyl $\mathrm{CoA}$ and is the rate-limiting enzyme of the fatty acid synthesis pathway. Malonyl CoA is not only required for fatty acid synthesis, but it also acts as an allosteric inhibitor of CPT-1, the rate-limiting enzyme in fatty acid oxidation in mitochondria. AMPK powerfully regulates this axis by inhibiting fatty acid synthesis and stimulating fatty acid oxidation.

Metabolic conditions such as glucose deprivation, ischemia, hypoxia, and hyper-osmotic stress activate AMPK, as cellular conditions that increase the intracellular AMP/ATP ratio (213, 214). Another metabolic effect of AMPK is that AMPK mediates the beneficial effects of two widely prescribed anti-diabetic drugs, Metformin and rosiglitazone; specifically, the activation of AMPK in liver by these drugs ameliorates some diabetic symptoms including excess weight gain (215). It is thought that the mechanism involves increases in cellular $\beta$-oxidation, and therefore a decrease in stored triacylglycerol. It is likely that the role of AMPK in mediating hepatic energy metabolism will continue to expand; however, it seems likely that AMPK will continue to emerge as a regulator of large scale changes in metabolic homeostasis rather than a player in the fine-tune control of metabolism in response to varied stimuli (such as specific dietary components).

\section{g. MITOGEN-ACTIVATED PROTEIN KINASES}

The phosphorylation of proteins at serine and threonine residues is a major mechanism in the regulation of metabolism, growth, differentiation, apoptosis, and gene expression. A major class of serine/threonine kinases mediating signal transduction in response to extracellular stimuli is the mitogen-activated protein kinases (MAPK) $(216,217)$. Mitogen-activated protein kinases (MAPKs) are activated by specific extracellular stimuli and act alone and in concert to 
effect rapid intracellular responses to those stimuli. Mammalian MAPKs include p38 MAPK, cJun n-terminal kinase (JNK), and extracellular signal-related kinases (ERK 1/2).

The cascade that regulates all the MAPKs consists of a MAPK kinase kinase (MKKK) and a MAPK kinase (MEK), leading to the sequential activation of the MAPK itself. MEKs recognize and phosphorylate the thr-X-tyr motif in the activation loop of all MAPKs, which are themselves serine/threonine kinases. MEKs are regulated by serine/threonine kinases and their cellular localization. The most common MAPK substrates are transcription factors, whose activities are regulated by phosphorylation (such as transcription factors downstream of estrogen, insulin, and glucocorticoid receptors)(216-219).

\section{h. EXTRACELLULAR SIGNAL-REGULATED KINASE}

Different MAPK cascades have been identified, but the best characterized in mammalian cells is the extracellular signal-regulated kinase (ERK) pathway. This leads to the activation of ERK1 and ERK2. A role for ERK 1/2 in cell growth and survival is well understood in a variety of tissues; however, a role for this MAPK in mediating the insulin signaling pathway and lipogenesis is just emerging. ERK $1 / 2$ are 44 and $42 \mathrm{kDa}$ proteins expressed in all tissues. ERK 1/2 are phosphorylated by MEK1 and MEK2, and are activated in response to treatment with fatty acids, growth factors, and cell stress (220). Erk1 and Erk2 are generally activated together, share greater than $85 \%$ sequence identity, and appear to serve a redundant role in the cell (217, 218, 221).

ERK $1 / 2$ is rapidly phosphorylated when cells are treated with insulin, and there is some evidence that ERK functions to antagonize the intracellular insulin response in response to polyunsaturated fatty acid (90). In this respect, ERK activation by $n-3$ polyunsaturated fatty acid (specifically docosahexaenoic acid) activates ERK, while also inhibiting the insulin stimulation of AKT. This activation of ERK mediates the proteasomal degradation of SREBP-1c in response to polyunsaturated fatty acids $(90,219,222)$. This data suggests a role for ERK in mediating hepatic lipogenesis, yet it remains to be seen whether this role is specific for the lipogenic pathway or whether ERK functions to antagonize insulin signaling after a variety of stimuli.

\section{i. $\quad$ 38 MAPK}


p38 mitogen-activated protein kinase (p38 MAPK) is a $38 \mathrm{kDa}$ member of the mitogenactivated protein kinase superfamily. p38 MAPK contains a TGY activation loop, which is phosphorylated by upstream kinases MKK3/6 for full activation (223). Rac and CDC42 are also upstream activators of p38 MAPK (224). A potential role of AMPK upstream of p38 MAPK has also been suggested, but has not yet been shown definitively $(147,225,226)$. Downstream targets of p38 MAPK include cAMP response binding protein (CREB), activating transcription factor -1 and-2 (ATF1, ATF2), CHOP, p53, C/EBP, and IRS-1 and -2 (223, 227). Through its effect on these transcription factors, p38 MAPK action can direct gene expression during times of cellular stress.

Activation of p38 MAPK occurs in response to a variety of cellular stimuli (228-230). In various tissues, these include the inflammatory cytokines, growth factors, G protein-coupled receptor activation, and other cell stressors (231). Elevation of plasma non-esterified fatty acids is a known activator of $\mathrm{p} 38$ MAPK (232). This activation results in an intracellular protective response mediated by $\mathrm{p} 38 \mathrm{MAPK}$, leading to events such as the production of heat shock proteins, immune responses, cell differentiation, or cell death.

In addition to its role in mediating cellular stress responses in a variety of tissues, p38 MAPK also plays a role in energy homeostasis in tissues such as brown adipose, muscle, and hepatocytes. p38 MAPK activation stimulates the mitochondrial oxidation, thermogenesis, and gluconeogenesis (233-238). p38 MAPK is activated by cAMP and glucagon in isolated hepatocytes, and through this activation p38 MAPK inhibits hepatic lipogenesis through its inhibition of SREBP-1c expression (238). In whole animals, p38 MAPK is activated in liver by fasting, and knock-down of p38 MAPK results in an elevation in circulating plasma triacylglycerol as well as hepatic triacylglycerol content (238). In response to non-esterified fatty acids, p38 MAPK is phosphorylated and the transcription of gluconeogenic genes are stimulated (such as PEPCK and G6Pase)(238). p38 MAPK also inhibits the posttranscriptional regulation of G6PD in liver in response to polyunsaturated fatty acids (146).

This data strongly suggests a central role for p38 MAPK in liver, in mediating the cellular response to fasting and re-feeding, as well as to specific nutrients in the diet (such as polyunsaturated fatty acids and glucose). However, the exact mechanism by which p38 regulates lipogenesis in the liver has not been established. 


\section{j. C-JUN N-TERMINAL PROTEIN KINASE}

The c-Jun N-terminal protein kinases (JNK1/2/3) bind to and phosphorylate c-Jun, a component of the AP-1 transcription complex. JNK proteins are 46 and $54 \mathrm{kDa}$, and JNK1/2/3 share greater than $85 \%$ sequence identity (239). JNK is a stress-activated protein kinase that is highly responsive to cytokines, g-protein coupled receptor activation, growth factors, and many other extracellular stimuli $(217,240)$. Like all other MAPKs, JNK is activated by upstream MEKKs and MEKs through phosphorylation within their thr-X-tyr loop. JNK activation results in cytokine production, the inflammatory response, apoptosis, actin reorganization, and cell transformation (241).

JNK phosphorylation is induced during diabetes and insulin resistance, possibly due to an increase in intracellular oxidative stress and the subsequent activation of MEK 4/7 (242); this activation of JNK leads to impairments in the insulin-signaling pathway because JNK can inhibit IRS-1 (through ser ${ }^{307}$ phosphorylation), and may also mediate some of the apoptotic effects of high circulating free fatty acids $(2,243-245)$. Knockdown of JNK in mice has been shown to improve type 2 diabetes, as well as a reduction in body weight and atherosclerosis $(2,245)$. While JNK definitely plays a role in antagonizing the insulin signal during times of stress, it does not appear that JNK plays a specific role in mediating the cellular response to normal physiological changes, such as the availability of nutrients between meals, or the response to different nutritional stimuli.

\section{PHYSIOLOGY OF LIPID DIGESTION, ABSORPTION, AND UPTAKE BY THE LIVER}

\section{a. ANIMAL AND CELL CULTURE MODELS}

For over 30 years it has been known that individuals with high circulating blood lipid levels can ameliorate this condition by including polyunsaturated fatty acids in their diets. The intracellular mechanism for this regulation is still unknown. Beginning in 1958, the work of Hill et al established that the rate of fatty acid synthesis in liver, and the activity of key lipogenic 
enzymes, was regulated by an increase in polyunsaturated fatty acids included in a mouse or rat diet (30). It was determined that polyunsaturated fatty acids of the $n-3$ and $n-6$ varieties inhibit hepatic lipogenesis at low levels in the diet, and that this inhibition is not due to a decrease in carbohydrate intake $(246,247)$. This finding prompted additional study of specific unsaturated fatty acids on the inhibition of hepatic lipogenesis (31-33, 246, 248-250).

In order to examine specific factors that influence hepatic gene expression, primary rat hepatocytes in culture have been the predominant model. The effects of non-esterified fatty acids on primary hepatocytes have been studied in order to address the mechanisms by which dietary fatty acids exert their inhibitory effects on hepatic lipogenesis; although this experimental paradigm has been incredibly useful in describing these mechanisms, we must be careful in broadly applying these results to the intact animal because this model mimics the physiological state only during starvation and uncontrolled diabetes. During these conditions, one of the mediators of the inhibitory effects of polyunsaturated fatty acid on lipogenesis is non-esterified fatty acid. Non-esterified fatty acids are released from adipose tissue into the blood during starvation (or during uncontrolled diabetes), when lipolysis is stimulated by glucagon and results in the hydrolysis of free fatty acid from glycerol (251). These non-esterified fatty acids are released from adipose tissue and travel through the blood bound to serum albumin. The nonesterified fatty acids are taken up by liver, where they bind to intracellular fatty acid binding proteins, and they become substrates for: $\beta$-oxidation, elongation and desaturation, triacylglycerol, phospholipid, and cholesterol synthesis, and may be converted to prostanoids (17). Although the effects of non-esterified fatty acids in primary hepatocytes generally mimic the effect of starvation in intact animal, it is important to consider that the mechanisms by which dietary fatty acids exert their inhibitory effects are still unknown. The physiology of dietary fat digestion, transport, and uptake by the liver (and how this differs from the transport of lipolysisderived non-esterified fatty acids) is described below.

\section{b. DIETARY LIPID DIGESTION, ABSORPTION, AND HEPATIC METABOLISM}

Dietary triacylglycerol and other lipid components are energy dense and water-insoluble. Without significant processing, dietary lipid would not be available to peripheral tissues in a usable state. The general mechanism by which lipid is digested begins with its emulsification, 
rendering it able to diffuse into the lumen of the enterocyte. Emulsification is accomplished both mechanically, by the mouth and stomach, and chemically, by the addition of cholesterol, phospholipids, protein, and polysaccharides to the emulsion particle in the stomach. As dietary triacylglycerol is hydrophobic, it resides in the interior of the emulsion particles.

Both lingual and gastric lipases work to hydrolyze the triacylglycerols associated with each emulsion particle. The action of these enzymes releases a single fatty acid and diacylglycerol (which both remain in the emulsion particle for further digestion in the intestine). In the small intestine the lipid components of emulsion particles are next acted upon by pancreatic lipase, colipase, carboxyl ester hydrolase, and phospholipase $\mathrm{A}_{2}$, which are secreted from the pancreas. The net result of these enzymes is the hydrolysis of lipid into its free fatty acid, 2-monoacylglycerol, free cholesterol, and lysophospholipid components.

As triacylglycerol is further hydrolyzed into free fatty acid and other lipid breakdown products, the emulsion particle becomes much smaller and is now called a mixed-micelle. The breakdown products converge at the surface of the enterocyte, where they either diffuse or are transported through the enterocyte membrane into its lumen.

Once in the enterocyte, these breakdown products are re-esterified into triacylglycerols, phospholipids, and cholesterol esters. Within the enterocyte, these products are then incorporated into a lipoprotein particle called a chylomicron. The chylomicron contains triacylglycerol and cholesterol in its core, surrounded by phospholipids and apolipoprotein B-48 on its exterior (252). Chylomicrons are then secreted into the intestinal lymphatic capillaries, and into the blood stream via the thoracic lymph duct (where they acquire ApoC-II and ApoE from the HDL pool) (253).

Chylomicrons interact with lipoprotein lipase on the surface of capillary endothelial cells. Lipoprotein lipase hydrolyzes triacylglycerol in the chylomicrons, releasing free fatty acids that can diffuse into peripheral tissues for $\beta$-oxidation or storage (254). Free fatty acids, released from the chylomicron, may enter cells via fatty acid transport proteins (FATP), through simple diffusion, or through yet unidentified transporters (255). Fatty acids are then used as substrates for $\beta$-oxidation, elongation, desaturation, and for biosynthesis of active compounds (45).

As chylomicrons are acted upon by lipases at the peripheral tissues, their fatty acid and cholesterol content decreases, producing a smaller, denser particle known as a chylomicron remnant that is ultimately taken up by the liver (252). The LDL receptor and the LDL-receptor 
related protein (LRP) are the primary proteins involved in chylomicron remnant removal (57). Roles for hepatic lipase, phospholipase, and heparin sulfate proteoglycans (HSPG) have also been described (57). It remains to be seen which of these pathways predominates. However, it is known that ApoE is necessary for the uptake of chylomicron remnants, as ApoE-depleted remnants will not be cleared (256).

Lysosomal enzymes in the liver hydrolyze the triacylglycerol that is left in the remnant as it is taken into the hepatocyte. This is a major source of fatty acid for the liver (257). Chylomicron remnants are enriched in fatty acids from the diet, therefore, the triacylglycerols that are taken up by the liver from chylomicron remnants also represent the same types of fats present in the diet (Figure 5)(258, 259).

\section{FIGURE 5.}

\section{CHYLOMICRON METABOLISM}

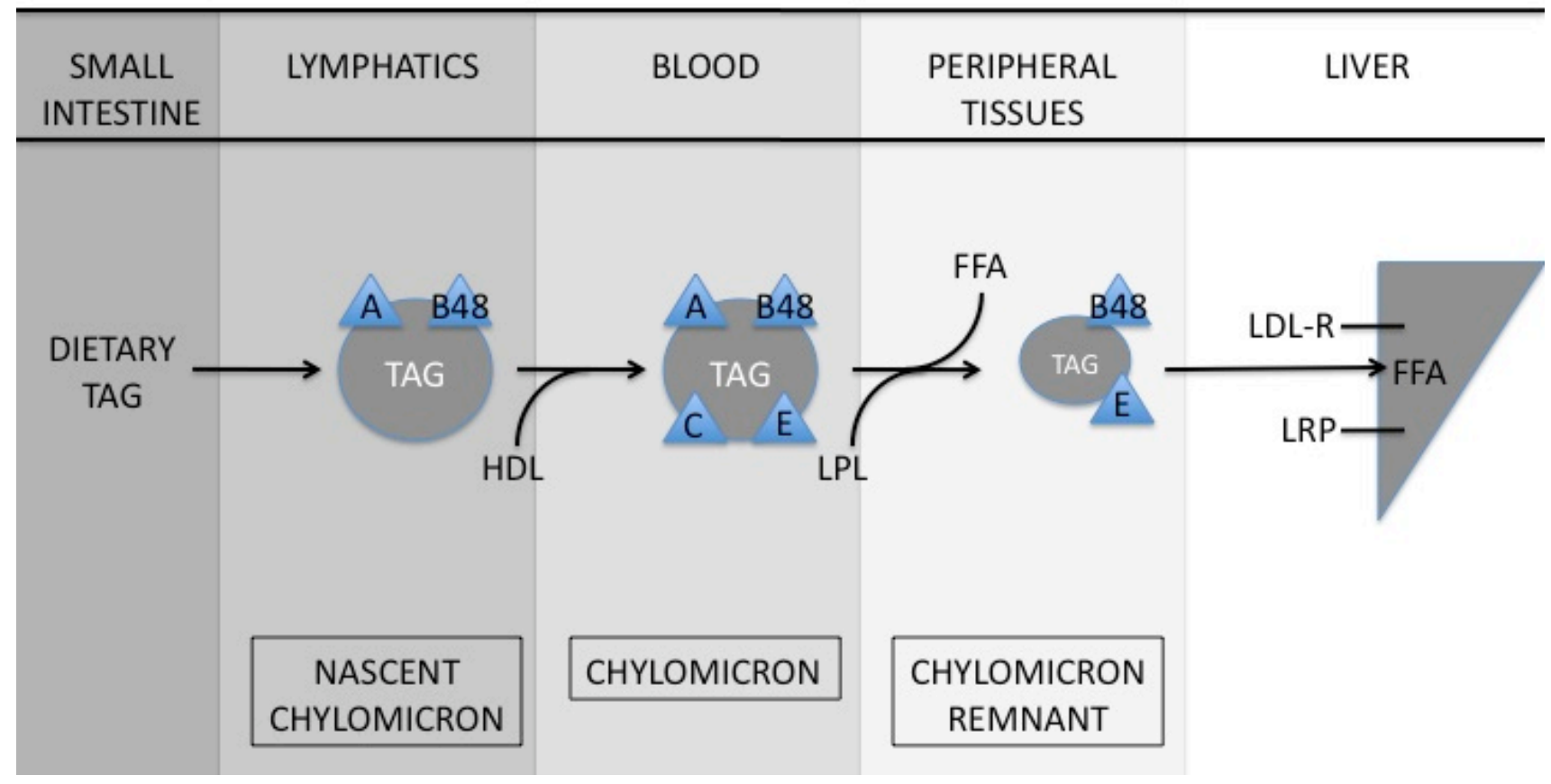




\section{c. FREE FATTY ACID TRAFFICKING ACROSS THE CELL MEMBRANE}

There are several evolutionarily conserved proteins responsible for the transport and metabolism of fatty acids entering the mammalian cell. These include at least 6 fatty acid transport proteins (FATP) and 5 long-chain acyl CoA synthetases (Acsl), which facilitate the unidirectional transport of fatty acids across the cell membrane through vectorial acylation (260). The roles of each of these isoforms are not clear, although they vary in tissue distribution and substrate specificity. Vectorial acylation is the process by which fatty acids enter the cell concomitantly with their esterification to CoA thioesters, making the fatty acyl CoA unable to diffuse back across the membrane. In this reaction, catalyzed by Acsl, substrate fatty acid, CoA, and ATP are required to form the acyl-CoA product and AMP.

Acsl possess activity towards long chain fatty acids, and each isoform is expressed in a unique pattern among tissues and within cellular organelles. The fact that there are many isoforms, located in a distinct intracellular pattern, with different substrate specificities, suggests that each isoform may have a distinct function. Acsl 1,4, and 5 are the predominant isoforms in liver (261). Interaction with specific FATP and/or Acsl classes seems to render the fatty acyl CoA more available to specific metabolic pathways within the cell. For example, it has now been shown that Acsl 4 activation of fatty acids directs these products towards mitochondrial $\beta$ oxidation, whereas interaction with other isoforms may direct fatty acyl CoA products towards cytoplasmic de novo lipogenesis (261).

Vectorial acylation is not the only mechanism for bringing exogenous free fatty acids into the cell. Fatty acids, like other hydrophilic compounds, are able to bind the cell membrane. Through this mechanism, they are thought to enter the cell through binding and flipping between the two leaflets of the cell membrane (262-264). Fatty acid transport combines delivery to the membrane, flipping between the leaflets, and protein-mediated mechanisms to then "pull" the fatty acids away from the membrane. Recently, it has been suggested that the flip between the membrane leaflet requires energy and possibly a specific FATP isoform, although this mechanism is poorly understood (265-267). The kinetics of this process are still unknown; especially, whether this process is saturable without protein chaperones, or whether it may occur in the presence of another fatty acid transport protein such as CD36 (267). However, CD36 
expression does not correlate with changes in the rate of fatty acid uptake (261). FATP isoforms, however, have been shown to directly interact with Acsl at the cell membrane (261).

Tissues with high rates of fatty acid uptake and lipid metabolism also have high levels of expression of one or more fatty acid binding proteins (FABPs). FABPs are cytoplasmic proteins that bind to both saturated and unsaturated fatty acids, and are involved in their transport between membranes $(268,269)$. Liver-type FABP (LFABP) is involved in lipid absorption and VLDL metabolism in liver, and is one of the most abundant proteins in liver (270). The functional importance of LFABP is demonstrated by LFABP-null mice, which have severe defects in $\beta$-oxidation, due to a lack of substrate availability $(271,272)$. Additionally, LFABPnull mice are protected from hepatic steatosis when they are fed a high-fat diet, unlike their wildtype counterparts $(271,272)$. LFABP has been found in the nucleus, where it directly interacts with PPAR- $\alpha$ to mediate gene expression (273). Due to differences in the affinity of LFABP binding to saturated versus unsaturated fatty acids, LFABP may be involved in partitioning fatty acids to specific metabolic pathways.

The availability of so many isoforms of intracellular proteins that bind fatty acids suggests that there are many factors influencing the binding of fatty acid to each isoform and the subsequent partitioning of that fatty acid to a specific metabolic pathway. That these factors may include the source of fatty acid (either from non-esterified fatty acid entering the cell during starvation, or from the hydrolysis of dietary triacylglycerol) is an important and unknown consideration in understanding how dietary polyunsaturated fat regulates energy homeostasis.

\section{HYPOTHESIS}

As described above, the potential for dietary polyunsaturated fatty acids to impact metabolic processes is significant. However, the specific mechanisms by which dietary polyunsaturated fatty acids inhibit de novo lipogenesis have been determined through experiments in which albumin-bound polyunsaturated fatty acids are added to primary rat hepatocytes in culture (40). This experimental model assumes that adding free fatty acids to cultured cells, which will increase the intracellular fatty acid concentration, will result in the same metabolic changes as dietary fat. This is an untested assumption. 
This model has serious limitations, not the least of which is that dietary polyunsaturated fat is not delivered to the liver as non-esterified fatty acids. Dietary triacylglycerol enters the peripheral circulation from the intestine as a nascent chylomicron and is taken up by the liver as a chylomicron remnant (252), which is significantly different from the uptake of albumin-bound fatty acid, which occurs predominantly during starvation.

As described above, there is evidence that the mode of entry of lipid into the hepatocyte can dictate its metabolic fate. Acyl-CoA synthetases are able to channel long chain fatty acids to specific metabolic pathways, specifically, non-esterified fatty acids entering via Acsl 1 appears to partition to the microsome for de novo lipogenesis, whereas fatty acids encountering other Acsl isoforms may partition towards $\beta$-oxidation (274-276).

The goal of these experiments is to define the differences between chylomicron remnant triacylglycerol and non-esterified polyunsaturated fatty acids in the regulation of hepatic de novo fatty acid synthesis, as well as their roles in the signal transduction mechanism. These experiments provide evidence for significant differences in the regulatory potential between albumin-bound non-esterified fatty acids and dietary triacylglycerol in the hepatocyte. This finding is novel, and is crucial in understanding the physiological effects of dietary fat on liver. These mechanisms are necessary for our understanding of metabolic diseases such as type 2 diabetes, heart disease, and metabolic syndrome, which all share defects in the ability of the liver to properly respond to dietary fat. 


\section{REFERENCES}

1. Gual, P., Y. Le Marchand-Brustel, and J. F. Tanti. 2005. Positive and negative regulation of insulin signaling through IRS-1 phosphorylation. Biochimie 87: 99-109.

2. Hirosumi, J., G. Tuncman, L. Chang, C. Z. Gorgun, K. T. Uysal, K. Maeda, M. Karin, and G. S. Hotamisligil. 2002. A central role for JNK in obesity and insulin resistance. Nature 420: 333-336.

3. Sampath, H., and J. M. Ntambi. 2004. Polyunsaturated fatty acid regulation of gene expression. Nutr Rev 62: 333-339.

4. Le, H. D., J. A. Meisel, V. E. de Meijer, K. M. Gura, and M. Puder. 2009. The essentiality of arachidonic acid and docosahexaenoic acid. Prostaglandins Leukot Essent Fatty Acids.

5. Adam, O., G. Wolfram, and N. Zollner. 1986. Effect of alpha-linolenic acid in the human diet on linoleic acid metabolism and prostaglandin biosynthesis. J Lipid Res 27: 421-426.

6. Marszalek, J. R., and H. F. Lodish. 2005. Docosahexaenoic acid, fatty acid-interacting proteins, and neuronal function: breastmilk and fish are good for you. Annu Rev Cell Dev Biol 21: 633-657.

7. Benatti, P., G. Peluso, R. Nicolai, and M. Calvani. 2004. Polyunsaturated fatty acids: biochemical, nutritional and epigenetic properties. J Am Coll Nutr 23: 281-302.

8. Holub, B. J. 2002. Clinical nutrition: 4. Omega-3 fatty acids in cardiovascular care. CMAJ 166: 608-615.

9. Schmitz, G., and J. Ecker. 2008. The opposing effects of n-3 and n-6 fatty acids. Prog Lipid Res 47: 147-155.

10. Jump, D. B., D. Botolin, Y. Wang, J. Xu, B. Christian, and O. Demeure. 2005. Fatty acid regulation of hepatic gene transcription. $J$ Nutr 135: 2503-2506.

11. Contreras, M. A., and S. I. Rapoport. 2002. Recent studies on interactions between n-3 and n-6 polyunsaturated fatty acids in brain and other tissues. Curr Opin Lipidol 13: 267-272. 12. Niu, S. L., D. C. Mitchell, S. Y. Lim, Z. M. Wen, H. Y. Kim, N. Salem, Jr., and B. J. Litman. 2004. Reduced G protein-coupled signaling efficiency in retinal rod outer segments in response to n-3 fatty acid deficiency. J Biol Chem 279: 31098-31104. 
13. Grossfield, A., S. E. Feller, and M. C. Pitman. 2006. A role for direct interactions in the modulation of rhodopsin by omega-3 polyunsaturated lipids. Proc Natl Acad Sci US A 103: 4888-4893.

14. Sugimoto, Y., and S. Narumiya. 2007. Prostaglandin E receptors. J Biol Chem 282: 11613-11617.

15. Rajamoorthi, K., H. I. Petrache, T. J. McIntosh, and M. F. Brown. 2005. Packing and viscoelasticity of polyunsaturated omega-3 and omega-6 lipid bilayers as seen by (2)H NMR and X-ray diffraction. J Am Chem Soc 127: 1576-1588.

16. Akbar, M., F. Calderon, Z. Wen, and H. Y. Kim. 2005. Docosahexaenoic acid: a positive modulator of Akt signaling in neuronal survival. Proc Natl Acad Sci U S A 102: 10858-10863.

17. Hillgartner, F. B., L. M. Salati, and A. G. Goodridge. 1995. Physiological and molecular mechanisms involved in nutritional regulation of fatty acid synthesis. Physiol Rev 75: 47-76.

18. Salati, L. M., W. Szeszel-Fedorowicz, H. Tao, M. A. Gibson, B. Amir-Ahmady, L. P. Stabile, and D. L. Hodge. 2004. Nutritional regulation of mRNA processing. J Nutr 134: 2437S2443S.

19. Wakil, S. J. 1989. Fatty acid synthase, a proficient multifunctional enzyme. Biochemistry 28: $4523-4530$.

20. Byers, D. M., and H. Gong. 2007. Acyl carrier protein: structure-function relationships in a conserved multifunctional protein family. Biochem Cell Biol 85: 649-662.

21. McGarry, J. D., G. P. Mannaerts, and D. W. Foster. 1977. A possible role for malonylCoA in the regulation of hepatic fatty acid oxidation and ketogenesis. $J$ Clin Invest 60: 265-270.

22. Rodbell, M. 1997. The complex regulation of receptor-coupled G-proteins. Adv Enzyme Regul 37: 427-435.

23. Krebs, H. A. 1966. The regulation of the release of ketone bodies by the liver. $A d v$ Enzyme Regul 4: 339-354.

24. Rous, S. 1971. The origin of hydrogen in fatty acid synthesis. Adv Lipid Res 9: 73-118.

25. Lindsay, D. B. 1975. Fatty acids as energy sources. Proc Nutr Soc 34: 241-248.

26. Postic, C., and J. Girard. 2008. The role of the lipogenic pathway in the development of hepatic steatosis. Diabetes Metab 34: 643-648. 
27. Fukuda, H., A. Katsurada, and N. Iritani. 1992. Nutritional and hormonal regulation of mRNA levels of lipogenic enzymes in primary cultures of rat hepatocytes. $J$ Biochem 111: 2530.

28. Salati, L. M., B. Adkins-Finke, and S. D. Clarke. 1988. Free fatty acid inhibition of the insulin induction of glucose-6-phosphate dehydrogenase in rat hepatocyte monolayers. Lipids $\mathbf{2 3}$ : $36-41$.

29. Kunau, W. H., V. Dommes, and H. Schulz. 1995. beta-oxidation of fatty acids in mitochondria, peroxisomes, and bacteria: a century of continued progress. Prog Lipid Res 34: 267-342.

30. Hill, R., J. M. Linazasoro, F. Chevallier, and I. L. Chaikoff. 1958. Regulation of hepatic lipogenesis: the influence of dietary fats. $J$ Biol Chem 233: 305-310.

31. Allmann, D. W., D. D. Hubbard, and D. M. Gibson. 1965. Fatty Acid Synthesis During Fat-Free Refeeding of Starved Rats. J Lipid Res 6: 63-74.

32. Wiegand, R. D., G. A. Rao, and R. Reiser. 1973. Dietary regulation of fatty acid synthetase and microsomal glycerophosphate acyltransferase activities in rat liver. $J$ Nutr 103: 1414-1424.

33. Clarke, S. D., D. R. Romsos, and G. A. Leveille. 1976. Specific inhibition of hepatic fatty acid synthesis exerted by dietary linoleate and linolenate in essential fatty acid adequate rats. Lipids 11: 485-490.

34. Baltzell, J. K., and C. D. Berdanier. 1985. Effect on the interaction of dietary carbohydrate and fat on the responses of rats to starvation-refeeding. $J$ Nutr 115: 104-110. 35. Wilson, M. D., R. D. Hays, and S. D. Clarke. 1986. Inhibition of liver lipogenesis by dietary polyunsaturated fat in severely diabetic rats. $J$ Nutr 116: 1511-1518.

36. Clarke, S. D., D. R. Romsos, and G. A. Leveille. 1977. Differential effects of dietary methyl esters of long-chain saturated and polyunsaturated fatty acids on rat liver and adipose tissue lipogenesis. J Nutr 107: 1170-1181.

37. Clarke, B. A., and S. D. Clarke. 1982. Suppression of rat liver fatty acid synthesis by eicosa-5,8,11,14-tetraynoic acid without a reduction in lipogenic enzymes. $J$ Nutr 112: 1212 1219.

38. Szepesi, B., A. K. Kamara, and S. D. Clarke. 1989. Lack of specificity of polyunsaturated fats in the inhibition of rat liver glucose-6-phosphate dehydrogenase. J Nutr 119: 161-165. 
39. Goodridge, A. G. 1973. Regulation of fatty acid synthesis in isolated hepatocytes. Evidence for a physiological role for long chain fatty acyl coenzyme A and citrate. $J$ Biol Chem 248: 4318-4326.

40. Salati, L. M., and S. D. Clarke. 1986. Fatty acid inhibition of hormonal induction of acetyl-coenzyme A carboxylase in hepatocyte monolayers. Arch Biochem Biophys 246: 82-89. 41. Goodridge, A. G., A. Garay, and P. Silpananta. 1974. Regulation of lipogenesis and the total activities of lipogenic enzymes in a primary culture of hepatocytes from prenatal and early postnatal chicks. J Biol Chem 249: 1469-1475.

42. Armstrong, M. K., W. L. Blake, and S. D. Clarke. 1991. Arachidonic acid suppression of fatty acid synthase gene expression in cultured rat hepatocytes. Biochem Biophys Res Commun 177: 1056-1061.

43. Jump, D. B., S. D. Clarke, A. Thelen, and M. Liimatta. 1994. Coordinate regulation of glycolytic and lipogenic gene expression by polyunsaturated fatty acids. J Lipid Res 35: 10761084.

44. Jump, D. B., and S. D. Clarke. 1999. Regulation of gene expression by dietary fat. Annu Rev Nutr 19: 63-90.

45. Jump, D. B. 2004. Fatty acid regulation of gene transcription. Crit Rev Clin Lab Sci 41: 41-78.

46. Jump, D. B. 2002. Dietary polyunsaturated fatty acids and regulation of gene transcription. Curr Opin Lipidol 13: 155-164.

47. Tao, H., W. Szeszel-Fedorowicz, B. Amir-Ahmady, M. A. Gibson, L. P. Stabile, and L. M. Salati. 2002. Inhibition of the splicing of glucose-6-phosphate dehydrogenase precursor mRNA by polyunsaturated fatty acids. J Biol Chem 277: 31270-31278.

48. Bradley, M. N., C. Hong, M. Chen, S. B. Joseph, D. C. Wilpitz, X. Wang, A. J. Lusis, A. Collins, W. A. Hseuh, J. L. Collins, R. K. Tangirala, and P. Tontonoz. 2007. Ligand activation of LXR beta reverses atherosclerosis and cellular cholesterol overload in mice lacking LXR alpha and apoE. J Clin Invest 117: 2337-2346.

49. Tontonoz, P., and D. J. Mangelsdorf. 2003. Liver X receptor signaling pathways in cardiovascular disease. Mol Endocrinol 17: 985-993.

50. Edwards, P. A., M. A. Kennedy, and P. A. Mak. 2002. LXRs; oxysterol-activated nuclear receptors that regulate genes controlling lipid homeostasis. Vascul Pharmacol 38: 249-256. 
51. Alberti, S., G. Schuster, P. Parini, D. Feltkamp, U. Diczfalusy, M. Rudling, B. Angelin, I. Bjorkhem, S. Pettersson, and J. A. Gustafsson. 2001. Hepatic cholesterol metabolism and resistance to dietary cholesterol in LXRbeta-deficient mice. J Clin Invest 107: 565-573.

52. Repa, J. J., and D. J. Mangelsdorf. 2000. The role of orphan nuclear receptors in the regulation of cholesterol homeostasis. Annu Rev Cell Dev Biol 16: 459-481.

53. Pawar, A., J. Xu, E. Jerks, D. J. Mangelsdorf, and D. B. Jump. 2002. Fatty acid regulation of liver X receptors (LXR) and peroxisome proliferator-activated receptor alpha (PPARalpha ) in HEK293 cells. J Biol Chem 277: 39243-39250.

54. Yoshikawa, T., H. Shimano, N. Yahagi, T. Ide, M. Amemiya-Kudo, T. Matsuzaka, M. Nakakuki, S. Tomita, H. Okazaki, Y. Tamura, Y. Iizuka, K. Ohashi, A. Takahashi, H. Sone, J. Osuga Ji, T. Gotoda, S. Ishibashi, and N. Yamada. 2002. Polyunsaturated fatty acids suppress sterol regulatory element-binding protein 1c promoter activity by inhibition of liver X receptor (LXR) binding to LXR response elements. J Biol Chem 277: 1705-1711.

55. Krey, G., O. Braissant, F. L'Horset, E. Kalkhoven, M. Perroud, M. G. Parker, and W. Wahli. 1997. Fatty acids, eicosanoids, and hypolipidemic agents identified as ligands of peroxisome proliferator-activated receptors by coactivator-dependent receptor ligand assay. Mol Endocrinol 11: 779-791.

56. Gottlicher, M., E. Widmark, Q. Li, and J. A. Gustafsson. 1992. Fatty acids activate a chimera of the clofibric acid-activated receptor and the glucocorticoid receptor. Proc Natl Acad Sci U S A 89: 4653-4657.

57. Clarke, S. D. 2001. Polyunsaturated fatty acid regulation of gene transcription: a molecular mechanism to improve the metabolic syndrome. J Nutr 131: 1129-1132.

58. Ferre, P. 2004. The biology of peroxisome proliferator-activated receptors: relationship with lipid metabolism and insulin sensitivity. Diabetes 53 Suppl 1: S43-50.

59. Issemann, I., and S. Green. 1990. Activation of a member of the steroid hormone receptor superfamily by peroxisome proliferators. Nature 347: 645-650.

60. Desvergne, B., and W. Wahli. 1999. Peroxisome proliferator-activated receptors: nuclear control of metabolism. Endocr Rev 20: 649-688.

61. Xu, H. E., M. H. Lambert, V. G. Montana, D. J. Parks, S. G. Blanchard, P. J. Brown, D. D. Sternbach, J. M. Lehmann, G. B. Wisely, T. M. Willson, S. A. Kliewer, and M. V. Milburn. 
1999. Molecular recognition of fatty acids by peroxisome proliferator-activated receptors. $M o l$ Cell 3: 397-403.

62. Kliewer, S. A., H. E. Xu, M. H. Lambert, and T. M. Willson. 2001. Peroxisome proliferator-activated receptors: from genes to physiology. Recent Prog Horm Res 56: 239-263.

63. Sapiro, J. M., M. T. Mashek, A. S. Greenberg, and D. G. Mashek. 2009. Hepatic triacylglycerol hydrolysis regulates peroxisome proliferator-activated receptor alpha activity. $J$ Lipid Res 50: 1621-1629.

64. Brown, M. S., and J. L. Goldstein. 1997. The SREBP pathway: regulation of cholesterol metabolism by proteolysis of a membrane-bound transcription factor. Cell 89: 331-340.

65. Osborne, T. F. 2000. Sterol regulatory element-binding proteins (SREBPs): key regulators of nutritional homeostasis and insulin action. J Biol Chem 275: 32379-32382.

66. Hua, X., J. Wu, J. L. Goldstein, M. S. Brown, and H. H. Hobbs. 1995. Structure of the human gene encoding sterol regulatory element binding protein-1 (SREBF1) and localization of SREBF1 and SREBF2 to chromosomes 17p11.2 and 22q13. Genomics 25: 667-673.

67. Miserez, A. R., G. Cao, L. C. Probst, and H. H. Hobbs. 1997. Structure of the human gene encoding sterol regulatory element binding protein 2 (SREBF2). Genomics 40: 31-40. 68. Shimomura, I., H. Shimano, J. D. Horton, J. L. Goldstein, and M. S. Brown. 1997. Differential expression of exons $1 \mathrm{a}$ and $1 \mathrm{c}$ in mRNAs for sterol regulatory element binding protein-1 in human and mouse organs and cultured cells. J Clin Invest 99: 838-845.

69. Espenshade, P. J., and A. L. Hughes. 2007. Regulation of sterol synthesis in eukaryotes. Annu Rev Genet 41: 401-427.

70. Todd, B. L., E. V. Stewart, J. S. Burg, A. L. Hughes, and P. J. Espenshade. 2006. Sterol regulatory element binding protein is a principal regulator of anaerobic gene expression in fission yeast. Mol Cell Biol 26: 2817-2831.

71. Briggs, M. R., C. Yokoyama, X. Wang, M. S. Brown, and J. L. Goldstein. 1993. Nuclear protein that binds sterol regulatory element of low density lipoprotein receptor promoter. I. Identification of the protein and delineation of its target nucleotide sequence. J Biol Chem 268: 14490-14496.

72. Wang, X., M. R. Briggs, X. Hua, C. Yokoyama, J. L. Goldstein, and M. S. Brown. 1993. Nuclear protein that binds sterol regulatory element of low density lipoprotein receptor promoter. II. Purification and characterization. J Biol Chem 268: 14497-14504. 
73. Kim, Y. C., and J. M. Ntambi. 1999. Regulation of stearoyl-CoA desaturase genes: role in cellular metabolism and preadipocyte differentiation. Biochem Biophys Res Commun 266: 1-4. 74. Yahagi, N., H. Shimano, A. H. Hasty, M. Amemiya-Kudo, H. Okazaki, Y. Tamura, Y. Iizuka, F. Shionoiri, K. Ohashi, J. Osuga, K. Harada, T. Gotoda, R. Nagai, S. Ishibashi, and N. Yamada. 1999. A crucial role of sterol regulatory element-binding protein-1 in the regulation of lipogenic gene expression by polyunsaturated fatty acids. J Biol Chem 274: 35840-35844.

75. Ferre, P., and F. Foufelle. 2007. SREBP-1c transcription factor and lipid homeostasis: clinical perspective. Horm Res 68: 72-82.

76. Goldstein, J. L., R. A. DeBose-Boyd, and M. S. Brown. 2006. Protein sensors for membrane sterols. Cell 124: 35-46.

77. Horton, J. D., N. A. Shah, J. A. Warrington, N. N. Anderson, S. W. Park, M. S. Brown, and J. L. Goldstein. 2003. Combined analysis of oligonucleotide microarray data from transgenic and knockout mice identifies direct SREBP target genes. Proc Natl Acad Sci U S A 100: 1202712032.

78. Yang, T., P. J. Espenshade, M. E. Wright, D. Yabe, Y. Gong, R. Aebersold, J. L. Goldstein, and M. S. Brown. 2002. Crucial step in cholesterol homeostasis: sterols promote binding of SCAP to INSIG-1, a membrane protein that facilitates retention of SREBPs in ER. Cell 110: 489-500.

79. Horton, J. D., Y. Bashmakov, I. Shimomura, and H. Shimano. 1998. Regulation of sterol regulatory element binding proteins in livers of fasted and refed mice. Proc Natl Acad Sci U S A 95: 5987-5992.

80. Kim, J. B., P. Sarraf, M. Wright, K. M. Yao, E. Mueller, G. Solanes, B. B. Lowell, and B. M. Spiegelman. 1998. Nutritional and insulin regulation of fatty acid synthetase and leptin gene expression through ADD1/SREBP1. J Clin Invest 101: 1-9.

81. Deng, X., L. M. Cagen, H. G. Wilcox, E. A. Park, R. Raghow, and M. B. Elam. 2002. Regulation of the rat SREBP-1c promoter in primary rat hepatocytes. Biochem Biophys Res Commun 290: 256-262.

82. Deng, X., C. Yellaturu, L. Cagen, H. G. Wilcox, E. A. Park, R. Raghow, and M. B. Elam. 2007. Expression of the rat sterol regulatory element-binding protein-1c gene in response to insulin is mediated by increased transactivating capacity of specificity protein 1 (Sp1). J Biol Chem 282: 17517-17529. 
83. Amemiya-Kudo, M., H. Shimano, A. H. Hasty, N. Yahagi, T. Yoshikawa, T. Matsuzaka, H. Okazaki, Y. Tamura, Y. Iizuka, K. Ohashi, J. Osuga, K. Harada, T. Gotoda, R. Sato, S. Kimura, S. Ishibashi, and N. Yamada. 2002. Transcriptional activities of nuclear SREBP-1a, -1c, and -2 to different target promoters of lipogenic and cholesterogenic genes. J Lipid Res 43: 12201235.

84. Yoshikawa, T., H. Shimano, M. Amemiya-Kudo, N. Yahagi, A. H. Hasty, T. Matsuzaka, H. Okazaki, Y. Tamura, Y. Iizuka, K. Ohashi, J. Osuga, K. Harada, T. Gotoda, S. Kimura, S. Ishibashi, and N. Yamada. 2001. Identification of liver X receptor-retinoid X receptor as an activator of the sterol regulatory element-binding protein 1c gene promoter. Mol Cell Biol 21: 2991-3000.

85. Chen, G., G. Liang, J. Ou, J. L. Goldstein, and M. S. Brown. 2004. Central role for liver $\mathrm{X}$ receptor in insulin-mediated activation of Srebp-1c transcription and stimulation of fatty acid synthesis in liver. Proc Natl Acad Sci U S A 101: 11245-11250.

86. Azzout-Marniche, D., D. Becard, C. Guichard, M. Foretz, P. Ferre, and F. Foufelle. 2000. Insulin effects on sterol regulatory-element-binding protein-1c (SREBP-1c) transcriptional activity in rat hepatocytes. Biochem J 350 Pt 2: 389-393.

87. Shimomura, I., Y. Bashmakov, S. Ikemoto, J. D. Horton, M. S. Brown, and J. L. Goldstein. 1999. Insulin selectively increases SREBP-1c mRNA in the livers of rats with streptozotocin-induced diabetes. Proc Natl Acad Sci U S A 96: 13656-13661.

88. Yabe, D., R. Komuro, G. Liang, J. L. Goldstein, and M. S. Brown. 2003. Liver-specific mRNA for Insig-2 down-regulated by insulin: implications for fatty acid synthesis. Proc Natl Acad Sci U S A 100: 3155-3160.

89. Yellaturu, C. R., X. Deng, L. M. Cagen, H. G. Wilcox, E. A. Park, R. Raghow, and M. B. Elam. 2005. Posttranslational processing of SREBP-1 in rat hepatocytes is regulated by insulin and cAMP. Biochem Biophys Res Commun 332: 174-180.

90. Botolin, D., Y. Wang, B. Christian, and D. B. Jump. 2006. Docosahexaneoic acid $(22: 6, n-3)$ regulates rat hepatocyte SREBP-1 nuclear abundance by Erk- and 26S proteasomedependent pathways. J Lipid Res 47: 181-192.

91. Taniguchi, C. M., K. Ueki, and R. Kahn. 2005. Complementary roles of IRS-1 and IRS-2 in the hepatic regulation of metabolism. J Clin Invest 115: 718-727. 
92. Matsumoto, M., W. Ogawa, K. Teshigawara, H. Inoue, K. Miyake, H. Sakaue, and M. Kasuga. 2002. Role of the insulin receptor substrate 1 and phosphatidylinositol 3-kinase signaling pathway in insulin-induced expression of sterol regulatory element binding protein $1 \mathrm{c}$ and glucokinase genes in rat hepatocytes. Diabetes 51: 1672-1680.

93. Sajan, M. P., M. L. Standaert, J. Rivas, A. Miura, Y. Kanoh, J. Soto, C. M. Taniguchi, C. R. Kahn, and R. V. Farese. 2009. Role of atypical protein kinase C in activation of sterol regulatory element binding protein-1c and nuclear factor kappa B (NFkappaB) in liver of rodents used as a model of diabetes, and relationships to hyperlipidaemia and insulin resistance.

Diabetologia 52: 1197-1207.

94. Sajan, M. P., M. L. Standaert, S. Nimal, U. Varanasi, T. Pastoor, S. Mastorides, U. Braun, M. Leitges, and R. V. Farese. 2009. The critical role of atypical protein kinase C in activating hepatic SREBP-1c and NF \{kappa\}B in obesity. J Lipid Res 50: 1133-1145.

95. Mater, M. K., A. P. Thelen, D. A. Pan, and D. B. Jump. 1999. Sterol response elementbinding protein 1c (SREBP1c) is involved in the polyunsaturated fatty acid suppression of hepatic S14 gene transcription. J Biol Chem 274: 32725-32732.

96. Lee, J. N., X. Zhang, J. D. Feramisco, Y. Gong, and J. Ye. 2008. Unsaturated fatty acids inhibit proteasomal degradation of Insig-1 at a postubiquitination step. J Biol Chem 283: 3377233783.

97. Stoeckman, A. K., and H. C. Towle. 2002. The role of SREBP-1c in nutritional regulation of lipogenic enzyme gene expression. J Biol Chem 277: 27029-27035.

98. Liang, G., J. Yang, J. D. Horton, R. E. Hammer, J. L. Goldstein, and M. S. Brown. 2002. Diminished hepatic response to fasting/refeeding and liver $\mathrm{X}$ receptor agonists in mice with selective deficiency of sterol regulatory element-binding protein-1c. J Biol Chem 277: 95209528.

99. Yamashita, H., M. Takenoshita, M. Sakurai, R. K. Bruick, W. J. Henzel, W. Shillinglaw, D. Arnot, and K. Uyeda. 2001. A glucose-responsive transcription factor that regulates carbohydrate metabolism in the liver. Proc Natl Acad Sci U S A 98: 9116-9121.

100. Iizuka, K., R. K. Bruick, G. Liang, J. D. Horton, and K. Uyeda. 2004. Deficiency of carbohydrate response element-binding protein (ChREBP) reduces lipogenesis as well as glycolysis. Proc Natl Acad Sci U S A 101: 7281-7286. 
101. Shih, H. M., Z. Liu, and H. C. Towle. 1995. Two CACGTG motifs with proper spacing dictate the carbohydrate regulation of hepatic gene transcription. J Biol Chem 270: 21991-21997. 102. Rufo, C., M. Teran-Garcia, M. T. Nakamura, S. H. Koo, H. C. Towle, and S. D. Clarke. 2001. Involvement of a unique carbohydrate-responsive factor in the glucose regulation of rat liver fatty-acid synthase gene transcription. J Biol Chem 276: 21969-21975.

103. Dentin, R., J. P. Pegorier, F. Benhamed, F. Foufelle, P. Ferre, V. Fauveau, M. A.

Magnuson, J. Girard, and C. Postic. 2004. Hepatic glucokinase is required for the synergistic action of ChREBP and SREBP-1c on glycolytic and lipogenic gene expression. J Biol Chem 279: 20314-20326.

104. Ishii, S., K. Iizuka, B. C. Miller, and K. Uyeda. 2004. Carbohydrate response element binding protein directly promotes lipogenic enzyme gene transcription. Proc Natl Acad Sci U S A 101: $15597-15602$.

105. Stoeckman, A. K., L. Ma, and H. C. Towle. 2004. Mlx is the functional heteromeric partner of the carbohydrate response element-binding protein in glucose regulation of lipogenic enzyme genes. J Biol Chem 279: 15662-15669.

106. Ma, L., L. N. Robinson, and H. C. Towle. 2006. ChREBP*Mlx is the principal mediator of glucose-induced gene expression in the liver. J Biol Chem 281: 28721-28730.

107. Ma, L., N. G. Tsatsos, and H. C. Towle. 2005. Direct role of ChREBP.Mlx in regulating hepatic glucose-responsive genes. J Biol Chem 280: 12019-12027.

108. Dentin, R., F. Benhamed, J. P. Pegorier, F. Foufelle, B. Viollet, S. Vaulont, J. Girard, and C. Postic. 2005. Polyunsaturated fatty acids suppress glycolytic and lipogenic genes through the inhibition of ChREBP nuclear protein translocation. J Clin Invest 115: 2843-2854.

109. Kabashima, T., T. Kawaguchi, B. E. Wadzinski, and K. Uyeda. 2003. Xylulose 5phosphate mediates glucose-induced lipogenesis by xylulose 5-phosphate-activated protein phosphatase in rat liver. Proc Natl Acad Sci US A 100: 5107-5112.

110. Kawaguchi, T., M. Takenoshita, T. Kabashima, and K. Uyeda. 2001. Glucose and cAMP regulate the L-type pyruvate kinase gene by phosphorylation/dephosphorylation of the carbohydrate response element binding protein. Proc Natl Acad Sci U S A 98: 13710-13715.

111. Kawaguchi, T., K. Osatomi, H. Yamashita, T. Kabashima, and K. Uyeda. 2002. Mechanism for fatty acid "sparing" effect on glucose-induced transcription: regulation of 
carbohydrate-responsive element-binding protein by AMP-activated protein kinase. $J$ Biol Chem 277: 3829-3835.

112. Tsatsos, N. G., and H. C. Towle. 2006. Glucose activation of ChREBP in hepatocytes occurs via a two-step mechanism. Biochem Biophys Res Commun 340: 449-456.

113. Cha, J. Y., and J. J. Repa. 2007. The liver X receptor (LXR) and hepatic lipogenesis. The carbohydrate-response element-binding protein is a target gene of LXR. J Biol Chem 282: 743751.

114. Siculella, L., F. Damiano, S. Sabetta, and G. V. Gnoni. 2004. n-6 PUFAs downregulate expression of the tricarboxylate carrier in rat liver by transcriptional and posttranscriptional mechanisms. J Lipid Res 45: 1333-1340.

115. Walker, J. D., L. A. Burmeister, A. Mariash, J. F. Bosman, J. Harmon, and C. N. Mariash. 1996. Insulin increases the processing efficiency of messenger ribonucleic acid-S14 nuclear precursor. Endocrinology 137: 2293-2299.

116. Jump, D. B., A. Bell, and V. Santiago. 1990. Thyroid hormone and dietary carbohydrate interact to regulate rat liver S14 gene transcription and chromatin structure. J Biol Chem 265: 3474-3478.

117. Xu, J., M. Teran-Garcia, J. H. Park, M. T. Nakamura, and S. D. Clarke. 2001.

Polyunsaturated fatty acids suppress hepatic sterol regulatory element-binding protein-1 expression by accelerating transcript decay. J Biol Chem 276: 9800-9807.

118. Tepperman, H. M., and J. Tepperman. 1964. Patterns of Dietary and Hormonal Induction of Certain Nadp-Linked Liver Enzymes. Am J Physiol 206: 357-361.

119. Rognstad, R. 1979. Rate-limiting steps in metabolic pathways. J Biol Chem 254: 18751878 .

120. Glock, G. E., and P. McLean. 1955. Effects of hormones on levels of oxidized and reduced diphosphopyridine nucleotide and triphosphopyridine nucleotide in liver and diaphragm. Biochem J 61: 397-402.

121. Pandolfi, P. P., F. Sonati, R. Rivi, P. Mason, F. Grosveld, and L. Luzzatto. 1995. Targeted disruption of the housekeeping gene encoding glucose 6-phosphate dehydrogenase (G6PD): G6PD is dispensable for pentose synthesis but essential for defense against oxidative stress. Embo J 14: 5209-5215. 
122. Kletzien, R. F., P. K. Harris, and L. A. Foellmi. 1994. Glucose-6-phosphate dehydrogenase: a "housekeeping" enzyme subject to tissue-specific regulation by hormones, nutrients, and oxidant stress. Faseb J 8: 174-181.

123. Dessi, S., B. Batetta, O. Spano, D. Pulisci, M. F. Mulas, S. Muntoni, M. Armeni, C. Sanna, R. Antonucci, and P. Pani. 1992. Serum lipoprotein pattern as modified in G6PDdeficient children during haemolytic anaemia induced by fava bean ingestion. Int J Exp Pathol 73: $157-160$.

124. Takizawa, T., I. Y. Huang, T. Ikuta, and A. Yoshida. 1986. Human glucose-6-phosphate dehydrogenase: primary structure and cDNA cloning. Proc Natl Acad Sci U S A 83: 4157-4161. 125. Mehta, A., P. J. Mason, and T. J. Vulliamy. 2000. Glucose-6-phosphate dehydrogenase deficiency. Baillieres Best Pract Res Clin Haematol 13: 21-38.

126. Vulliamy, T., P. Mason, and L. Luzzatto. 1992. The molecular basis of glucose-6phosphate dehydrogenase deficiency. Trends Genet 8: 138-143.

127. Stabile, L. P., S. A. Klautky, S. M. Minor, and L. M. Salati. 1998. Polyunsaturated fatty acids inhibit the expression of the glucose-6-phosphate dehydrogenase gene in primary rat hepatocytes by a nuclear posttranscriptional mechanism. J Lipid Res 39: 1951-1963.

128. Fukuda, H., and N. Iritani. 1991. Diurnal variations of lipogenic enzyme mRNA quantities in rat liver. Biochim Biophys Acta 1086: 261-264.

129. Hodge, D. L., and L. M. Salati. 1997. Nutritional regulation of the glucose-6-phosphate dehydrogenase gene is mediated by a nuclear posttranscriptional mechanism. Arch Biochem Biophys 348: 303-312.

130. Stabile, L. P., D. L. Hodge, S. A. Klautky, and L. M. Salati. 1996. Posttranscriptional regulation of glucose-6-phosphate dehydrogenase by dietary polyunsaturated fat. Arch Biochem Biophys 332: 269-279.

131. Prostko, C. R., R. S. Fritz, and R. F. Kletzien. 1989. Nutritional regulation of hepatic glucose-6-phosphate dehydrogenase. Transient activation of transcription. Biochem J 258: 295299.

132. Amir-Ahmady, B., and L. M. Salati. 2001. Regulation of the processing of glucose-6phosphate dehydrogenase mRNA by nutritional status. J Biol Chem 276: 10514-10523. 
133. Le Hir, H., D. Gatfield, E. Izaurralde, and M. J. Moore. 2001. The exon-exon junction complex provides a binding platform for factors involved in mRNA export and nonsensemediated mRNA decay. Embo J 20: 4987-4997.

134. Hilleren, P., T. McCarthy, M. Rosbash, R. Parker, and T. H. Jensen. 2001. Quality control of mRNA 3'-end processing is linked to the nuclear exosome. Nature 413: 538-542.

135. Berget, S. M. 1995. Exon recognition in vertebrate splicing. J Biol Chem 270: 24112414.

136. Blencowe, B. J. 2000. Exonic splicing enhancers: mechanism of action, diversity and role in human genetic diseases. Trends Biochem Sci 25: 106-110.

137. Dreyfuss, G., M. J. Matunis, S. Pinol-Roma, and C. G. Burd. 1993. hnRNP proteins and the biogenesis of mRNA. Annu Rev Biochem 62: 289-321.

138. Liu, H. X., M. Zhang, and A. R. Krainer. 1998. Identification of functional exonic splicing enhancer motifs recognized by individual SR proteins. Genes Dev 12: 1998-2012.

139. Rothrock, C. R., A. E. House, and K. W. Lynch. 2005. HnRNP L represses exon splicing via a regulated exonic splicing silencer. Embo J 24: 2792-2802.

140. Hui, J., K. Stangl, W. S. Lane, and A. Bindereif. 2003. HnRNP L stimulates splicing of the eNOS gene by binding to variable-length CA repeats. Nat Struct Biol 10: 33-37.

141. Ibrahim, E. C., T. D. Schaal, K. J. Hertel, R. Reed, and T. Maniatis. 2005.

Serine/arginine-rich protein-dependent suppression of exon skipping by exonic splicing enhancers. Proc Natl Acad Sci U S A 102: 5002-5007.

142. Huang, S., and D. L. Spector. 1996. Dynamic organization of pre-mRNA splicing factors. J Cell Biochem 62: 191-197.

143. Misteli, T. 1999. RNA splicing: What has phosphorylation got to do with it? Curr Biol 9: R198-200.

144. Sacco-Bubulya, P., and D. L. Spector. 2002. Disassembly of interchromatin granule clusters alters the coordination of transcription and pre-mRNA splicing. J Cell Biol 156: 425436.

145. Griffith, B. N., C. M. Walsh, W. Szeszel-Fedorowicz, A. T. Timperman, and L. M. Salati. 2006. Identification of hnRNPs K, L and A2/B1 as candidate proteins involved in the nutritional regulation of mRNA splicing. Biochim Biophys Acta 1759: 552-561. 
146. Talukdar, I., W. Szeszel-Fedorowicz, and L. M. Salati. 2005. Arachidonic acid inhibits the insulin induction of glucose-6-phosphate dehydrogenase via p38 MAP kinase. J Biol Chem 280: 40660-40667.

147. Kohan, A. B., Talukdar, I., Walsh, C.M., Salati, L.M. 2009. A role for AMPK in the inhibition of glucose-6-phosphate dehydrogenase by polyunsaturated fatty acids. Biochem Biophys Res Commun.

148. Pessin, J. E., D. C. Thurmond, J. S. Elmendorf, K. J. Coker, and S. Okada. 1999. Molecular basis of insulin-stimulated GLUT4 vesicle trafficking. Location! Location! Location! J Biol Chem 274: 2593-2596.

149. Schinner, S., W. A. Scherbaum, S. R. Bornstein, and A. Barthel. 2005. Molecular mechanisms of insulin resistance. Diabet Med 22: 674-682.

150. Pessin, J. E., and A. R. Saltiel. 2000. Signaling pathways in insulin action: molecular targets of insulin resistance. J Clin Invest 106: 165-169.

151. White, M. F. 1998. The IRS-signalling system: a network of docking proteins that mediate insulin action. Mol Cell Biochem 182: 3-11.

152. Patti, M. E., and C. R. Kahn. 1998. The insulin receptor--a critical link in glucose homeostasis and insulin action. J Basic Clin Physiol Pharmacol 9: 89-109.

153. Skolnik, E. Y., A. Batzer, N. Li, C. H. Lee, E. Lowenstein, M. Mohammadi, B. Margolis, and J. Schlessinger. 1993. The function of GRB2 in linking the insulin receptor to Ras signaling pathways. Science 260: 1953-1955.

154. Cheatham, B., C. J. Vlahos, L. Cheatham, L. Wang, J. Blenis, and C. R. Kahn. 1994. Phosphatidylinositol 3-kinase activation is required for insulin stimulation of pp70 S6 kinase, DNA synthesis, and glucose transporter translocation. Mol Cell Biol 14: 4902-4911.

155. Araki, E., M. A. Lipes, M. E. Patti, J. C. Bruning, B. Haag, 3rd, R. S. Johnson, and C. R. Kahn. 1994. Alternative pathway of insulin signalling in mice with targeted disruption of the IRS-1 gene. Nature 372: 186-190.

156. Tamemoto, H., T. Kadowaki, K. Tobe, T. Yagi, H. Sakura, T. Hayakawa, Y. Terauchi, K. Ueki, Y. Kaburagi, S. Satoh, and et al. 1994. Insulin resistance and growth retardation in mice lacking insulin receptor substrate-1. Nature 372: 182-186. 
157. Withers, D. J., J. S. Gutierrez, H. Towery, D. J. Burks, J. M. Ren, S. Previs, Y. Zhang, D. Bernal, S. Pons, G. I. Shulman, S. Bonner-Weir, and M. F. White. 1998. Disruption of IRS-2 causes type 2 diabetes in mice. Nature 391: 900-904.

158. Liu, S. C., Q. Wang, G. E. Lienhard, and S. R. Keller. 1999. Insulin receptor substrate 3 is not essential for growth or glucose homeostasis. J Biol Chem 274: 18093-18099.

159. Fantin, V. R., Q. Wang, G. E. Lienhard, and S. R. Keller. 2000. Mice lacking insulin receptor substrate 4 exhibit mild defects in growth, reproduction, and glucose homeostasis. Am J Physiol Endocrinol Metab 278: E127-133.

160. Bruning, J. C., J. Winnay, B. Cheatham, and C. R. Kahn. 1997. Differential signaling by insulin receptor substrate 1 (IRS-1) and IRS-2 in IRS-1-deficient cells. Mol Cell Biol 17: 15131521.

161. Fantin, V. R., J. D. Sparling, J. W. Slot, S. R. Keller, G. E. Lienhard, and B. E. Lavan. 1998. Characterization of insulin receptor substrate 4 in human embryonic kidney 293 cells. $J$ Biol Chem 273: 10726-10732.

162. Sesti, G., M. Federici, M. L. Hribal, D. Lauro, P. Sbraccia, and R. Lauro. 2001. Defects of the insulin receptor substrate (IRS) system in human metabolic disorders. Faseb J 15: 20992111.

163. Hotamisligil, G. S., P. Peraldi, A. Budavari, R. Ellis, M. F. White, and B. M. Spiegelman. 1996. IRS-1-mediated inhibition of insulin receptor tyrosine kinase activity in TNF-alpha- and obesity-induced insulin resistance. Science 271: 665-668.

164. Aguirre, V., T. Uchida, L. Yenush, R. Davis, and M. F. White. 2000. The c-Jun NH(2)terminal kinase promotes insulin resistance during association with insulin receptor substrate-1 and phosphorylation of Ser(307). J Biol Chem 275: 9047-9054.

165. Mothe, I., and E. Van Obberghen. 1996. Phosphorylation of insulin receptor substrate-1 on multiple serine residues, 612, 632, 662, and 731, modulates insulin action. J Biol Chem 271: 11222-11227.

166. Ravichandran, L. V., D. L. Esposito, J. Chen, and M. J. Quon. 2001. Protein kinase Czeta phosphorylates insulin receptor substrate-1 and impairs its ability to activate phosphatidylinositol 3-kinase in response to insulin. J Biol Chem 276: 3543-3549. 
167. De Fea, K., and R. A. Roth. 1997. Modulation of insulin receptor substrate-1 tyrosine phosphorylation and function by mitogen-activated protein kinase. J Biol Chem 272: 3140031406.

168. Aguirre, V., E. D. Werner, J. Giraud, Y. H. Lee, S. E. Shoelson, and M. F. White. 2002. Phosphorylation of Ser307 in insulin receptor substrate-1 blocks interactions with the insulin receptor and inhibits insulin action. $J$ Biol Chem 277: 1531-1537.

169. Fujishiro, M., Y. Gotoh, H. Katagiri, H. Sakoda, T. Ogihara, M. Anai, Y. Onishi, H. Ono, M. Abe, N. Shojima, Y. Fukushima, M. Kikuchi, Y. Oka, and T. Asano. 2003. Three mitogenactivated protein kinases inhibit insulin signaling by different mechanisms in 3T3-L1 adipocytes. Mol Endocrinol 17: 487-497.

170. Kim, J. K., J. J. Fillmore, Y. Chen, C. Yu, I. K. Moore, M. Pypaert, E. P. Lutz, Y. Kako, W. Velez-Carrasco, I. J. Goldberg, J. L. Breslow, and G. I. Shulman. 2001. Tissue-specific overexpression of lipoprotein lipase causes tissue-specific insulin resistance. Proc Natl Acad Sci U S A 98: 7522-7527.

171. Myers, M. G., Jr., J. M. Backer, X. J. Sun, S. Shoelson, P. Hu, J. Schlessinger, M. Yoakim, B. Schaffhausen, and M. F. White. 1992. IRS-1 activates phosphatidylinositol 3'-kinase by associating with src homology 2 domains of p85. Proc Natl Acad Sci U S A 89: 10350-10354.

172. Shepherd, P. R., B. T. Nave, and K. Siddle. 1995. Insulin stimulation of glycogen synthesis and glycogen synthase activity is blocked by wortmannin and rapamycin in 3T3-L1 adipocytes: evidence for the involvement of phosphoinositide 3-kinase and p70 ribosomal protein-S6 kinase. Biochem J 305 ( Pt 1): 25-28.

173. Alessi, D. R., and P. Cohen. 1998. Mechanism of activation and function of protein kinase B. Curr Opin Genet Dev 8: 55-62.

174. Alessi, D. R., S. R. James, C. P. Downes, A. B. Holmes, P. R. Gaffney, C. B. Reese, and P. Cohen. 1997. Characterization of a 3-phosphoinositide-dependent protein kinase which phosphorylates and activates protein kinase Balpha. Curr Biol 7: 261-269.

175. Walker, K. S., M. Deak, A. Paterson, K. Hudson, P. Cohen, and D. R. Alessi. 1998. Activation of protein kinase B beta and gamma isoforms by insulin in vivo and by 3phosphoinositide-dependent protein kinase-1 in vitro: comparison with protein kinase B alpha. Biochem J 331 ( Pt 1): 299-308. 
176. Burgering, B. M., and P. J. Coffer. 1995. Protein kinase B (c-Akt) in phosphatidylinositol-3-OH kinase signal transduction. Nature 376: 599-602.

177. Stephens, L., K. Anderson, D. Stokoe, H. Erdjument-Bromage, G. F. Painter, A. B.

Holmes, P. R. Gaffney, C. B. Reese, F. McCormick, P. Tempst, J. Coadwell, and P. T. Hawkins. 1998. Protein kinase B kinases that mediate phosphatidylinositol 3,4,5-trisphosphate-dependent activation of protein kinase B. Science 279: 710-714.

178. Sarbassov, D. D., D. A. Guertin, S. M. Ali, and D. M. Sabatini. 2005. Phosphorylation and regulation of Akt/PKB by the rictor-mTOR complex. Science 307: 1098-1101.

179. Scheid, M. P., and J. R. Woodgett. 2001. PKB/AKT: functional insights from genetic models. Nat Rev Mol Cell Biol 2: 760-768.

180. Nakae, J., and D. Accili. 1999. The mechanism of insulin action. J Pediatr Endocrinol Metab 12 Suppl 3: 721-731.

181. Biggs, W. H., 3rd, J. Meisenhelder, T. Hunter, W. K. Cavenee, and K. C. Arden. 1999. Protein kinase B/Akt-mediated phosphorylation promotes nuclear exclusion of the winged helix transcription factor FKHR1. Proc Natl Acad Sci U S A 96: 7421-7426.

182. Guo, S., G. Rena, S. Cichy, X. He, P. Cohen, and T. Unterman. 1999. Phosphorylation of serine 256 by protein kinase B disrupts transactivation by FKHR and mediates effects of insulin on insulin-like growth factor-binding protein-1 promoter activity through a conserved insulin response sequence. J Biol Chem 274: 17184-17192.

183. Greer, E. L., and A. Brunet. 2005. FOXO transcription factors at the interface between longevity and tumor suppression. Oncogene 24: 7410-7425.

184. Barthel, A., D. Schmoll, and T. G. Unterman. 2005. FoxO proteins in insulin action and metabolism. Trends Endocrinol Metab 16: 183-189.

185. Zimmermann, S., and K. Moelling. 1999. Phosphorylation and regulation of Raf by Akt (protein kinase B). Science 286: 1741-1744.

186. Taniguchi, C. M., B. Emanuelli, and C. R. Kahn. 2006. Critical nodes in signalling pathways: insights into insulin action. Nat Rev Mol Cell Biol 7: 85-96.

187. Han, S., C. P. Liang, M. Westerterp, T. Senokuchi, C. L. Welch, Q. Wang, M. Matsumoto, D. Accili, and A. R. Tall. 2009. Hepatic insulin signaling regulates VLDL secretion and atherogenesis in mice. J Clin Invest 119: 1029-1041. 
188. Semple, R. K., A. Sleigh, P. R. Murgatroyd, C. A. Adams, L. Bluck, S. Jackson, A. Vottero, D. Kanabar, V. Charlton-Menys, P. Durrington, M. A. Soos, T. A. Carpenter, D. J. Lomas, E. K. Cochran, P. Gorden, S. O'Rahilly, and D. B. Savage. 2009. Postreceptor insulin resistance contributes to human dyslipidemia and hepatic steatosis. J Clin Invest 119: 315-322. 189. Zhang, W., S. Patil, B. Chauhan, S. Guo, D. R. Powell, J. Le, A. Klotsas, R. Matika, X. Xiao, R. Franks, K. A. Heidenreich, M. P. Sajan, R. V. Farese, D. B. Stolz, P. Tso, S. H. Koo, M. Montminy, and T. G. Unterman. 2006. FoxO1 regulates multiple metabolic pathways in the liver: effects on gluconeogenic, glycolytic, and lipogenic gene expression. J Biol Chem 281: 10105-10117.

190. Sul, H. S., M. J. Latasa, Y. Moon, and K. H. Kim. 2000. Regulation of the fatty acid synthase promoter by insulin. $J$ Nutr 130: 315S-320S.

191. Suzuki, A., K. Akimoto, and S. Ohno. 2003. Protein kinase C lambda/iota (PKClambda/iota): a PKC isotype essential for the development of multicellular organisms. $J$ Biochem 133: 9-16.

192. Leitges, M., L. Sanz, P. Martin, A. Duran, U. Braun, J. F. Garcia, F. Camacho, M. T. Diaz-Meco, P. D. Rennert, and J. Moscat. 2001. Targeted disruption of the zetaPKC gene results in the impairment of the NF-kappaB pathway. Mol Cell 8: 771-780.

193. Jaken, S. 1996. Protein kinase C isozymes and substrates. Curr Opin Cell Biol 8: 168173.

194. Mellor, H., and P. J. Parker. 1998. The extended protein kinase C superfamily. Biochem J 332 ( Pt 2): 281-292.

195. Newton, A. C. 1995. Protein kinase C: structure, function, and regulation. J Biol Chem 270: $28495-28498$.

196. Newton, A. C. 1997. Regulation of protein kinase C. Curr Opin Cell Biol 9: 161-167. 197. Parekh, D. B., W. Ziegler, and P. J. Parker. 2000. Multiple pathways control protein kinase C phosphorylation. Embo J 19: 496-503.

198. Sajan, M. P., M. L. Standaert, A. Miura, C. R. Kahn, and R. V. Farese. 2004. Tissuespecific differences in activation of atypical protein kinase $\mathrm{C}$ and protein kinase $\mathrm{B}$ in muscle, liver, and adipocytes of insulin receptor substrate-1 knockout mice. Mol Endocrinol 18: 25132521. 
199. Farese, R. V., M. P. Sajan, and M. L. Standaert. 2005. Insulin-sensitive protein kinases (atypical protein kinase $\mathrm{C}$ and protein kinase $\mathrm{B} / \mathrm{Akt}$ ): actions and defects in obesity and type II diabetes. Exp Biol Med (Maywood) 230: 593-605.

200. Farese, R. V., M. P. Sajan, and M. L. Standaert. 2005. Atypical protein kinase C in insulin action and insulin resistance. Biochem Soc Trans 33: 350-353.

201. Matsumoto, M., W. Ogawa, K. Akimoto, H. Inoue, K. Miyake, K. Furukawa, Y. Hayashi, H. Iguchi, Y. Matsuki, R. Hiramatsu, H. Shimano, N. Yamada, S. Ohno, M. Kasuga, and T. Noda. 2003. PKClambda in liver mediates insulin-induced SREBP-1c expression and determines both hepatic lipid content and overall insulin sensitivity. J Clin Invest 112: 935-944.

202. Taniguchi, C. M., T. Kondo, M. Sajan, J. Luo, R. Bronson, T. Asano, R. Farese, L. C. Cantley, and C. R. Kahn. 2006. Divergent regulation of hepatic glucose and lipid metabolism by phosphoinositide 3-kinase via Akt and PKClambda/zeta. Cell Metab 3: 343-353.

203. Murakami, K., and A. Routtenberg. 1985. Direct activation of purified protein kinase C by unsaturated fatty acids (oleate and arachidonate) in the absence of phospholipids and $\mathrm{Ca} 2+$. FEBS Lett 192: 189-193.

204. Bell, R. M., and D. J. Burns. 1991. Lipid activation of protein kinase C. J Biol Chem 266: 4661-4664.

205. Laybutt, D. R., C. Schmitz-Peiffer, A. K. Saha, N. B. Ruderman, T. J. Biden, and E. W. Kraegen. 1999. Muscle lipid accumulation and protein kinase $\mathrm{C}$ activation in the insulin-resistant chronically glucose-infused rat. Am J Physiol 277: E1070-1076.

206. Zick, Y. 2001. Insulin resistance: a phosphorylation-based uncoupling of insulin signaling. Trends Cell Biol 11: 437-441.

207. Liu, Y. F., K. Paz, A. Herschkovitz, A. Alt, T. Tennenbaum, S. R. Sampson, M. Ohba, T. Kuroki, D. LeRoith, and Y. Zick. 2001. Insulin stimulates PKCzeta -mediated phosphorylation of insulin receptor substrate-1 (IRS-1). A self-attenuated mechanism to negatively regulate the function of IRS proteins. J Biol Chem 276: 14459-14465.

208. Kahn, B. B., T. Alquier, D. Carling, and D. G. Hardie. 2005. AMP-activated protein kinase: ancient energy gauge provides clues to modern understanding of metabolism. Cell Metab 1: $15-25$.

209. Hardie, D. G. 2004. The AMP-activated protein kinase pathway--new players upstream and downstream. J Cell Sci 117: 5479-5487. 
210. Hawley, S. A., J. Boudeau, J. L. Reid, K. J. Mustard, L. Udd, T. P. Makela, D. R. Alessi, and D. G. Hardie. 2003. Complexes between the LKB1 tumor suppressor, STRAD alpha/beta and MO25 alpha/beta are upstream kinases in the AMP-activated protein kinase cascade. $J$ Biol 2: 28 .

211. Davies, S. P., A. T. Sim, and D. G. Hardie. 1990. Location and function of three sites phosphorylated on rat acetyl-CoA carboxylase by the AMP-activated protein kinase. Eur $J$ Biochem 187: 183-190.

212. Munday, M. R., D. G. Campbell, D. Carling, and D. G. Hardie. 1988. Identification by amino acid sequencing of three major regulatory phosphorylation sites on rat acetyl-CoA carboxylase. Eur J Biochem 175: 331-338.

213. Hardie, D. G., J. W. Scott, D. A. Pan, and E. R. Hudson. 2003. Management of cellular energy by the AMP-activated protein kinase system. FEBS Lett 546: 113-120.

214. Carling, D. 2004. The AMP-activated protein kinase cascade--a unifying system for energy control. Trends Biochem Sci 29: 18-24.

215. Fryer, L. G., A. Parbu-Patel, and D. Carling. 2002. The Anti-diabetic drugs rosiglitazone and metformin stimulate AMP-activated protein kinase through distinct signaling pathways. $J$ Biol Chem 277: 25226-25232.

216. Gibson, S., C. Widmann, and G. L. Johnson. 1999. Differential involvement of MEK kinase 1 (MEKK1) in the induction of apoptosis in response to microtubule-targeted drugs versus DNA damaging agents. J Biol Chem 274: 10916-10922.

217. Widmann, C., S. Gibson, M. B. Jarpe, and G. L. Johnson. 1999. Mitogen-activated protein kinase: conservation of a three-kinase module from yeast to human. Physiol Rev 79: 143180.

218. Treisman, R. 1996. Regulation of transcription by MAP kinase cascades. Curr Opin Cell Biol 8: 205-215.

219. Roth, G., J. Kotzka, L. Kremer, S. Lehr, C. Lohaus, H. E. Meyer, W. Krone, and D. Muller-Wieland. 2000. MAP kinases Erk1/2 phosphorylate sterol regulatory element-binding protein (SREBP)-1a at serine 117 in vitro. $J$ Biol Chem 275: 33302-33307.

220. Payne, D. M., A. J. Rossomando, P. Martino, A. K. Erickson, J. H. Her, J. Shabanowitz, D. F. Hunt, M. J. Weber, and T. W. Sturgill. 1991. Identification of the regulatory 
phosphorylation sites in pp42/mitogen-activated protein kinase (MAP kinase). Embo J 10: 885892.

221. Boulton, T. G., S. H. Nye, D. J. Robbins, N. Y. Ip, E. Radziejewska, S. D. Morgenbesser, R. A. DePinho, N. Panayotatos, M. H. Cobb, and G. D. Yancopoulos. 1991. ERKs: a family of protein-serine/threonine kinases that are activated and tyrosine phosphorylated in response to insulin and NGF. Cell 65: 663-675.

222. Kotzka, J., D. Muller-Wieland, G. Roth, L. Kremer, M. Munck, S. Schurmann, B. Knebel, and W. Krone. 2000. Sterol regulatory element binding proteins (SREBP)-1a and SREBP-2 are linked to the MAP-kinase cascade. J Lipid Res 41: 99-108.

223. Herlaar, E., and Z. Brown. 1999. p38 MAPK signalling cascades in inflammatory disease. Mol Med Today 5: 439-447.

224. McDermott, E. P., and L. A. O'Neill. 2002. Ras participates in the activation of p38 MAPK by interleukin-1 by associating with IRAK, IRAK2, TRAF6, and TAK-1. J Biol Chem 277: 7808-7815.

225. Hayashi, T., M. F. Hirshman, N. Fujii, S. A. Habinowski, L. A. Witters, and L. J. Goodyear. 2000. Metabolic stress and altered glucose transport: activation of AMP-activated protein kinase as a unifying coupling mechanism. Diabetes 49: 527-531.

226. Yoon, M. J., G. Y. Lee, J. J. Chung, Y. H. Ahn, S. H. Hong, and J. B. Kim. 2006. Adiponectin increases fatty acid oxidation in skeletal muscle cells by sequential activation of AMP-activated protein kinase, p38 mitogen-activated protein kinase, and peroxisome proliferator-activated receptor alpha. Diabetes 55: 2562-2570.

227. Ono, K., and J. Han. 2000. The p38 signal transduction pathway: activation and function. Cell Signal 12: 1-13.

228. Conze, D., J. Lumsden, H. Enslen, R. J. Davis, G. Le Gros, and M. Rincon. 2000. Activation of p38 MAP kinase in T cells facilitates the immune response to the influenza virus. Mol Immunol 37: 503-513.

229. Rincon, M., D. Conze, L. Weiss, N. L. Diehl, K. A. Fortner, D. Yang, R. A. Flavell, H. Enslen, A. Whitmarsh, and R. J. Davis. 2000. Conference highlight: do T cells care about the mitogen-activated protein kinase signalling pathways? Immunol Cell Biol 78: 166-175.

230. Diehl, N. L., H. Enslen, K. A. Fortner, C. Merritt, N. Stetson, C. Charland, R. A. Flavell, R. J. Davis, and M. Rincon. 2000. Activation of the p38 mitogen-activated protein kinase 
pathway arrests cell cycle progression and differentiation of immature thymocytes in vivo. $J \operatorname{Exp}$ Med 191: 321-334.

231. Wu, Z., P. J. Woodring, K. S. Bhakta, K. Tamura, F. Wen, J. R. Feramisco, M. Karin, J. Y. Wang, and P. L. Puri. 2000. p38 and extracellular signal-regulated kinases regulate the myogenic program at multiple steps. Mol Cell Biol 20: 3951-3964.

232. Evans, J. L., I. D. Goldfine, B. A. Maddux, and G. M. Grodsky. 2002. Oxidative stress and stress-activated signaling pathways: a unifying hypothesis of type 2 diabetes. Endocr Rev 23: $599-622$.

233. Cao, W., A. V. Medvedev, K. W. Daniel, and S. Collins. 2001. beta-Adrenergic activation of p38 MAP kinase in adipocytes: cAMP induction of the uncoupling protein 1 (UCP1) gene requires p38 MAP kinase. J Biol Chem 276: 27077-27082.

234. Cao, W., K. W. Daniel, J. Robidoux, P. Puigserver, A. V. Medvedev, X. Bai, L. M. Floering, B. M. Spiegelman, and S. Collins. 2004. p38 mitogen-activated protein kinase is the central regulator of cyclic AMP-dependent transcription of the brown fat uncoupling protein 1 gene. Mol Cell Biol 24: 3057-3067.

235. Cao, W., Q. F. Collins, T. C. Becker, J. Robidoux, E. G. Lupo, Jr., Y. Xiong, K. W. Daniel, L. Floering, and S. Collins. 2005. p38 Mitogen-activated protein kinase plays a stimulatory role in hepatic gluconeogenesis. J Biol Chem 280: 42731-42737.

236. Fan, M., J. Rhee, J. St-Pierre, C. Handschin, P. Puigserver, J. Lin, S. Jaeger, H. Erdjument-Bromage, P. Tempst, and B. M. Spiegelman. 2004. Suppression of mitochondrial respiration through recruitment of p160 myb binding protein to PGC-1alpha: modulation by 338 MAPK. Genes Dev 18: 278-289.

237. Xiong, Y., Q. F. Collins, J. An, E. Lupo, Jr., H. Y. Liu, D. Liu, J. Robidoux, Z. Liu, and W. Cao. 2007. p38 mitogen-activated protein kinase plays an inhibitory role in hepatic lipogenesis. J Biol Chem 282: 4975-4982.

238. Collins, Q. F., Y. Xiong, E. G. Lupo, Jr., H. Y. Liu, and W. Cao. 2006. p38 Mitogenactivated protein kinase mediates free fatty acid-induced gluconeogenesis in hepatocytes. $J$ Biol Chem 281: 24336-24344.

239. Hibi, M., A. Lin, T. Smeal, A. Minden, and M. Karin. 1993. Identification of an oncoprotein- and UV-responsive protein kinase that binds and potentiates the c-Jun activation domain. Genes Dev 7: 2135-2148. 
240. Davis, R. J. 2000. Signal transduction by the JNK group of MAP kinases. Cell 103: 239252.

241. Ip, Y. T., and R. J. Davis. 1998. Signal transduction by the c-Jun N-terminal kinase (JNK)--from inflammation to development. Curr Opin Cell Biol 10: 205-219.

242. Tournier, C., A. J. Whitmarsh, J. Cavanagh, T. Barrett, and R. J. Davis. 1999. The MKK7 gene encodes a group of c-Jun NH2-terminal kinase kinases. Mol Cell Biol 19: 1569-1581.

243. Nakatani, Y., H. Kaneto, D. Kawamori, K. Yoshiuchi, M. Hatazaki, T. A. Matsuoka, K. Ozawa, S. Ogawa, M. Hori, Y. Yamasaki, and M. Matsuhisa. 2005. Involvement of endoplasmic reticulum stress in insulin resistance and diabetes. J Biol Chem 280: 847-851.

244. Nakatani, Y., H. Kaneto, D. Kawamori, M. Hatazaki, T. Miyatsuka, T. A. Matsuoka, Y. Kajimoto, M. Matsuhisa, Y. Yamasaki, and M. Hori. 2004. Modulation of the JNK pathway in liver affects insulin resistance status. $J$ Biol Chem 279: 45803-45809.

245. Tuncman, G., J. Hirosumi, G. Solinas, L. Chang, M. Karin, and G. S. Hotamisligil. 2006. Functional in vivo interactions between JNK1 and JNK2 isoforms in obesity and insulin resistance. Proc Natl Acad Sci U S A 103: 10741-10746.

246. Triscari, J., J. G. Hamilton, and A. C. Sullivan. 1978. Comparative effects of saturated and unsaturated lipids on hepatic lipogenesis and cholesterogenesis in vivo in the meal-fed rat. $J$ Nutr 108: 815-825.

247. Herzberg, G. R., and N. Janmohamed. 1980. Regulation of hepatic lipogenesis by dietary maize oil or tripalmitin in the meal-fed mouse. Br J Nutr 43: 571-579.

248. Jansen, G. R., C. F. Hutchon, and M. E. Zanetti. 1966. Studies on lipogenesis in vivo. Effect of dietary fat or starvation on conversion of [14]glucose into fat ad turnover of newly synthsized fat. Biochem J 99: 323-332.

249. Sabine, J. R., H. McGrath, and S. Abraham. 1969. Dietary fat and the inhibition of hepatic lipogenesis in the mouse. $J$ Nutr 98: 312-318.

250. Waterman, R. A., D. R. Romsos, A. C. Tsai, E. R. Miller, and G. A. Leveille. 1975. Influence of dietary safflower oil and tallow on growth, plasma lipids and lipogenesis in rats, pigs and chicks. Proc Soc Exp Biol Med 150: 347-351.

251. Newsholme, E. A. 1976. Carbohydrate metabolism in vivo: regulation of the blood glucose level. Clin Endocrinol Metab 5: 543-578. 
252. Redgrave, T. G. 1970. Formation of cholesteryl ester-rich particulate lipid during metabolism of chylomicrons. J Clin Invest 49: 465-471.

253. Brown, M. S., P. T. Kovanen, and J. L. Goldstein. 1981. Regulation of plasma cholesterol by lipoprotein receptors. Science 212: 628-635.

254. Olivecrona, T., G. Liu, M. Hultin, and G. Bengtsson-Olivecrona. 1993. Regulation of lipoprotein lipase. Biochem Soc Trans 21: 509-513.

255. Stahl, A., R. E. Gimeno, L. A. Tartaglia, and H. F. Lodish. 2001. Fatty acid transport proteins: a current view of a growing family. Trends Endocrinol Metab 12: 266-273.

256. Redgrave, T. G. 2004. Chylomicron metabolism. Biochem Soc Trans 32: 79-82.

257. Jung, H. R., S. M. Turner, R. A. Neese, S. G. Young, and M. K. Hellerstein. 1999.

Metabolic adaptations to dietary fat malabsorption in chylomicron-deficient mice. Biochem J 343 Pt 2: 473-478.

258. Maldonado, E. N., Y. Chico, K. M. Botham, M. I. Aveldano, and B. Ochoa. 2003. Influence of the fatty acid composition of lipids in chylomicron remnants derived from fish or corn oil on the lipid profile of cultured rat hepatocytes. J Physiol Biochem 59: 85-100.

259. Lambert, M. S., K. M. Botham, and P. A. Mayes. 1996. Modification of the fatty acid composition of dietary oils and fats on incorporation into chylomicrons and chylomicron remnants. Br J Nutr 76: 435-445.

260. Zou, Z., F. Tong, N. J. Faergeman, C. Borsting, P. N. Black, and C. C. DiRusso. 2003. Vectorial acylation in Saccharomyces cerevisiae. Fat1p and fatty acyl-CoA synthetase are interacting components of a fatty acid import complex. J Biol Chem 278: 16414-16422. 261. Sandoval, A., P. Fraisl, E. Arias-Barrau, C. C. Dirusso, D. Singer, W. Sealls, and P. N. Black. 2008. Fatty acid transport and activation and the expression patterns of genes involved in fatty acid trafficking. Arch Biochem Biophys 477: 363-371.

262. Hamilton, J. A., R. A. Johnson, B. Corkey, and F. Kamp. 2001. Fatty acid transport: the diffusion mechanism in model and biological membranes. $J$ Mol Neurosci 16: 99-108; discussion 151-107.

263. Kamp, F., W. Guo, R. Souto, P. F. Pilch, B. E. Corkey, and J. A. Hamilton. 2003. Rapid flip-flop of oleic acid across the plasma membrane of adipocytes. J Biol Chem 278: 7988-7995. 264. Kamp, F., and J. A. Hamilton. 2006. How fatty acids of different chain length enter and leave cells by free diffusion. Prostaglandins Leukot Essent Fatty Acids 75: 149-159. 
265. Kampf, J. P., and A. M. Kleinfeld. 2007. Is membrane transport of FFA mediated by lipid, protein, or both? An unknown protein mediates free fatty acid transport across the adipocyte plasma membrane. Physiology (Bethesda) 22: 7-14.

266. Kampf, J. P., D. Parmley, and A. M. Kleinfeld. 2007. Free fatty acid transport across adipocytes is mediated by an unknown membrane protein pump. Am J Physiol Endocrinol Metab 293: E1207-1214.

267. Kampf, J. P., D. Cupp, and A. M. Kleinfeld. 2006. Different mechanisms of free fatty acid flip-flop and dissociation revealed by temperature and molecular species dependence of transport across lipid vesicles. J Biol Chem 281: 21566-21574.

268. Liu, R. Z., X. Li, and R. Godbout. 2008. A novel fatty acid-binding protein (FABP) gene resulting from tandem gene duplication in mammals: transcription in rat retina and testis.

Genomics 92: 436-445.

269. Storch, J., and B. Corsico. 2008. The emerging functions and mechanisms of mammalian fatty acid-binding proteins. Annu Rev Nutr 28: 73-95.

270. McArthur, M. J., B. P. Atshaves, A. Frolov, W. D. Foxworth, A. B. Kier, and F. Schroeder. 1999. Cellular uptake and intracellular trafficking of long chain fatty acids. J Lipid Res 40: 1371-1383.

271. Martin, G. G., H. Danneberg, L. S. Kumar, B. P. Atshaves, E. Erol, M. Bader, F. Schroeder, and B. Binas. 2003. Decreased liver fatty acid binding capacity and altered liver lipid distribution in mice lacking the liver fatty acid-binding protein gene. J Biol Chem 278: 2142921438.

272. Newberry, E. P., Y. Xie, S. M. Kennedy, J. Luo, and N. O. Davidson. 2006. Protection against Western diet-induced obesity and hepatic steatosis in liver fatty acid-binding protein knockout mice. Hepatology 44: 1191-1205.

273. Wolfrum, C., C. M. Borrmann, T. Borchers, and F. Spener. 2001. Fatty acids and hypolipidemic drugs regulate peroxisome proliferator-activated receptors alpha - and gammamediated gene expression via liver fatty acid binding protein: a signaling path to the nucleus. Proc Natl Acad Sci U S A 98: 2323-2328.

274. Fulgencio, J. P., C. Kohl, J. Girard, and J. P. Pegorier. 1996. Troglitazone inhibits fatty acid oxidation and esterification, and gluconeogenesis in isolated hepatocytes from starved rats. Diabetes 45: 1556-1562. 
275. Coleman, R. A., T. M. Lewin, and D. M. Muoio. 2000. Physiological and nutritional regulation of enzymes of triacylglycerol synthesis. Annu Rev Nutr 20: 77-103.

276. Muoio, D. M., T. M. Lewin, P. Wiedmer, and R. A. Coleman. 2000. Acyl-CoAs are functionally channeled in liver: potential role of acyl-CoA synthetase. Am J Physiol Endocrinol Metab 279: E1366-1373. 


\title{
X. CHAPTER 2 - REPRINTED WITH PERMISSON FROM BBRC.
}

\section{A ROLE FOR AMPK IN THE INHIBITION OF GLUCOSE-6-PHOSPHATE DEHYDROGENASE BY POLYUNSATURATED FATTY ACIDS}

\author{
Alison B. Kohan ${ }^{*}$, Indrani Talukdar ${ }^{* \#}$, Callee M. Walsh, and Lisa M. Salati ${ }^{*}$ \\ Department of Biochemistry, West Virginia University, Morgantown, WV
}

${ }^{*}$ These authors contributed equally to this work.

${ }^{* *}$ Address correspondence to:

Lisa M. Salati, PhD,

1 Medical Center Dr.

Department of Biochemistry, West Virginia University Health Sciences Center, Box 9142, Morgantown, WV 26506.

Tel.: 304-293-7759

E-mail: 1salati@hsc.wvu.edu

\#present address: Burnham Institute for Medical Research, La Jolla, California 92037 


\begin{abstract}
:
Both polyunsaturated fatty acids and AMPK promote energy partitioning away from energy consuming processes, such as fatty acid synthesis, towards energy generating processes, such as $\beta$-oxidation. In this report, we demonstrate that arachidonic acid activates AMPK in primary rat hepatocytes, and that this effect is p38 MAPK-dependent. Activation of AMPK mimics the inhibition by arachidonic acid of the insulin-mediated induction of G6PD. Similar to intracellular signaling by arachidonic acid, AMPK decreases insulin signal transduction, increasing Ser ${ }^{307}$ phosphorylation of IRS-1 and a subsequent decrease in AKT phosphorylation. Overexpression of dominant-negative AMPK abolishes the effect of arachidonic acid on G6PD expression. These data suggest a role for AMPK in the inhibition of G6PD by polyunsaturated fatty acids.
\end{abstract}

KEYWORDS: polyunsaturated fatty acids, lipogenesis, primary hepatocytes, AMP-activated protein kinase. 


\section{INTRODUCTION:}

Polyunsaturated fatty acids have multiple regulatory actions within cells including activating cellular signaling pathways and regulating gene expression. The mechanism by which polyunsaturated fatty acids transduce their signal within cells is not completely understood. The inhibition of acetyl-CoA carboxylase (ACC), fatty acid synthase (FAS), and spot 14 (S14) expression in rat liver by polyunsaturated fatty acids is associated with the activation of AMPactivated protein kinase (AMPK) $[1 ; 2 ; 3]$. Yet, the ability of dietary polyunsaturated fatty acids to activate AMPK in all tissues is not uniformly observed and a role for AMPK in regulating the transcription of glucose-responsive genes is controversial $[4 ; 5 ; 6 ; 7]$. Therefore, we asked if a lipogenic gene regulated exclusively at a posttranscriptional level would involve AMPK activity in the inhibition of its expression by polyunsaturated fatty acids.

Glucose-6-phosphate dehydrogenase (G6PD) is the rate-limiting enzyme in the pentose phosphate pathway. G6PD catalyzes the first reaction in this pathway by converting glucose-6phosphate to 6-phosphogluconolactone $[8 ; 9 ; 10]$. NADPH is concomitantly produced during this reaction, providing $50-75 \%$ of the necessary reducing equivalents for fatty acid biosynthesis in liver [9]. G6PD expression is inhibited by polyunsaturated fat through a posttranscriptional mechanism involving decreases in the efficiency of splicing of the pre-mRNA [11]. The signaling pathway causing increased expression of G6PD involves insulin activation of the phosphatidylinositol 3-kinase (PI 3-kinase) pathway resulting in the accumulation of G6PD mRNA [12]. Polyunsaturated fatty acids such as arachidonic acid inhibit accumulation of G6PD mRNA by inhibiting insulin signaling through the activation of p38 mitogen activated protein kinase (p38 MAPK) and the subsequent $\operatorname{Ser}^{307}$ phosphorylation of insulin receptor substrate-1 
(IRS-1) [12]. Upstream kinases stimulating the phosphorylation of p38 MAPK have remained elusive.

AMPK has been suggested to play a role in mediating the actions of fatty acids in cells. AMPK is a sensor of cellular energy because it is activated by an increase in the AMP/ATP ratio [13]. Activation of AMPK leads cells to abandon energy-consuming pathways (such as glycogenolysis and fatty acid synthesis) and to stimulate energy-producing pathways (such as $\beta$ oxidation and glycolysis). Polyunsaturated fatty acids have a similar activity within cells via the short-term inhibition of ACC activity that regulates both fatty acid synthesis and oxidation, as well as via long-term changes in the expression of genes in glycolysis, lipogenesis and fatty acid oxidation [14].

Due to the coinciding roles of both polyunsaturated fatty acids and AMPK in energy homeostasis, the role of AMPK in mediating the inhibitory effects of polyunsaturated fatty acids on lipogenic enzymes seems probable. In this report, we demonstrate that AMPK is an inhibitor of G6PD expression and that inhibition of AMPK activity abrogates the inhibitory action of polyunsaturated fatty acids on the accumulation of G6PD mRNA. 


\section{MATERIALS AND METHODS:}

Animal care and cell culture - Male Sprague-Dawley rats (150-200g) were maintained on standard rodent chow under a normal light-dark cycle. Animal experiments were conducted in conformity with the Public Health Service policy on Humane Care and Use of Laboratory Animals, additionally; the Institutional Animal Care and Use Committee of the Division of Laboratory Animal Resources at West Virginia University approved all experimental procedures. Hepatocytes were isolated from the liver by a modification of the method of Seglen [15], as described previously [11]. Hepatocytes $\left(3 \times 10^{6}\right)$ were plated onto $60 \mathrm{~mm}$ collagen-coated plates in Hi/Wo/Ba medium (Waymouth MB752/1 plus $20 \mathrm{mM}$ HEPES, pH7.4, $0.5 \mathrm{mM}$ serine, 0.5 $\mathrm{mM}$ alanine, $0.2 \%$ bovine serum albumin) plus $5 \%$ newborn calf serum to facilitate cell adhesion. Two hours post-isolation hepatocytes were washed twice with serum-free media, and were incubated overnight with serum-free media and $0.3 \mathrm{mg}$ Matrigel per plate (BD PharMingen) at $37^{\circ} \mathrm{C}$ in a humidified atmosphere of $5 \% \mathrm{CO}_{2}$ and $95 \%$ air. Treatments were added to the hepatocytes in fresh serum-free media, without Matrigel, after $20 \mathrm{~h}$ in culture (time zero). Hepatocytes not receiving $175 \mu \mathrm{M}$ arachidonic acid (Nu-Check Prep: complexed with 4 $\mathrm{mM}$ bovine serum albumin and butylated-hydroxytoluene $0.1 \%$ ) were treated with an equivalent volume of serum free media containing $4 \mathrm{mM}$ bovine serum albumin and butylatedhydroxytoluene $0.1 \%$ solution. All media contained supplemental a-tocopherol $(5 \mu \mathrm{g} / \mathrm{ml}$ of medium). The AMPK activator, aminoimidazole carboxamide ribonucleotide (AICAR) was purchased from Toronto Research Chemicals Inc. The p38 MAP kinase inhibitor, SB203580 was purchased from Calbiochem. 
Protein isolation and Western blot analysis - Preparation of cell lysates and western analysis was as described [12]. The primary antibodies against phosphorylated AKT $\left(\operatorname{Ser}^{473}\right)$, phosphorylated IRS-1 $\left(\operatorname{Ser}^{307}\right)$, phosphorylated p38 MAPK $\left(\mathrm{Thr}^{180} / \mathrm{Tyr}^{182}\right)$, phosphorylated AMPK $\left(\operatorname{Thr}^{172}\right)$, phosphorylated ACC $\left(\operatorname{Ser}^{79}\right)$, phosphorylated PKC (pan, $\beta$ II Ser ${ }^{660}$ ), phosphorylated S6K-1, $\left(\mathrm{Thr}^{389}\right.$ ), phosphorylated MAP kinase kinase (MKK) 3/6 and total AKT, IRS-1, p38 MAPK, AMPK, ACC, tubulin were obtained from Cell Signaling Technology. Antirabbit IgG conjugated with horseradish peroxidase (Cell Signaling Technology) was used as the secondary antibody, and the immunocomplexes were detected by enhanced chemiluminescence (Pierce). Images were visualized with film (Pierce) and quantified by densitometry using ImageQuant software (Amersham Biosciences).

Adenoviral Vectors - Adenovirus expressing dominant-negative AMPK (kinase-dead due to K45R mutation in $\alpha 2$ subunit, with a 5' myc tag)(a gift from Dr. M. Birnbaum)[16] and adenovirus expressing green fluorescent protein (GFP; a gift from Dr. C.J. Rhodes)[17] were amplified in HEK 293 cells. Virus was purified by $\mathrm{CsCl}$ gradient in which the virus was layered over $1.25 \mathrm{~g} / \mathrm{ml} \mathrm{CsCl}$ in $100 \mathrm{mM}$ Tris $(\mathrm{pH} 8.0)$ and $1.4 \mathrm{~g} / \mathrm{ml} \mathrm{CsCl}$ in $100 \mathrm{mM}$ Tris $(\mathrm{pH} 8.0)$, and spun at 35,000 rpm for $1 \mathrm{~h}$ at $4^{\circ} \mathrm{C}$ in a SW-41 rotor. The viral band was excised and overlayered with $1.34 \mathrm{~g} / \mathrm{ml} \mathrm{CsCl}$ in $100 \mathrm{mM}$ Tris $(\mathrm{pH} 8.0)$ and spun at $60,000 \mathrm{rpm}$ for $10 \mathrm{~h}$ at $4^{\circ} \mathrm{C}$ in a VTi 65.2 rotor. The viral fraction was then desalted using a sephadex G-25 column (Pharmacia). Viral titer was determined using the Adeno-X Rapid Titer kit (Clontech) per the manufacturer's instructions. The purified virus was stored in $30 \%$ glycerol in PBS at $-80^{\circ} \mathrm{C}$.

Isolation of Total RNA and quantitative real-time RT-PCR - Total RNA was isolated from 
two plates per treatment using Tri-Reagent (Ambion) according to manufacturer's instructions. Abundance of specific mRNA was measured using real-time reverse transcriptase polymerase chain reaction (RT-PCR). RNA (150-200 ng) was DNase I-treated and expression of all mRNAs was determined by real-time PCR (BioRad iCycler iQ) analysis. G6PD and RPL32 mRNAs were measured using TaqMan probes. ACC, SCD, FAS, S14, and cyclophilin B mRNAs were measured using Quantitect SYBR green (QIAGEN) according to the manufacturer's instructions. Sequences for primers and probes are as follows glucose 6-phosphate dehydrogenase, sense, 5'TATGTCTATGGCAGCCGAGGT-3', antisense, 5'- GCAGAGTGCAGATGGTGTAAG -3'; fatty acid synthase, sense, 5'-TGCAACTGTGCGTTAGCCACC-3', antisense, 5'TGTTTCAGGGGAGAAGAGACC-3'; stearoyl-coA desaturase, sense, 5'AGCTCAGCCAAATGCTGTGTTGTC-3', antisense, 5'TGCCTTGATCAGTCACAGACACCT-3'; spot 14, sense, 5'CAGGAGGTGACGCAGAAATAC-3', antisense, 5'-GTGAGGTAAATACAGCGTCCC-3'; cyclophilin B, sense, 5'-CGTGGGCTCCGTTGTCTT-3', antisense, 5'TGACTTTAGGTCCCTTCTTCTTATC-3'; RPL32, sense, 5'AAACTGGCGGAAACCCAGAG-3'; antisense, 5'-GCAGCACTTCCAGCTCCTTG-3'; G6PD probe, 5'-FAM/CCACAGAGGCAGATGAGCTGATGAAGAA/3BHQ-3'; RPL32 probe, 5'-/56FAM/CCAGATCCTGATGCCCAACATTGC-3'. The relative amount of each mRNA was calculated using the comparative threshold cycle method. Expression of cyclophilin B or RPL32 was used as a control and the amount of each mRNA was calculated relative to this control. 
Statistics - Statistics were performed using GraphPad Prism (version 4.0). Overall statistical significance was determined by one-way ANOVA; multiple comparisons were made using a Bonferroni post-test if the overall $p$-value after ANOVA was $p<0.05$. 


\section{RESULTS:}

Phosphorylation of AMPK at $\mathrm{Thr}^{172}$ is a measure of AMPK activation [13]. Incubation of primary rat hepatocytes with arachidonic acid induced AMPK phosphorylation compared to cells not treated with insulin or arachidonic acid (NA or I); total AMPK levels did not change (Fig. 1). The activation of AMPK in response to arachidonic acid was rapid and was detected as early as $10 \mathrm{~min}$ and retained through $60 \mathrm{~min}$ (data not shown). ACC phosphorylation at $\mathrm{Ser}^{79}$ was induced by treatment with arachidonic acid further indicating that arachidonic acid activates AMPK and its downstream targets in rat hepatocytes (Fig. 1)[18; 19]. Coincident with the activation of AMPK, p38 MAPK and its upstream kinase MKK 3/6 were also activated (Fig. 1). The coincident activation of these signaling molecules supports the hypothesis that the AMPK signaling pathway as well as the inhibitory p38 MAPK pathway are cooperating to inhibit G6PD expression.

To test for a role of AMPK signaling in the inhibition of G6PD expression, accumulation of G6PD mRNA was measured after treatment with AICAR, a pharmacological activator of AMPK [20]. Insulin induced G6PD mRNA accumulation five-fold compared to no addition, and the addition of AICAR to the hepatocytes inhibited this increase by $50 \%$ (Fig. 2A). This mimics the extent of inhibition of G6PD mRNA by arachidonic acid [12]. The abundance of G6PD mRNA is expressed relative to RPL32 mRNA abundance. In all experiments, RPL32 expression was not regulated by AICAR (data not shown). Hepatocytes were also treated with metformin, another pharmacological activator of AMPK, to test if AMPK activation by a different compound can also inhibit G6PD expression [21]. Like AICAR, metformin also inhibited the insulin-induction of G6PD mRNA by $50 \%$ or more (data not shown). As expected, AICAR enhanced AMPK phosphorylation in these cells (Fig. 2B). In addition, this stimulation of 
AMPK was accompanied by a 5-fold increase in p38 MAPK activation as compared to insulin alone (Figs. 2B and 2C). Thus, activation of AMPK by AICAR mimics the effect of arachidonic acid on G6PD expression and p38 MAPK activation.

Arachidonic acid activation of p38 MAPK is accompanied by phosphorylation of IRS-1 at $\mathrm{Ser}^{307}$, which decreases insulin signal transduction and ultimately inhibits G6PD expression [12]. Incubation with AICAR also induced $\mathrm{Ser}^{307}$ phosphorylation of IRS-1 (Fig. 2D). In addition, the insulin-mediated activation of AKT, a measure of PI 3-kinase activity, was completely abolished in the presence of AICAR. These results suggest that like arachidonic acid, activation of AMPK with AICAR interferes with the PI 3-kinase pathway resulting in a decrease in the expression of G6PD mRNA.

In order to determine whether the activation of $\mathrm{p} 38$ MAPK by AICAR plays a role in the inhibition of G6PD, hepatocytes were treated with the p38 MAP kinase inhibitor SB203580. Insulin induced G6PD mRNA accumulation by 3-fold despite the presence of SB203580; however, the AICAR-mediated inhibition of the G6PD mRNA expression was completely abolished (Fig. 3A). Thus, the AICAR-mediated inhibition of G6PD mRNA expression involves the p38 MAP kinase pathway.

The effect of AMPK activation by AICAR on the expression of other lipogenic genes was also determined. In primary rat hepatocytes, insulin stimulates the accumulation of mRNA for FAS, SCD, and S14 by 3 to 10-fold (Fig. 3B). The insulin stimulation of these genes was inhibited by AICAR, 53\%, 55\% and 59\%, respectively. Treatment with the p38 MAP kinase inhibitor SB203580 blocked this effect of AICAR on these genes. The abundance of these mRNA is expressed relative to cyclophilin. AICAR and SB203580 did not affect the abundance of cyclophilin mRNA indicating the selectivity of these treatments (data not shown). Therefore, 
other lipogenic genes are inhibited when AMPK is activated, and this inhibition is attenuated when p38 MAPK activity is blocked.

To confirm a role of AMPK in the arachidonic acid mediated inhibition of G6PD, hepatocytes were infected with adenovirus expressing dominant-negative AMPK. Hepatocytes not receiving dominant-negative AMPK were infected with adenovirus expressing green fluorescent protein (GFP). Infection with the dominant-negative AMPK dramatically decreased the activation of AMPK by arachidonic acid as measured by changes in ACC phosphorylation, a downstream target of AMPK (Fig. 4A). Virus expressing GFP did not alter AMPK activity. Western analysis against the Myc tag of the dominant-negative AMPK further confirmed expression of the adenovirus in the cells (data not shown). In hepatocytes infected with the control adenovirus, insulin treatment induced G6PD expression by 4-fold and treatment with arachidonic acid significantly inhibited this stimulation by 54\% (Fig. 4B). Dominant-negative AMPK blocked the inhibition by arachidonic acid. This data provides evidence for a role of AMPK in the arachidonic acid-mediated inhibition of G6PD. 


\section{DISCUSSION:}

Polyunsaturated fatty acids are potent regulators of cellular function and yet the signal transduction mechanisms that they use have remained elusive. In our previous studies, we have shown that arachidonic acid-mediated inhibition of insulin-induced G6PD expression involves the activation of p38 MAPK pathway, which in turn interferes with the PI 3-kinase pathway through the $\mathrm{Ser}^{307}$ phosphorylation of IRS-1, thus inhibiting the insulin-mediated induction of G6PD [12]. Fatty acids are also known to activate additional signaling pathways including AMPK [2]. In this report we present the following lines of evidence that arachidonic acid activation of AMPK is involved in the inhibition of G6PD expression. First, activation of AMPK, per se, inhibits the insulin induction of G6PD mRNA (Fig. 2A). Second, activation of AMPK by AICAR concomitantly activates p38 MAPK, results in $\mathrm{Ser}^{307}$ phosphorylation of IRS1, and inhibits AKT phosphorylation similar to the action of arachidonic acid (Figs. 2B, 2C, and 2D)[12]. Inhibition of p38 MAPK blocks the effect of AICAR on accumulation of G6PD mRNA (Fig. 3A). These changes in the activity of signaling pathways and G6PD expression occur within the same time frame as arachidonic acid activation of AMPK and arachidonic acid inhibition of G6PD expression. Finally, arachidonic acid inhibition of G6PD mRNA requires active AMPK, as the expression of a dominant negative AMPK blocks this inhibition (Fig. 4B). Thus, our data are consistent with the hypothesis that activation of AMPK by arachidonic acid enhances p38 MAP kinase activity resulting in the inhibition of insulin signal transduction and thereby G6PD expression.

The role of AMPK in mediating the effects of polyunsaturated fats on liver metabolism is controversial. Studies examining AMPK activation in response to dietary lipid are inconclusive $[1 ; 4 ; 5 ; 7]$. These may reflect the difficulty in retaining the phosphorylation state of proteins 
during the preparation of tissue lysates. Alternatively, AMPK activation may not be a primary mechanism in regulation by dietary fatty acids. In this regard, incubation of rat hepatocytes with chylomicron remnants, the mode of delivery of dietary fat to liver, does not activate AMPK (Kohan and Salati, submitted for publication). In contrast, liver is exposed to high concentrations of non-esterified fatty acids during times of enhanced lipolysis. AMPK activation occurs rapidly in response to free fatty acids (Fig.1) and may play an important role in the partitioning of liver metabolism towards fatty acid oxidation and gluconeogenesis. It is not clear why activation of AMPK by fatty acids is observed by some laboratories (Fig. 1)[6] and not by others $[4 ; 5]$. AMPK activation occurs rapidly and may require measurement at earlier time points or may be unique to specific fatty acids. Alternatively, procedural differences in hepatocyte culture and harvesting techniques may be responsible. Nonetheless, activation of AMPK by polyunsaturated fatty acids coincides with inhibition of G6PD expression.

The activities of the lipogenic enzymes, including G6PD, are coordinately regulated. Yet, the details of this regulation differ between the different lipogenic enzymes. G6PD is unique in that its regulation occurs primarily at a posttranscriptional step. The inhibition of G6PD and other lipogenic enzymes by AMPK suggests that this kinase is an important upstream signaling molecule impacting multiple steps in gene expression and altering the capacity of hepatocytes for fatty acid biosynthesis. 


\section{ACKNOWLEDGEMENTS:}

This work was supported by National Institutes of Health Grant DK46897 (to L.M.S.), National Institutes of Health T32 HL090610 (to A.B.K.). 


\section{REFERENCES:}

[1] G. Suchankova, M. Tekle, A.K. Saha, N.B. Ruderman, S.D. Clarke, and T.W. Gettys, Dietary polyunsaturated fatty acids enhance hepatic AMP-activated protein kinase activity in rats. Biochem Biophys Res Commun 326 (2005) 851-8.

[2] M. Foretz, D. Carling, C. Guichard, P. Ferre, and F. Foufelle, AMP-activated protein kinase inhibits the glucose-activated expression of fatty acid synthase gene in rat hepatocytes. J Biol Chem 273 (1998) 14767-71.

[3] D. Carling, V.A. Zammit, and D.G. Hardie, A common bicyclic protein kinase cascade inactivates the regulatory enzymes of fatty acid and cholesterol biosynthesis. FEBS Lett 223 (1987) 217-22.

[4] J. Xu, B. Christian, and D.B. Jump, Regulation of rat hepatic L-pyruvate kinase promoter composition and activity by glucose, $\mathrm{n}-3$ polyunsaturated fatty acids, and peroxisome proliferator-activated receptor-alpha agonist. J Biol Chem 281 (2006) 18351-62.

[5] R. Dentin, F. Benhamed, J.P. Pegorier, F. Foufelle, B. Viollet, S. Vaulont, J. Girard, and C. Postic, Polyunsaturated fatty acids suppress glycolytic and lipogenic genes through the inhibition of ChREBP nuclear protein translocation. J Clin Invest 115 (2005) 2843-54.

[6] T. Kawaguchi, K. Osatomi, H. Yamashita, T. Kabashima, and K. Uyeda, Mechanism for fatty acid "sparing" effect on glucose-induced transcription: regulation of carbohydrateresponsive element-binding protein by AMP-activated protein kinase. J Biol Chem 277 (2002) 3829-35.

[7] A. Dobrzyn, P. Dobrzyn, M. Miyazaki, and J.M. Ntambi, Polyunsaturated fatty acids do not activate AMP-activated protein kinase in mouse tissues. Biochem Biophys Res Commun $332(2005) 892-6$. 
[8] H.M. Tepperman, and J. Tepperman, Patterns of Dietary and Hormonal Induction of Certain Nadp-Linked Liver Enzymes. Am J Physiol 206 (1964) 357-61.

[9] R. Rognstad, Rate-limiting steps in metabolic pathways. J Biol Chem 254 (1979) 1875-8.

[10] G.E. Glock, and P. McLean, Effects of hormones on levels of oxidized and reduced diphosphopyridine nucleotide and triphosphopyridine nucleotide in liver and diaphragm. Biochem J 61 (1955) 397-402.

[11] H. Tao, W. Szeszel-Fedorowicz, B. Amir-Ahmady, M.A. Gibson, L.P. Stabile, and L.M. Salati, Inhibition of the splicing of glucose-6-phosphate dehydrogenase precursor mRNA by polyunsaturated fatty acids. J Biol Chem 277 (2002) 31270-8.

[12] I. Talukdar, W. Szeszel-Fedorowicz, and L.M. Salati, Arachidonic acid inhibits the insulin induction of glucose-6-phosphate dehydrogenase via p38 MAP kinase. J Biol Chem (2005).

[13] B.B. Kahn, T. Alquier, D. Carling, and D.G. Hardie, AMP-activated protein kinase: ancient energy gauge provides clues to modern understanding of metabolism. Cell Metab 1 (2005) 15-25.

[14] J. Girard, D. Perdereau, F. Foufelle, C. Prip-Buus, and P. Ferre, Regulation of lipogenic enzyme gene expression by nutrients and hormones. FASEB J 8 (1994) 36-42.

[15] P.O. Seglen, Preparation of rat liver cells. 3. Enzymatic requirements for tissue dispersion. Exp Cell Res 82 (1973) 391-8.

[16] J. Mu, J.T. Brozinick, Jr., O. Valladares, M. Bucan, and M.J. Birnbaum, A role for AMPactivated protein kinase in contraction- and hypoxia-regulated glucose transport in skeletal muscle. Mol Cell 7 (2001) 1085-94. 
[17] C.E. Wrede, L.M. Dickson, M.K. Lingohr, I. Briaud, and C.J. Rhodes, Protein kinase B/Akt prevents fatty acid-induced apoptosis in pancreatic beta-cells (INS-1). J Biol Chem 277 (2002) 49676-84.

[18] M.R. Munday, D.G. Campbell, D. Carling, and D.G. Hardie, Identification by amino acid sequencing of three major regulatory phosphorylation sites on rat acetyl-CoA carboxylase. Eur J Biochem 175 (1988) 331-8.

[19] S.P. Davies, A.T. Sim, and D.G. Hardie, Location and function of three sites phosphorylated on rat acetyl-CoA carboxylase by the AMP-activated protein kinase. Eur J Biochem 187 (1990) 183-90.

[20] J.M. Corton, J.G. Gillespie, S.A. Hawley, and D.G. Hardie, 5-aminoimidazole-4carboxamide ribonucleoside. A specific method for activating AMP-activated protein kinase in intact cells? Eur J Biochem 229 (1995) 558-65.

[21] G. Zhou, R. Myers, Y. Li, Y. Chen, X. Shen, J. Fenyk-Melody, M. Wu, J. Ventre, T. Doebber, N. Fujii, N. Musi, M.F. Hirshman, L.J. Goodyear, and D.E. Moller, Role of AMP-activated protein kinase in mechanism of metformin action. J Clin Invest 108 (2001) 1167-74. 


\section{FIGURE LEGENDS:}

Figure 1. Arachidonic acid induces activation of AMPK. Primary rat hepatocytes were plated on collagen coated dishes and incubated in $\mathrm{Hi} / \mathrm{Wo} / \mathrm{Ba}$ medium. After $20 \mathrm{~h}$ in culture, the medium was replaced with $\mathrm{Hi} / \mathrm{Wo} / \mathrm{Ba}$ with or without insulin $(40 \mathrm{nM}$; I) and albumin-bound arachidonic acid (175 $\mu \mathrm{M}$; AA). Total cell lysates were isolated $10 \mathrm{~min}$ after treatment. Western blot analysis was performed against phosphorylated AMPK $\left(\mathrm{Thr}^{172}\right.$ ) and total AMPK, phosphorylated ACC $\left(\operatorname{Ser}^{79}\right)$, and total ACC, phosphorylated MKK 3/6, and phosphorylated p38 MAPK $\left(\mathrm{Thr}^{180} / \mathrm{Tyr}^{182}\right.$ ) and total p38 MAP kinase. A representative blot is shown. Repetition demonstrating the same results was as follows: $n=3$ experiments for phosphorylated and total AMPK and ACC, $\mathrm{n}=2$ for P-MKK 3/6, $\mathrm{n}=7$ for phosphorylated and total p38 MAP kinase. $N A$, no addition; $P-A M P K$, phosphorylated AMPK; $P-A C C$, phosphorylated ACC; $P-M K K$ 3/6, phosphorylated MKK 3/6; $P$-p38, phosphorylated p38 MAP kinase.

\section{Figure 2. Activation of AMPK inhibits the insulin-mediated induction of G6PD mRNA}

and insulin signal transduction. Primary rat hepatocytes were plated on collagen coated dishes and incubated in $\mathrm{Hi} / \mathrm{Wo} / \mathrm{Ba}$ medium. A. After $20 \mathrm{~h}$ in culture, the medium was replaced with $\mathrm{Hi} / \mathrm{Wo} / \mathrm{Ba}$ with or without insulin $(40 \mathrm{nM}$; I) and AICAR $(0.5 \mathrm{mM})$. Media was replaced every $12 \mathrm{~h}$ with one of identical composition, and RNA was isolated after $24 \mathrm{~h}$ of treatment (2 plates/treatment). G6PD mRNA is calculated relative to RPL32 mRNA. Values are expressed as the fold-increase over no addition (NA). Each bar represents the mean $\pm \mathrm{SE}$ of $\mathrm{n}=4$ independent primary hepatocyte isolations. B. After $24 \mathrm{~h}$ in culture, the medium was replaced with $\mathrm{Hi} / \mathrm{Wo} / \mathrm{Ba}$ with or without insulin $(40 \mathrm{nM}$; I) and AICAR $(0.5 \mathrm{mM})$. Total cell lysates were isolated $10 \mathrm{~min}$ after treatments. Western blot analysis was performed against phosphorylated AMPK $\left(\mathrm{Thr}^{172}\right)$, 
and phosphorylated and total p38 MAPK. A representative blot is shown. C. Densitometry was performed with ImageQuant software (Molecular Dynamics), and values were calculated as arbitrary densitometric units of phosphorylated/total protein. Values are expressed as the foldincrease over no addition (NA). Each bar represents the mean \pm SE of $n=4$ independent primary hepatocyte isolations. D. Hepatocytes were treated with or without AICAR $(0.5 \mathrm{mM}) 24 \mathrm{~h}$ prior to the addition of insulin $(40 \mathrm{nM}$; I). Total cell lysates were prepared 10 min after the addition of insulin. Western blot analysis was performed against total and phosphorylated IRS-1 (Ser $\left.{ }^{307}\right)$ and AKT $\left(\operatorname{Ser}^{473}\right)$. A representative blot is shown and represents the mean $\pm \mathrm{SE}$ of $\mathrm{n}=4$ independent primary hepatocyte isolations.

\section{Figure 3. Inhibition of lipogenic genes by polyunsaturated fatty acids by AMPK requires}

p38 MAPK. After $20 \mathrm{~h}$ in culture, the medium was replaced with $\mathrm{Hi} / \mathrm{Wo} / \mathrm{Ba}$ with or without the p38 MAP kinase inhibitor SB203580 $(10 \mu \mathrm{M}$; SB) or AICAR $(0.5 \mathrm{mM})$ for $2 \mathrm{~h}$. Cells were then treated with or without insulin (40 nM; I). Media was replaced every $12 \mathrm{~h}$ with one of identical composition, and RNA was isolated after $24 \mathrm{~h}$ of treatment (2 plates/treatment). A. G6PD mRNA is calculated relative to RPL32 mRNA. Values are expressed as the fold-increase over no addition (NA). Each bar represents the mean $\pm \mathrm{SE}$ of $\mathrm{n}=4$ independent primary hepatocyte isolations. B. FAS, SCD, and S14 mRNA abundance is calculated relative to rat cyclophilin B. Values are expressed as the fold-increase over no addition (NA). Each bar represents the mean \pm $\mathrm{SE}$ of $\mathrm{n}=3$ independent primary hepatocyte isolations.

\section{Figure 4. Inhibition of AMPK activity blocks the arachidonic acid inhibition of G6PD}

expression. Primary rat hepatocytes were plated on collagen coated dishes and incubated in 
$\mathrm{Hi} / \mathrm{Wo} / \mathrm{Ba}$ medium. After $2 \mathrm{~h}$ in culture, hepatocytes were infected with 1, 5, and 10 infectious units/cell of either dominant-negative AMPK expressing adenovirus (DNAMPK) or control adenovirus expressing GFP. After $2 \mathrm{~h}$, cells were washed twice, and media was replaced with one containing Matrigel. After $20 \mathrm{~h}$ in culture, the medium was replaced with $\mathrm{Hi} / \mathrm{Wo} / \mathrm{Ba}$ with or without insulin (40 nM; I) and arachidonic acid (175 $\mu \mathrm{M}$; AA). A. After 10 minutes of treatment, cell lysates were prepared and Western analysis was performed against phosphorylated ACC $\left(\mathrm{Ser}^{79}\right)$ and against tubulin as a loading control. B. For isolation of mRNA, media was replaced every $12 \mathrm{~h}$ with one of identical composition, and RNA was isolated after $24 \mathrm{~h}$ of treatment (2 plates/treatment). G6PD mRNA abundance is calculated relative to rat cyclophilin B. Values are expressed as the fold-increase over no addition (NA). Each bar represents the mean $\pm \mathrm{SE}$ of $n=3$ independent primary hepatocyte isolations. 
FIG. 1

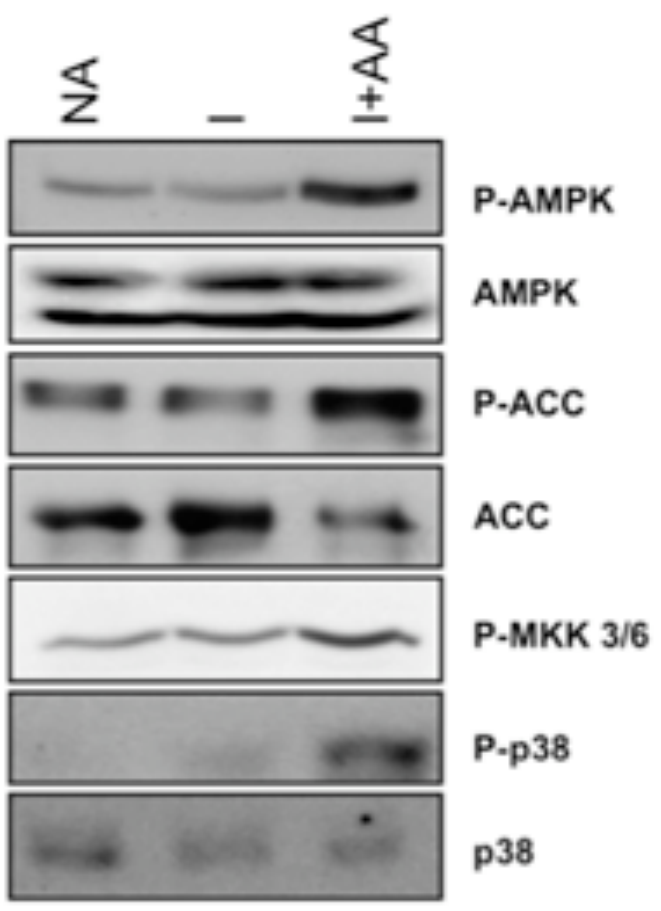


FIG. 2
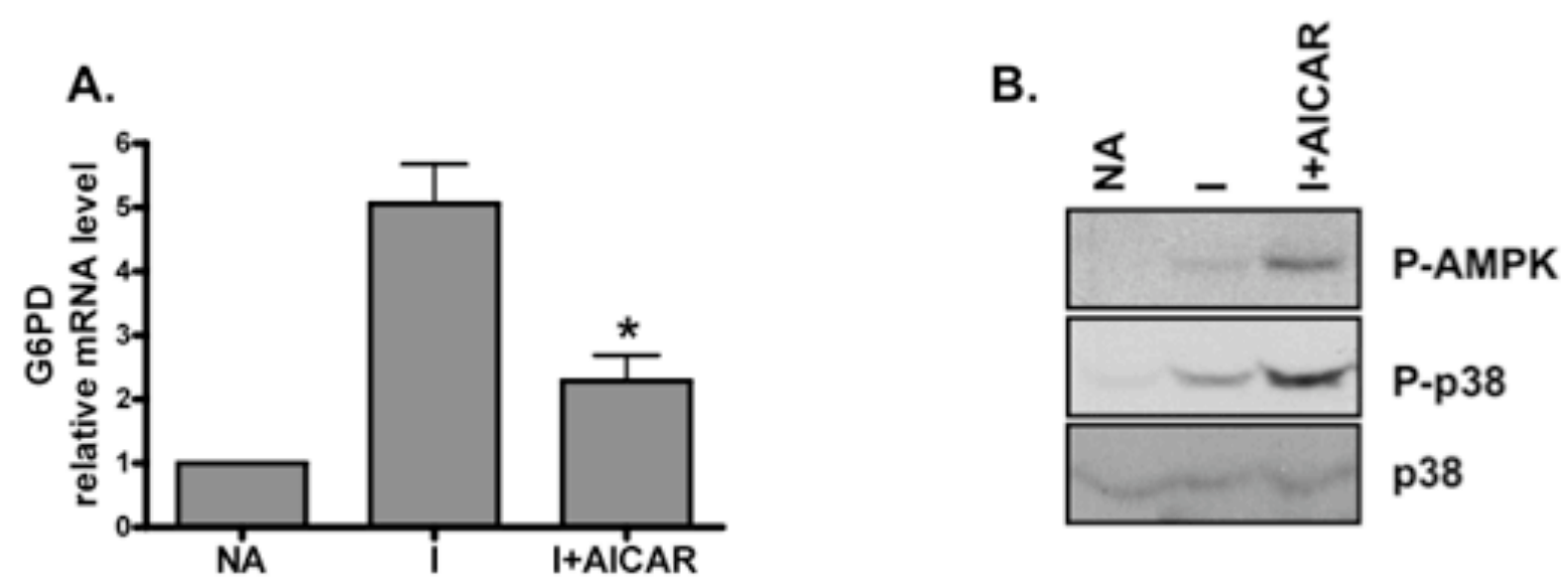

c.
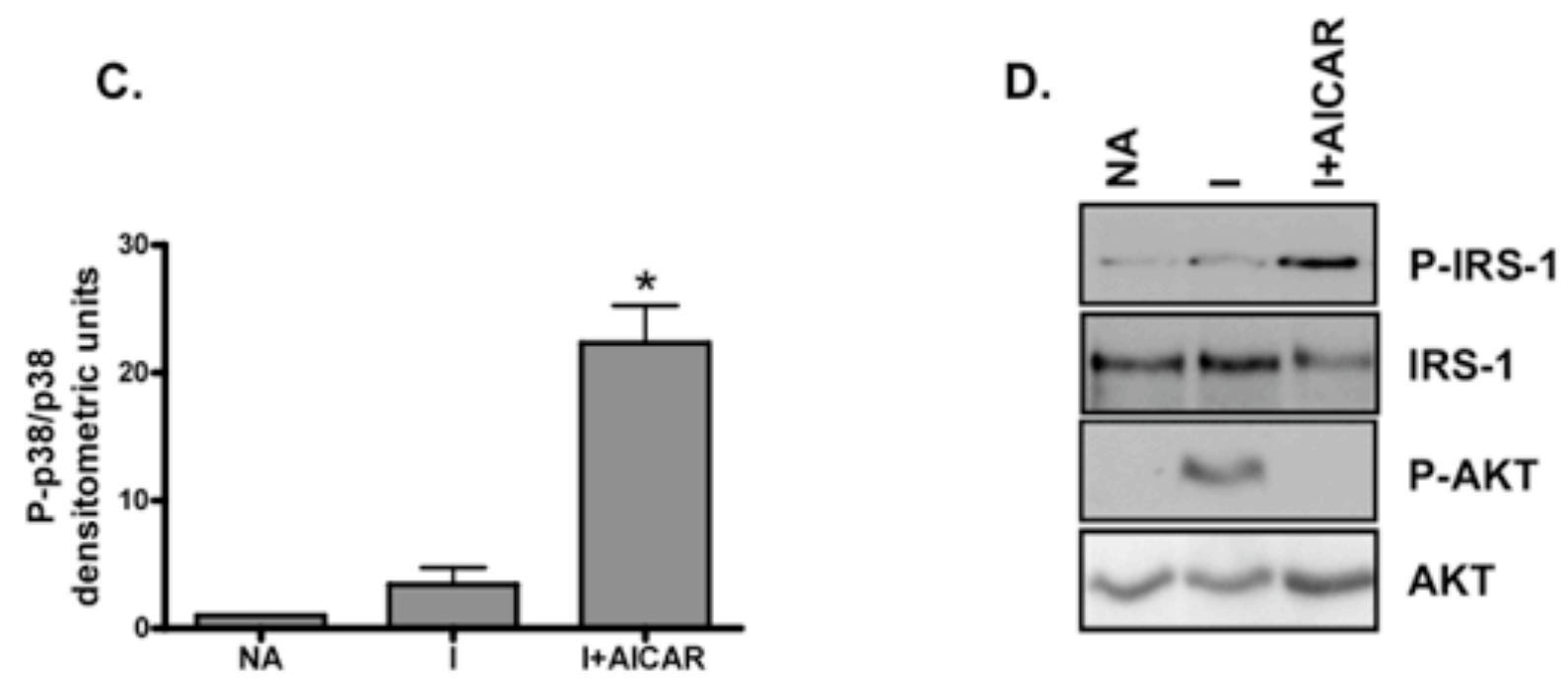
FIG. 3

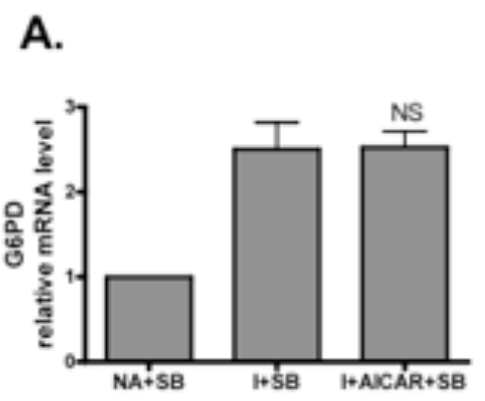

B.
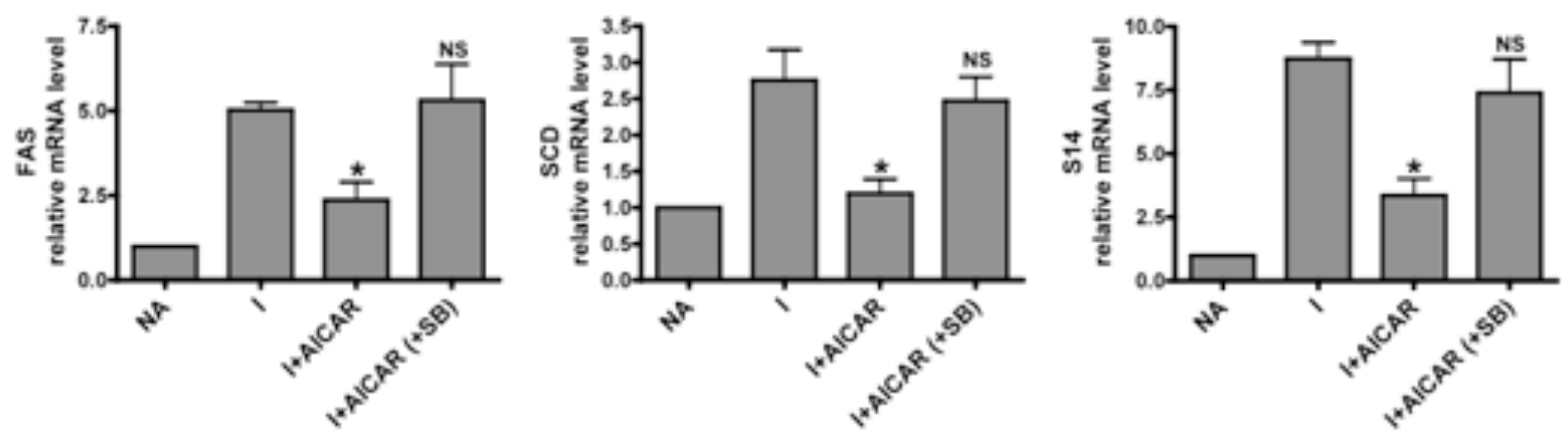
FIG. 4

A.

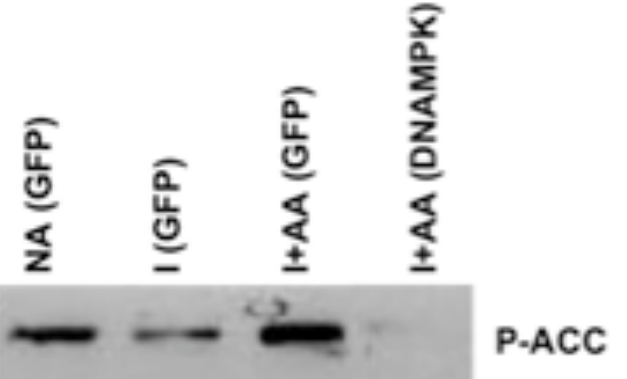

$$
\begin{aligned}
& -0 \text { TUBULIN }
\end{aligned}
$$

B.

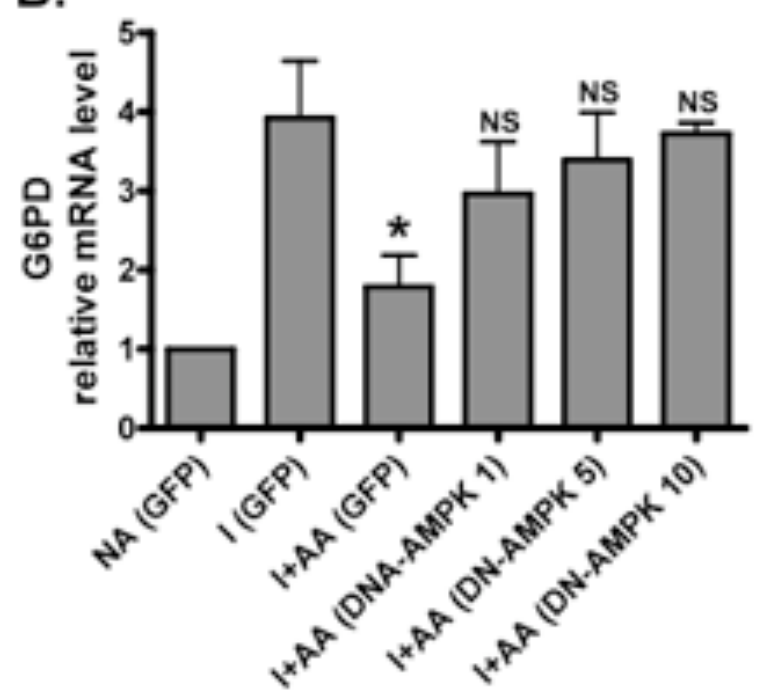




\section{CHAPTER 3.}

CHYLOMICRON REMNANTS AND NON-ESTERIFIED FATTY ACIDS EXHIBIT MARKED DIFFERENCES IN THEIR ABILITY TO RECAPITULATE THE INHIBITION OF LIPOGENESIS BY DIETARY POLYUNSATURATED FAT

Alison B. Kohan ${ }^{1 *}$, Yang Qing ${ }^{2 *}$, Patrick Tso ${ }^{2}$, and Lisa M. Salati ${ }^{1 *}$

${ }^{1}$ Department of Biochemistry, West Virginia University, Morgantown, WV

${ }^{2}$ Department of Pathology and Laboratory Medicine, University of Cincinnati, Cincinnati, OH

Running title: Chylomicron remnants inhibit lipogenic enzymes

${ }^{1 *}$ This author planned and conducted all the experiments contained herein, as well as prepared written manuscript

${ }^{2 *}$ This author isolated lymph from rats fed safflower oil or lard

*Address correspondence to:

Lisa M. Salati, PhD,

1 Medical Center Dr.

Department of Biochemistry, West Virginia University Health Sciences Center, Box 9142,

Morgantown, WV 26506.

Tel.: 304-293-7759

E-mail: 1salati@hsc.wvu.edu 


\section{ABSTRACT:}

Primary hepatocytes treated with non-esterified polyunsaturated fatty acids have been used as a model for describing the inhibitory effects of dietary polyunsaturated fats on lipogenic gene expression. This model resembles starvation or uncontrolled diabetes but not dietary fat ingestion, which is delivered to liver via chylomicron remnants. Chylomicron remnants enriched with polyunsaturated fatty acids stimulate a unique pattern of intracellular signaling. These remnants enhance p38 mitogen activated protein kinase (MAPK) activity but do not inhibit insulin signaling or induce extracellular-signal related kinase (ERK) or AMP-activated protein kinase (AMPK) activation as do non-esterified polyunsaturated fatty acids. Polyunsaturated fatty acids-enriched remnants and non-esterified polyunsaturated fatty acids both inhibit the rate of fatty acid synthesis and the expression of the lipogenic genes, particularly those regulated by sterol response element binding protein-1c (SREBP-1c). Saturated fatty acid-enriched remnants fail to inhibit the lipogenic genes indicating that the inhibitory action of dietary polyunsaturated fats involves regulatory mechanisms in liver. In contrast, polyunsaturated fatty acids-enriched remnants fail to inhibit malic enzyme, glucokinase, L-pyruvate kinase, and cytochrome P450-7 $\alpha$ (Cyp-7 $\alpha$ ) expression despite their inhibition by non-esterified fatty acids. These genes are regulated independently of SREBP-1c. Therefore, non-esterified polyunsaturated fatty acids do not accurately model all aspects of regulation of hepatic metabolism by dietary fat.

KEYWORDS: polyunsaturated fatty acids, non-esterified fatty acids, lipogenesis, dietary fat, nutritional regulation of gene expression, primary hepatocytes, chylomicron remnants, dietary triacylglycerol. 


\section{INTRODUCTION:}

Cardiovascular disease is a leading cause of morbidity and mortality in both developed and developing nations $(1,2)$. It is well established that the amount and type of fat in the diet plays a crucial role in the development of cardiovascular disease (1-4). Increased plasma triacylglycerol directly correlates with the severity and progression of atherosclerosis, and is associated with an increased risk of obesity, diabetes, and coronary heart disease $(5,6)$. Dietary polyunsaturated fatty acids protect against these diseases, in part by the inhibition of triacylglycerol synthesis and secretion from the liver $(7,8)$. This effect is mediated by a decrease in the expression of the lipogenic enzymes involved in the synthesis of fatty acids and thereby triacylglycerol (9-12). The actions of dietary fat are unique to polyunsaturated fatty acids of the n6 and n3 families. Saturated and monounsaturated fatty acids fail to inhibit de novo lipogenesis $(13,14)$. Polyunsaturated fatty acids also enhance the clearance of triacylglycerol from the periphery through their inhibition of apolipoprotein (apo) CIII expression $(15,16)$. Additionally, n6 polyunsaturated fatty acids, found in vegetable oils, ameliorate cardiovascular disease through favorable changes in insulin signaling $(7,8,17)$. The potential, therefore, of dietary polyunsaturated fatty acids to ameliorate atherosclerosis and metabolic diseases is significant.

To determine the role of dietary polyunsaturated fatty acids in the inhibition of de novo lipogenesis, and to model their regulatory and signaling potential, albumin-bound polyunsaturated fatty acids are added to primary rat hepatocytes in culture (18). This model presumes that the increase in intracellular polyunsaturated fatty acid concentration caused by free fatty acids result in the same metabolic changes as dietary fat. Formal proof is lacking. The model has also had a significant limitation in defining the mechanisms responsible for the regulatory differences between polyunsaturated fatty acids and saturated fatty acids, because 
incubation of primary rat hepatocytes with the saturated fatty acid, palmitate causes a rapid depletion in cellular ATP concentrations and stimulates apoptosis $(18,19)$. Furthermore, nonesterified polyunsaturated fatty acids do not recapitulate the manner in which fatty acids from the diet are delivered to liver.

Dietary triacylglycerol is delivered to the periphery via the intestinally derived chylomicron. Dietary triacylglycerol and other lipid components are energy dense and waterinsoluble. Without significant processing, dietary lipid would not be available to peripheral tissues in a usable state. The nascent chylomicron produced in the enterocyte contains triacylglycerol and cholesterol in its core, surrounded by phospholipids and apo B-48 on its exterior (20). Nascent chylomicrons are secreted into the intestinal lymphatic vessels and enter the bloodstream via the thoracic lymph duct, where they acquire apo C-II and apo E from the HDL pool (21). Chylomicrons interact with lipoprotein lipase on the surface of capillary endothelial cells. Lipoprotein lipase hydrolyzes free fatty acids from triacylglycerol in the chylomicrons, releasing free fatty acids that enter into extrahepaptic tissues for $\beta$-oxidation or storage (22). Lipase interaction with the chylomicron produces a smaller, more dense particle known as a chylomicron remnant, which contains 15 to $35 \%$ of its original dietary triacylglycerol and is cleared from circulation by the liver (20). Assimilation of the remnant-derived triacylglycerol into the hepatocytes involves both the action of hepatic lipase on the extracellular surface and receptor-mediated endocytosis followed by lysosomal enzyme hydrolysis of chylomicron remnant triacylglycerol releasing free fatty acids (23-25). Studies examining the regulatory impact of triacylglycerol from the diet as chylomicron remnants are limited.

In contrast to fatty acids derived from lipoproteins, uptake of albumin-bound fatty acid by the liver represents the primary mechanism for providing cellular energy during starvation and 
uncontrolled diabetes. Free fatty acids are released from triacylglycerol stores in adipose tissue during stimulated lipolysis and enter the bloodstream where they associate with albumin providing a mechanism for transport the water-insoluble lipid. Within the liver sinusoids, the free fatty acids dissociate from the albumin and enter hepatocytes by diffusion and/or the action of specific fatty acid transporters $(26,27)$. Not only do the mechanisms of uptake differ between non-esterified fatty acids and chylomicron remnants but also the hormonal milieu is substantially different between the starved and the postprandial state.

A body of evidence is developing that support the notion that the mode of entry of lipid into the hepatocyte can dictate its metabolic fate. Acyl-CoAs appear to be channeled into specific pathways dependent upon their interaction with specific acyl-CoA synthetase (ACS) or fatty acid transport protein (FATP) isoforms. For example, non-esterified fatty acids entering via ACS1 appear to partition to the microsome for triacylglycerol synthesis, whereas fatty acids encountering other ACS isoforms may partition towards $\beta$-oxidation (28-30). Fatty acids entering via FATP5 are shunted toward triacylglycerol synthesis (31). The differential fates of fatty acids entering via hepatic lipase hydrolysis of remnant triacylglycerol or via lysosomal digestion of the remnant are not known. These data suggest that the potential for fatty acids to regulate lipogenic enzyme expression may also be related to their mode of entry into the hepatocyte.

The goal of these experiments is to define the differences between chylomicron remnant triacylglycerol and non-esterified polyunsaturated fatty acids in regulating key signal transduction intermediates and in inhibiting the expression of lipogenic genes. In addition, the incubation of primary rat hepatocytes with chylomicron remnants derived from dietary sources of fat provides a novel method to test the regulatory action of polyunsaturated fatty acids versus 
saturated fatty acids on the expression of lipogenic and glycolytic genes. The finding that there are significant metabolic differences between the effect of non-esterified polyunsaturated fatty acids and dietary triacylglycerol on the liver, in terms of both lipogenic, glycolytic, and signaling pathways is novel, and is crucial for understanding the physiological effect of dietary fat on liver. These mechanisms may be exploited for understanding the metabolic defects in diseases such as type-2 diabetes, heart disease, and metabolic syndrome, which all share defects in the ability of the liver to properly respond to dietary fat. 


\section{MATERIALS AND METHODS:}

Animal care and cell culture - Male Sprague-Dawley rats (150-200g) were maintained on standard rodent chow (unless otherwise indicated) under a normal light-dark cycle. Animal experiments were conducted in conformity with the Public Health Service policy on Humane Care and Use of Laboratory Animals, additionally; the Institutional Animal Care and Use Committee of the Division of Laboratory Animal Resources at West Virginia University approved all experimental procedures. Hepatocytes were isolated from the liver by a modification of the method of Seglen (32), as described previously (33). Hepatocytes (3 x $\left.10^{6}\right)$ were plated onto $60 \mathrm{~mm}$ collagen-coated plates in Hi/Wo/Ba medium (Waymouth MB752/1 plus $20 \mathrm{mM}$ HEPES, pH7.4, $0.5 \mathrm{mM}$ serine, $0.5 \mathrm{mM}$ alanine, $0.2 \%$ bovine serum albumin) plus $5 \%$ newborn calf serum to facilitate cell adhesion. Two hours post-isolation hepatocytes were washed twice with serum-free media, and were incubated overnight with serum-free media and $0.3 \mathrm{mg}$ Matrigel per plate (BD PharMingen) at $37^{\circ} \mathrm{C}$ in a humidified atmosphere of $5 \% \mathrm{CO}_{2}$ and 95\% air. Treatments were added to the hepatocytes in fresh serum-free media, without Matrigel, after $20 \mathrm{~h}$ in culture (time zero). Hepatocytes not receiving $175 \mu \mathrm{M}$ arachidonic acid (Nu-Check Prep: complexed with $4 \mathrm{mM}$ bovine serum albumin and butylated-hydroxytoluene $0.1 \%$ ) were treated with an equivalent volume of serum free media containing $4 \mathrm{mM}$ bovine serum albumin and butylated-hydroxytoluene $0.1 \%$ solution. All media contained supplemental $\alpha$-tocopherol $(5 \mu \mathrm{g} / \mathrm{ml}$ of medium). Any additional hormones and/or treatments added are described in each figure legend.

Protein isolation and Western blot analysis - After rinsing once in cold PBS, hepatocytes were harvested in $300 \mu \mathrm{l}$ cell lysis buffer (20 mM Tris, $\mathrm{pH} 7.5,150 \mathrm{mM} \mathrm{NaCl}, 1 \mathrm{mM}$ EGTA, 1\% 
Triton X-100, $1 \mathrm{mM}$ sodium orthovanadate, $1 \mathrm{mM}$ sodium fluoride, $2.5 \mathrm{mM}$ sodium pyrophosphate, $1 \mathrm{mM}$ beta-glycerophosphate, $1 \mathrm{X}$ complete protease inhibitor cocktail (Roche) and $1 \mathrm{mM}$ phenylmethylsulfonyl fluoride). Hepatocytes were sonicated for 151 -second pulses on ice. After centrifugation at $14,000 \mathrm{xg}$ for $5 \mathrm{~min}$ at $4^{\circ} \mathrm{C}$, insoluble debris was removed. For analysis of SREBP-1c cell lysates were prepared from hepatocytes as described by Hansmannel et al (34). The BCA protein assay kit (Pierce) was used to determine protein concentration. The cell lysates (20-40 $\mu \mathrm{g}$ protein) were then separated by $7.5-12 \%$ SDS-PAGE and transferred to polyvinylidene difluoride membranes in a transfer buffer consisting of $20 \mathrm{mM}$ Tris- $\mathrm{HCl}, \mathrm{pH} 6.8$, $154 \mathrm{mM}$ glycine, and 20\% methanol. Membranes were blocked with 5\% nonfat dry milk in Trisbuffered saline with $0.1 \%$ Tween and incubated with primary antibodies, followed by incubation with anti-rabbit IgG horseradish peroxidase-linked secondary antibody (Cell Signaling). Primary antibodies against phosphorylated (P) -AKT $\left(\operatorname{Ser}^{473}\right)$, P-p38 MAPK $\left(\mathrm{Thr}^{180} / \mathrm{Tyr}^{182}\right)$, P-ERK (Thr ${ }^{202} / \mathrm{Tyr}^{204}$ ), P-AMPK $\left(\mathrm{Thr}^{172}\right.$ ), and their total forms were obtained from Cell Signaling. Total SREBP-1c antibody was obtained from Santa Cruz. Chemiluminescence was detected by ECL plus (Amersham) and imaged using film or the Typhoon 9410 (GE Healthcare). Densitometry was performed with ImageQuant software (Molecular Dynamics).

Immunoprecipitation analysis - Cellular lysates (1mg total protein; pre-cleared with Protein Aagarose beads) were incubated with $4 \mathrm{mg}$ of total insulin receptor substrate (IRS)-1 antibody (Millipore, 06-248) for $1 \mathrm{~h}$ at $4^{\circ} \mathrm{C}$. Each reaction was then incubated with Protein A-agarose beads for an additional $1 \mathrm{~h}$ at $4^{\circ} \mathrm{C}$. After centrifugation, supernatants were removed and the beads were washed three times in cell lysis buffer, complete with protease and phosphatase inhibitors. Electrophoresis sample loading buffer $(80 \mu 1)$ was then added to the beads and the 
samples were boiled for $5 \mathrm{~min}$ and subjected to Western analysis using antibodies against phosphotyrosine (Millipore, 4G10 Platinum) and P-IRS-1 $\left(\operatorname{Ser}^{307}\right)$.

Isolation of Total RNA and quantitative real-time RT-PCR - Total RNA was isolated from 6 x $10^{6}$ hepatocytes (two $60 \mathrm{~mm}$ plates) per treatment using Tri-Reagent (Ambion) according to manufacturer's instructions. RNA (150 ng) was DNase I-treated and expression of all mRNAs except G6PD was determined in duplicate by quantitative real-time PCR (BioRad iCycler iQ) analysis using Quantitect SYBR green (QIAGEN) according to the manufacturer's instructions. G6PD mRNA was determined by quantitative real-time PCR analysis using Quantitect Probe (QIAGEN) with the following sequence: 5'-

FAM/CCACAGAGGCAGATGAGCTGATGAAGAA/3BHQ-3'. Sequences for primers are provided in supplemental Table S1. Expression of cyclophilin B was used as a control and the amount of each mRNA was calculated relative to this control. The relative amount of mRNA was calculated using the comparative threshold cycle method.

Preparation of chylomicron remnants - Lymph fistula rats with duodenal and intestinal lymph duct fistulae (35) were infused ( $3 \mathrm{ml} / \mathrm{h}$ ) with a lipid emulsion containing safflower oil or lard ( $0.36 \mathrm{~g} /$ animal; lard was warmed to melt it) and $19 \mathrm{mM}$ sodium taurocholate in PBS (pH 6.4). Lymph was collected hourly for $6 \mathrm{~h}$. Whole chylomicrons and remnants were isolated as described previously (36). Briefly, lymph was layered under $0.9 \% \mathrm{NaCl}$ and centrifuged at $25,000 \mathrm{~g}$ for $60 \mathrm{~min}$ at $4^{\circ} \mathrm{C}$ in a $50 \mathrm{Ti}$ fixed angle rotor (Beckman). Large chylomicrons were harvested by removing the top 1 to $1.5 \mathrm{ml}$ fraction. Chyle triacylglycerol was digested with lipoprotein lipase by mixing $3 \mathrm{ml}$ of the chylomicron fraction with $9 \mathrm{mls} 5 \%$ fatty acid-free bovine serum albumin and $3 \mathrm{ml}$ of post-heparin plasma, and incubating for $1 \mathrm{~h}$ at $28^{\circ} \mathrm{C}$. Post- 
heparin plasma was isolated as described $\{$ Nilsson, $1977 \# 672\}$. Chylomicron remnants were purified by adjusting the density to $1.063 \mathrm{~g} / \mathrm{ml}$ with $\mathrm{NaCl}$ and $\mathrm{KBr}$. This solution was overlayered with $1.1 \% \mathrm{NaCl}(\mathrm{d}=1.006 \mathrm{~g} / \mathrm{ml})$ and centrifuged at $37,000 \mathrm{~g}$ for $100 \mathrm{~min}$ at $4^{\circ} \mathrm{C}$ in a SW41 swinging bucket rotor (Beckman). The top $1.5 \mathrm{ml}$ was collected. Chylomicron remnants were dialyzed against PBSA for $24 \mathrm{~h}$. Remnant triacylglyercol was quantitated using the Triglyceride and Free Glycerol kit (Sigma-Aldrich); the amount of chylomicron remnant added is expressed as the $\mu \mathrm{g}$ amount of triacylglcyerol in the remnants. $100 \mu \mathrm{g}$ of remnant triacylglycerol added to a plate of hepatocytes containing $3 \mathrm{ml}$ of medium results in an amount of fatty acid equivalent to approximately $115 \mu \mathrm{M}$.

Measurement of fatty acid synthesis - The rate of de novo fatty acid synthesis was measured in primary rat hepatocytes using the tritiated water method (37). Cells were incubated with 0.2 $\mathrm{mCi} / \mathrm{ml}^{3} \mathrm{H}_{2} \mathrm{O}$ during the last $3 \mathrm{~h}$ of a $24 \mathrm{~h}$ treatment with insulin $(80 \mathrm{nM})$ and arachidonic acid $(175 \mu \mathrm{m})$ or chylomicron remnants $(100 \mu \mathrm{g})$. Incorporation of tritium into saponifiable lipids was determined as described (37).

Statistics - Statistics were performed using GraphPad Prism (version 4.0). Overall statistical significance was determined by one-way ANOVA; multiple comparisons were made using a Bonferroni post-test if the overall $p$-value after ANOVA was $p<0.05$. 


\section{RESULTS:}

Chylomicron remnants were synthesized ex vivo by incubating purified chylomicrons with post-heparin plasma as a source of lipoprotein lipase. Remnants prepared using this method acquire ApoC-II, to activate hepatic lipoprotein lipase, and Apo E, for clearance by the liver, from HDL present in the post-heparin plasma $(38,39)$. Despite hydrolysis of the chylomicron triacylglycerol by plasma lipoprotein lipase, the remnant retains $15 \%$ to $30 \%$ of its triacylglycerol and the fatty acid composition of this triacylglycerol reflects the composition of the test meal and contributions from intestinal de novo fatty acid synthesis.

For collection of lymph, the rats were intubated intraduodenally with safflower oil or lard. Safflower oil is unique amongst the vegetable oils in that it contains nearly all n6 polyunsaturated fatty acid. In contrast, lard is a mixed fat that is enriched in saturated fatty acids but can contain appreciable quantities of $n 6$ and $n 3$ polyunsaturated fatty acids (40)(Supplemental Table S2). The total lipid content of the prepared chylomicron remnants was determined by gas chromatography (Fig. 1A). Chylomicron remnants derived from rats intubated with safflower oil (polyunsaturated fatty acid-enriched remnants) contained 57.7\% polyunsaturated fatty acids compared with only $21.3 \%$ polyunsaturated fatty acids in chylomicron remnants derived from rats intubated with lard (saturated fatty acid-enriched remnants). The polyunsaturated fatty acids in both types of remnants were predominantly n6 fatty acids (Fig. 1B). As expected, saturated fatty acid-enriched chylomicron remnants contained twice the saturated fat content compared to polyunsaturated fatty acid-enriched chylomicron remnants $(45.2 \%$ versus $21.2 \%)$. These fatty acids were from the $\mathrm{n} 9$ family and their presence in polyunsaturated fatty acid-enriched chylomicron remnants likely represents fatty acids synthesized de novo by the intestine or were present in the bile phospholipid and absorbed into 
the intestinal cell. Thus, these two pools of chylomicron remnants have a similar fatty acid composition as the polyunsaturated- or saturated fat-enriched meals.

Free fatty acids stimulate multiple signaling kinases within hepatocytes. Key amongst these are AMPK and the MAPKs (41-44). In primary rat hepatocytes, incubation with albuminbound non-esterified arachidonic acid inhibits phosphatidylinositol 3-kinase (PI3-kinase) activity and glucose-6-phosphate dehydrogenase (G6PD) mRNA expression through a p38 MAPKdependent mechanism (44); while docosahexaenoic acid, through modulations in the ERK signaling cascade, can affect transcription of lipogenic genes (45). In order to determine what signaling molecules are activated by treatment with chylomicron remnants, primary hepatocytes were incubated with polyunsaturated fatty acid-enriched chylomicron remnants (100 $\mu \mathrm{g}$ triacylglycerol) or albumin-bound arachidonic acid (175 $\mu \mathrm{M}$ fatty acid) for 5, 10, and $30 \mathrm{~min}$ (Fig. 2A). Treatment with $100 \mu \mathrm{g}$ of remnant triacylglycerol (per plate of hepatocytes) results in a fatty acid concentration of approximately $115 \mu \mathrm{M}$. These concentrations of polyunsaturated fatty acid-enriched chylomicron remnants and arachidonic acid result in maximal inhibition of G6PD expression (Supplementary Fig. 1)(46). Both non-esterified arachidonic acid and polyunsaturated fatty acid-enriched chylomicron remnants significantly increased p38 MAPK phosphorylation at 5 and 10 min; however, the increase in p38 MAPK phosphorylation was not observed after 30 min of incubation with polyunsaturated fatty acid-enriched chylomicron remnants. In contrast, only albumin-bound arachidonic acid resulted in a sustained two-fold activation of ERK (Fig. 2B). The increase in ERK phosphorylation at 5 min is observed regardless of treatment and likely reflects perturbation of the hepatocytes by the medium change. 
Neither free fatty acid nor polyunsaturated fatty acid-enriched chylomicron remnants activated JNK (data not shown).

Free fatty acids are known to stimulate AMPK phosphorylation $(41,42)$. Consistent with this, arachidonic acid caused an increase in AMPK phosphorylation. The increase of 50\% or more at 5 and 10 min of incubation, but by 30 min AMPK phosphorylation had decreased below no addition or insulin alone (Fig. 2A). In contrast, polyunsaturated fatty acid-enriched chylomicron remnants did not result in a significant increase in AMPK phosphorylation but did result in the same drop in phosphorylation after 30 min of incubation (Fig. 2B). The reason for this drop is not clear but was consistently observed across experiments.

We next asked how treatment with polyunsaturated fatty acid-enriched chylomicron remnants would affect the insulin-signaling pathway and in particularly activation of PI3-kinase. Phosphorylation of AKT provides a reliable measure of PI3-kinase activation and changes in AKT phosphorylation by fatty acids reflect changes in PI3-kinase activity by direct measurements (44). In this regard, treatment with arachidonic acid inhibited AKT phosphorylation by approximately $45 \%$ at 5 minutes, and sustained this inhibition through 30 minutes (Fig. 2A). Treatment with polyunsaturated fatty acid-enriched chylomicron remnants does not inhibit AKT phosphorylation at any time point; the apparent decrease at 30 min was not significantly different from treatment with insulin alone (Fig. 2B). Extending the incubation of hepatocytes with polyunsaturated fatty acid-enriched chylomicron remnants for 60 and 90 minutes does not result in an inhibition of AKT phosphorylation (data not shown).

IRS-1 phosphorylation is integral to maintenance of insulin responsiveness (47). Phosphorylation of IRS-1 at Tyr ${ }^{608}$ and Tyr ${ }^{628}$ by the insulin receptor forms docking sites for the regulatory subunit of PI3-kinase, and thus propagates the insulin signal. As expected, incubation 
of hepatocytes for 60 minutes enhanced the tyrosine phosphorylation of IRS-1 (Fig. 2C). Albumin-bound arachidonic acid inhibited the insulin stimulation of tyrosine phosphorylation of IRS-1; however, incubation with polyunsaturated fatty acid-enriched chylomicron remnants did not inhibit the tyrosine phosphorylation of IRS-1 (Fig. 2C).

Phosphorylation of IRS-1 at $\mathrm{Ser}^{307}, \mathrm{Ser}^{612}$, and $\mathrm{Ser}^{632}$ uncouples IRS-1 from the insulin receptor and occludes the PI3-kinase binding sites $(48,49)$. Furthermore, serine phosphorylation at IRS-1 decreases the pool of IRS-1 available for tyrosine phosphorylation (50). We have shown previously that treatment of hepatocytes with arachidonic acid inhibits the insulin-signaling cascade through a decrease in AKT phosphorylation coincident with IRS-1 serine phosphorylation (44). To test if polyunsaturated fatty acid-enriched chylomicron remnants share this mechanism, hepatocytes were incubated with polyunsaturated fatty acid-enriched chylomicron remnants or arachidonic acid for 60 minutes (Fig. 2C). As expected, arachidonic acid treatment increases IRS- ${ }^{\text {ser307 }}$ phosphorylation by almost 3-fold, whereas polyunsaturated fatty acid-enriched chylomicron remnant treatment did not increase IRS-1 ${ }^{\text {ser307 }}$ phosphorylation above treatment with insulin alone. Thus, polyunsaturated fatty acid-enriched chylomicron remnants do not result in the down-regulation of insulin signaling that is observed with free fatty acids.

Providing polyunsaturated fatty acid to hepatocytes as chylomicron remnants, the manner in which dietary fat reaches the liver, results in discrete differences in the activation and inhibition of signal transduction pathways within the liver. We next asked if these signaling differences resulted in differential effects of albumin-bound fatty acids and chylomicron remnants on hepatic lipogenesis. The rate of de novo fatty acid synthesis was measured by 
calculating the incorporation of ${ }^{3} \mathrm{H}_{2} \mathrm{O}$ into saponifiable lipid. Insulin enhanced the rate of de novo fatty acid synthesis by 3.5 -fold (Fig. 3). Addition of either arachidonic acid or chylomicron remnants inhibited lipogenic rate by $50 \%$. The hallmark of the regulation of fatty acid synthesis is that inhibition by dietary fat is specific for polyunsaturated fat of the $\mathrm{n} 6$ and $\mathrm{n} 3$ families and does not occur following consumption of saturated fat $(13,18)$. Treatment of hepatocytes with saturated fat-enriched chylomicron remnants does not inhibit the insulin stimulation of fatty acid synthesis. Thus, regulation of lipogenic rate by polyunsaturated fatty acid- and saturated fatty acid-enriched chylomicron remnants is consistent with regulation by dietary fat in intact liver. Because lipogenic rate was measured during the last $3 \mathrm{~h}$ of a $24 \mathrm{~h}$ incubation with the remnants or arachidonic acid, the decrease in rate is likely caused by a combination of short term regulation of pacesetting enzymes, such as acetyl-CoA carboxylase, and inhibition of the expression genes for the lipogenic enzymes.

G6PD has been a useful prototype for studying regulation of lipogenic enzymes because its expression is stimulated by insulin and inhibited by polyunsaturated fatty acid, in the absence of other hormones such as glucocorticoids or thyroid hormone that could confound the interpretation of the results. Dietary polyunsaturated fatty acid causes a rapid inhibition of G6PD expression; a decrease in mRNA accumulation is detected within $4 \mathrm{~h}$ of starting a polyunsaturated fatty acid containing diet and is maximal by $8 \mathrm{~h}(46)$. This time is consistent with the appearance of high concentrations of chylomicron remnants in the blood (51). In primary hepatocytes, arachidonic acid inhibition of G6PD mRNA accumulation follows a similar time course (Fig. 4A)(33). Incubation with a maximally inhibitory concentration of polyunsaturated fatty acid (Supplemental Fig. S1) also results in a significant inhibition of G6PD mRNA expression (Fig. 4A). This inhibition is observed by $4 \mathrm{~h}$ and continues through $24 \mathrm{~h}$. 
The inhibition by polyunsaturated fatty acid requires the presence of insulin, which induces G6PD expression (44). In this regard, insulin stimulated G6PD mRNA accumulation by 3-fold and polyunsaturated fatty acid-enriched chylomicron remnants inhibited this accumulation by $45 \%$ or more (Fig. 4B). Polyunsaturated fatty acid-enriched chylomicron remnants in the absence of insulin have no effect on G6PD expression. Since safflower oil contains approximately $78 \%$ linoleic acid (Supplemental Table S2), we compared the effect of nonesterified linoleic acid, as well as the longer chain fatty acids, arachidonic acid and eicosapentaenoic acid, to the effect of polyunsaturated fatty acid-enriched chylomicron remnants. Non-esterified polyunsaturated fatty acids (arachidonic acid, linoleic acid, and eicosapentaenoic acid) inhibit this stimulation by $45-60 \%$, similar to the extent of inhibition by polyunsaturated fatty acid-enriched chylomicron remnants. Furthermore, inhibition by chylomicron remnants was specific for polyunsaturated fatty acid-enriched chylomicron remnants; treatment with the saturated fatty acid-enriched chylomicron remnants did not inhibit G6PD. Thus, the small amounts of n6 polyunsaturated fatty acids in saturated fatty acid-enriched chylomicron remnants were insufficient to inhibit G6PD expression. We also treated hepatocytes with nascent chylomicrons, which are excluded from uptake by hepatocytes due to their large size and lack of ApoE for recognition by cell surface receptors. Treatment with either polyunsaturated fatty acidor saturated fatty acid-enriched chylomicrons did not inhibit G6PD mRNA expression. Thus, the polyunsaturated fatty acid-enriched chylomicron remnants inhibition of G6PD expression is consistent with chylomicron remnants as a mediator of dietary fat effects on the liver.

Regulation of G6PD expression by dietary fat occurs exclusively at a posttranscriptional step. We next asked if the inhibitory effect of polyunsaturated fatty acid-enriched chylomicron remnants would extend to other lipogenic genes. Polyunsaturated fatty acids of the $\mathrm{n} 3$ and $n 6$ 
families are well-established suppressors of SREBP-1c activity, either as non-esterified fatty acids or as part of the diet $(52,53)$. Therefore, we asked whether polyunsaturated fatty acidenriched chylomicron remnants would inhibit the expression of SREBP-1c mRNA (Fig. 5A). The addition of insulin increased SREBP-1c mRNA expression by 3-fold. Addition of arachidonic acid, eicosapentaenoic acid or linoleic acid inhibited this increase $64 \%$ or more. Polyunsaturated fatty acid-enriched chylomicron remnants also inhibited the insulin induction of SREBP-1c mRNA by $60 \%$. Saturated fatty acid-enriched chylomicron remnants had no effect on SREBP-1c mRNA expression. Treatment with nascent chylomicrons or remnants alone did not affect SREBP-1c mRNA abundance. The activity of SREBP-1c as a transcription factor requires its cleavage by specific proteases and thereby release from intracellular membranes (54). Release of active or mature SREBP-1c is also inhibited by polyunsaturated fatty acid (Fig. 5B) $(55,56)$. Treatment with polyunsaturated fatty acid-enriched chylomicron remnants resulted in a similar decrease in mature SREBP-1c production as observed with non-esterified arachidonic acid whereas treatment with saturated fatty acid-enriched chylomicron remnants or nascent chylomicrons did not inhibit mature SREBP-1c protein formation. Therefore, polyunsaturated fatty acid-enriched chylomicron remnants mimic the effect of dietary polyunsaturated fatty acids on SREBP-1c expression and activity.

Fatty acid synthase, acetyl-CoA carboxylase-1, stearoyl-CoA desaturase 1, ATP-citrate lyase, and S14 are SREBP-1c target genes. Changes in SREBP-1c activity should therefore regulate these genes in parallel. Insulin increased the expression of these genes. These hepatocytes only received insulin; therefore this induction is less than what was seen in some reports in which the medium was supplemented with additional hormones (57). Polyunsaturated fatty acid-enriched chylomicron remnants significantly inhibited the expression of fatty acid 
synthase, acetyl-CoA carboxylase-1, stearoyl-CoA desaturase 1, ATP-citrate lyase, and S14 mRNAs and the magnitude of this decrease is the same as that observed with the non-esterified fatty acids (Fig. 6). These results are in parallel to the changes in the amount of mature SREBP1c or SREBP-1c mRNA. Saturated fatty acid-enriched chylomicron remnants did not inhibit expression of fatty acid synthase, acetyl-CoA carboxylase-1, or stearoyl-CoA desaturase 1. A small decrease was observed in the expression of ATP-citrate lyase and S14 following treatment with saturated fatty acid-enriched chylomicron remnants and this may be due to the minor amounts of $\mathrm{n} 6$ fatty acids in these particles. Because saturated fatty acid-enriched chylomicron remnants do not inhibit SREBP-1c expression or maturation, the effect of saturated fatty acidenriched chylomicron remnants on ATP-citrate lyase and S14 must involve pathways distinct from the other SREBP-1c targets.

In addition to the lipogenic enzymes, genes in the glycolytic (glucokinase and Lpyruvate kinase) and bile acid synthetic (Cyp-7 $\alpha$ ) pathways are also coordinately regulated by polyunsaturated fatty acid. Inhibition of these genes by polyunsaturated fatty acid does not involve SREBP-1c but uses transcription factors including the carbohydrate response element binding protein (ChREBP) and the liver X receptor (LXR). Malic enzyme, a lipogenic enzyme, was also examined because like G6PD, its regulation does not appear to directly involve SREBP$1 \mathrm{c}$ and may also be regulated at posttranscriptional steps (58). Expression of each of these genes was enhanced by insulin and significantly inhibited by albumin bound polyunsaturated fatty acids (Fig. 7). In contrast, polyunsaturated fatty acid-enriched chylomicron remnants did not significantly inhibit the mRNA expression of malic enzyme, L-pyruvate kinase, or Cyp-7 $\alpha$ compared to treatment with insulin. As each of these enzymes is inhibited by dietary 
polyunsaturated fatty acid, the mechanism for inhibition in intact animals must involve another dietary-derived humoral factor. 


\section{DISCUSSION:}

Primary rat hepatocytes in culture have provided the best model system to decipher the mechanisms by which dietary fat regulates hepatic metabolism and lipogenic gene expression. Compared to liver cell lines, hepatocytes in primary culture retain more liver-specific traits and the components of the signaling pathways involved in regulating liver-specific gene expression (18). In the intact animal, the liver is exposed to fatty acids in two distinct ways: dietary (or exogenous) fatty acids in the form of triacylglycerols are delivered to the liver in chylomicron remnants, and adipose-derived (endogenous) non-esterified fatty acids are presented to the liver bound to serum albumin in a non-covalent manner. Yet, to model regulation of liver metabolism by dietary fat, primary rat hepatocytes have traditionally been incubated with albumin bound non-esterified fatty acids. While a facile treatment method, it does not duplicate the presentation of dietary fatty acids, which occurs via chylomicron remnants. Treatment of hepatocytes with non-esterified fatty acids presumes that the regulatory effects of polyunsaturated fatty acids, regardless of source, occur via an increase in intracellular fatty acid concentration, an untested assumption. Primary hepatocytes in culture express functioning versions of the necessary receptors and cell-surface molecules for chylomicron remnant uptake and thus, their regulatory potential can be measured (59). In the present report we measured the regulatory actions of chylomicron remnants as a model for the effects of dietary polyunsaturated fatty acids on the liver.

Polyunsaturated fatty acid-enriched chylomicron remnants inhibit both the rate of hepatic fatty acid synthesis (Fig. 3) and expression of the lipogenic genes SREBP-1c, fatty acid synthase, acetyl-CoA carboxylase, stearoyl-CoA desaturase 1, ATP-citrate lyase, and S14 (Figs. 4-6). In this regard, the regulatory potential of polyunsaturated fatty acid-enriched chylomicron remnants 
is similar to regulation by non-esterified polyunsaturated fatty acids. The inhibition of lipogenesis was specific for remnants derived from polyunsaturated dietary lipids; saturated fatenriched chylomicron remnants did not inhibit lipogenic rate or expression of the lipogenic genes. This comparison is not possible with non-esterified fatty acids; the toxicity of palmitate and stearate in primary hepatocytes confounds the interpretation of these results $(18,19)$. Thus the differential inhibitory effects of dietary polyunsaturated fatty acids versus saturated fatty acids are recapitulated by incubation of primary hepatocytes with chylomicron remnants derived from different fats and these effects appear to be mediated by regulatory events within the liver cell.

In contrast to genes of the lipogenic pathway, remnants do not inhibit the accumulation of mRNA for glucokinase, L-pyruvate kinase, Cyp-7 $\alpha$, and malic enzyme, although these genes are inhibited by non-esterified polyunsaturated fatty acids (Fig. 7). Accompanying this difference, polyunsaturated fatty acid-enriched chylomicron remnants and non-esterified polyunsaturated fatty acids do not stimulate the same intracellular signaling pathways (Fig. 2). In contrast to nonesterified polyunsaturated fatty acids, polyunsaturated fatty acid-enriched chylomicron remnants do not decrease insulin signaling to AKT nor do they activate AMPK or ERK. While lipids from both sources activate p38 MAPK, the activation is sustained in cells incubated with nonesterified fatty acid but disappears by $30 \mathrm{~min}$ in hepatocytes incubated with chylomicron remnants (Fig. 2A).

The inhibition of SREBP-1c dependent genes by polyunsaturated fatty acid-enriched chylomicron remnants appears to be mediated by changes in SREBP-1c activity (Fig. 5) and this is consistent with this being the mechanisms for inhibition of these genes by dietary fat $(10,56$, $57,60,61)$. The lack of effect of polyunsaturated fatty acid-enriched chylomicron remnants on 
SREBP-1c independent genes may involve differences between remnant and non-esterified fatty acids in decreasing insulin signal transduction (Fig. 2)(44). Expression of glucokinase and malic enzyme are highly dependent on stimulation by insulin (62). L-pyruvate kinase expression is not directly stimulated by insulin, but its stimulation by a glucose-derived metabolite requires glucokinase activity and thus, indirectly, insulin action (63). An alternative possibility for this difference between genes is that fatty acids from polyunsaturated fatty acid-enriched chylomicron remnants may be oxidized or metabolized more quickly than non-esterified polyunsaturated fatty acids, such that the intracellular concentration of fatty acid or relevant metabolite necessary for inhibition of SREBP-1c independent genes may only be achieved with non-esterified polyunsaturated fatty acids. The decrease in p38 MAPK activation by $30 \mathrm{~min}$ of chylomicron remnant treatment is consistent with this possibility (Fig. 2B). In contrast to transcriptionally regulated enzymes, G6PD is not transcriptionally regulated and inhibition of G6PD mRNA accumulation by both polyunsaturated fatty acid-enriched chylomicron remnants and non-esterified fatty acids indicates additional potential mechanisms that do not involve transcription factors.

From the perspective of identifying intracellular signaling pathways, incubation of primary rat hepatocytes with non-esterified fatty acids appear to be a better model of the starved state or uncontrolled diabetes than a model for regulation by dietary fat. In intact animals, free fatty acids concentrations in blood rise sharply during stimulated lipolysis, a hallmark of starvation. In this regard, the fatty acid activation of p38 MAPK and the inhibition of AKT activation and Tyr-phosphorylation of IRS-1 are observed with both non-esterified fatty acids in primary hepatocytes and in liver during diabetes (Fig. 2)(44, 64). This suggests that fatty signaling and not just hormonal signaling is involved in the metabolic shift toward glucose 
production and away from glycolytic flux and lipogenesis. In the fed state, dietary polyunsaturated fatty acids (presented as triacylglycerols in chylomicron remnants) play a role in long-term adaptation to nutritional status by inhibiting the capacity of the liver to synthesize fatty acids de novo. The signaling cascades involved do not appear to involve sustained changes in insulin signal transduction but appear to interact with alternative machinery within the cell such as the activity of the lipogenic transcription factor, SREBP-1c.

Thus mode of presentation of lipid to the liver is a determinant of its intracellular action. Internalization of remnant triacylglycerol involves remnant binding to cell surface heparan sulfate proteoglycans and the LDL receptor (LDLR) or the LDLR-related protein (LRP)(65-68). Uptake of the remnant fatty acid can occur by both hepatic lipase hydrolysis on the extracellular surface and lysosomal digestion of the internalized remnant particle (69). Albumin-bound nonesterified fatty acids enter the hepatocyte through disassociation from albumin at the extracellular surface and either diffusion into the cell or entry via fatty acid transport proteins (70).

Several lines of evidence indicate that mode of uptake will alter intracellular metabolism of fatty acids. Although the acyl groups from dietary triacylglycerol and adipose-derived nonesterified fatty acids are not chemically distinct, uptake appears to be coupled to different intracellular enzymes, such as distinct fatty acid transport proteins (FATP) and acyl-CoA synthetases (ACS). When polyunsaturated fatty acids are activated by ACS4 they become preferentially destined for peroxisomal oxidation, rather than a substrate for other intracellular metabolic pathways (71-73). Fatty acid uptake mediated by FATP5, however, causes fatty acids to be shunted toward de novo triacylglycerol synthesis (31). The primary fate of fatty acids derived from remnant uptake is not known, although they can be incorporated into intracellular 
lipids and oxidized by beta-oxidation (74). Fatty acids derived from hydrolysis of internal triacylglycerol stores preferentially activate PPAR-alpha in liver and therefore function in an intracellular signaling pathway (75). Triacylglycerol derived from remnants may share this mechanism. It is tempting to speculate that differences in the regulatory actions of non-esterified polyunsaturated fatty acids and chylomicron remnant derived fatty acids are due to these differences in metabolic partitioning.

Therefore, incubation of primary hepatocytes with non-esterified polyunsaturated fatty acids represents a different paradigm than regulation of liver metabolism by dietary polyunsaturated fatty acids. While some effects of dietary fat as modeled with chylomicron remnants are recapitulated by non-esterified polyunsaturated fatty acids, albumin-bound fatty acids represent an important mechanism of energy delivery in the starved state and in uncontrolled diabetes mellitus. Furthermore, the inhibition of insulin signal transduction by nonesterified polyunsaturated fatty acids resembles the insulin resistant state of the liver during adaptation to prolonged feeding of a high-fat diet. In contrast, polyunsaturated fatty acidenriched chylomicron remnants do not decrease insulin signaling suggesting that the decrease in lipogenic rate and capacity involve separate mechanisms. Thus, the method of lipid delivery to hepatocytes is an important consideration in deciphering mechanisms involved in transduction of dietary fat signals within the liver. 


\begin{abstract}
ABBREVIATIONS:
ACS, acyl-CoA synthetase; AMPK, AMP activated protein kinase; Apo, apolipoprotein; ChREBP, carbohydrate response element binding protein; Cyp7a, cytochrome P450 7a; ERK, extracellular-signaling kinase; FATP, fatty acid transport protein; G6PD, glucose-6-phosphate dehydrogenase; IRS, insulin receptor substrate; LDLR, LDL receptor; LRP1, LDL receptor related protein 1; LXR, liver X receptor; MAPK, mitogen activated protein kinase; PI3-kinase, phosphatidylinositol 3-kinase; SREBP-1c, sterol response element binding protein-1c
\end{abstract}

\title{
ACKNOWLEDGEMENTS:
}

This work was supported by National Institutes of Health Grant DK46897 (to L.M.S.), National Institutes of Health T32 HL090610 (to A.B.K.) and the Mouse Metabolic Phenotyping Center at University of Cincinnati - DK059630 (to PT). We thank DoBin Choi and the West Virginia INBRE program for help with the AKT western blots and Callee M. Walsh for experimental advice and for critical reviews of the manuscript. 


\section{REFERENCES:}

1. Yusuf, S., S. Hawken, S. Ounpuu, T. Dans, A. Avezum, F. Lanas, M. McQueen, A. Budaj, P. Pais, J. Varigos, and L. Lisheng. 2004. Effect of potentially modifiable risk factors associated with myocardial infarction in 52 countries (the INTERHEART study): case-control study. Lancet 364: 937-952.

2. Yusuf, S., S. Reddy, S. Ounpuu, and S. Anand. 2001. Global burden of cardiovascular diseases: part I: general considerations, the epidemiologic transition, risk factors, and impact of urbanization. Circulation 104: 2746-2753.

3. Ahrens, E. H., Jr., W. Insull, Jr., R. Blomstrand, J. Hirsch, T. T. Tsaltas, and M. L.

Peterson. 1957. The influence of dietary fats on serum-lipid levels in man. Lancet 272: 943-953.

4. Hegsted, D. M., R. B. McGandy, M. L. Myers, and F. J. Stare. 1965. Quantitative effects of dietary fat on serum cholesterol in man. Am J Clin Nutr 17: 281-295.

5. Austin, M. A. 1988. Epidemiologic associations between hypertriglyceridemia and coronary heart disease. Semin Thromb Hemost 14: 137-142.

6. Karpe, F. 1997. Postprandial lipid metabolism in relation to coronary heart disease. Proc Nutr Soc 56: 671-678.

7. Hu, F. B., J. E. Manson, and W. C. Willett. 2001. Types of dietary fat and risk of coronary heart disease: a critical review. J Am Coll Nutr 20: 5-19.

8. Sanders, T. A., F. R. Oakley, G. J. Miller, K. A. Mitropoulos, D. Crook, and M. F. Oliver. 1997. Influence of n-6 versus n-3 polyunsaturated fatty acids in diets low in saturated fatty acids on plasma lipoproteins and hemostatic factors. Arterioscler Thromb Vasc Biol 17: 3449-3460. 
9. Hill, R., J. M. Linazasoro, F. Chevallier, and I. L. Chaikoff. 1958. Regulation of hepatic lipogenesis: the influence of dietary fats. J Biol Chem 233: 305-310.

10. Jump, D. B., and S. D. Clarke. 1999. Regulation of gene expression by dietary fat. Annu Rev Nutr 19: 63-90.

11. Ntambi, J. M. 1999. Regulation of stearoyl-CoA desaturase by polyunsaturated fatty acids and cholesterol. J Lipid Res 40: 1549-1558.

12. Waterman, R. A., D. R. Romsos, A. C. Tsai, E. R. Miller, and G. A. Leveille. 1975. Influence of dietary safflower oil and tallow on growth, plasma lipids and lipogenesis in rats, pigs and chicks. Proc Soc Exp Biol Med 150: 347-351.

13. Bartley, J. C., and S. Abraham. 1972. Hepatic lipogenesis in fasted, re-fed rats and mice: response to dietary fats of differing fatty acid composition. Biochim Biophys Acta 280: 258-266. 14. Clarke, S. D., D. R. Romsos, and G. A. Leveille. 1976. Specific inhibition of hepatic fatty acid synthesis exerted by dietary linoleate and linolenate in essential fatty acid adequate rats. Lipids 11: 485-490.

15. Montoya, M. T., A. Porres, S. Serrano, J. C. Fruchart, P. Mata, J. A. Gerique, and G. R. Castro. 2002. Fatty acid saturation of the diet and plasma lipid concentrations, lipoprotein particle concentrations, and cholesterol efflux capacity. Am J Clin Nutr 75: 484-491.

16. Sato, R., W. Miyamoto, J. Inoue, T. Terada, T. Imanaka, and M. Maeda. 1999. Sterol regulatory element-binding protein negatively regulates microsomal triglyceride transfer protein gene transcription. J Biol Chem 274: 24714-24720.

17. Mozaffarian, D., A. Ascherio, F. B. Hu, M. J. Stampfer, W. C. Willett, D. S. Siscovick, and E. B. Rimm. 2005. Interplay between different polyunsaturated fatty acids and risk of coronary heart disease in men. Circulation 111: 157-164. 
18. Salati, L. M., and S. D. Clarke. 1986. Fatty acid inhibition of hormonal induction of acetyl-coenzyme A carboxylase in hepatocyte monolayers. Arch Biochem Biophys 246: 82-89. 19. Wei, Y., D. Wang, F. Topczewski, and M. J. Pagliassotti. 2006. Saturated fatty acids induce endoplasmic reticulum stress and apoptosis independently of ceramide in liver cells. Am J Physiol Endocrinol Metab 291: E275-281.

20. Redgrave, T. G. 1970. Formation of cholesteryl ester-rich particulate lipid during metabolism of chylomicrons. J Clin Invest 49: 465-471.

21. Brown, M. S., P. T. Kovanen, and J. L. Goldstein. 1981. Regulation of plasma cholesterol by lipoprotein receptors. Science 212: 628-635.

22. Olivecrona, T., G. Liu, M. Hultin, and G. Bengtsson-Olivecrona. 1993. Regulation of lipoprotein lipase. Biochem Soc Trans 21: 509-513.

23. Krapp, A., S. Ahle, S. Kersting, Y. Hua, K. Kneser, M. Nielsen, J. Gliemann, and U. Beisiegel. 1996. Hepatic lipase mediates the uptake of chylomicrons and beta-VLDL into cells via the LDL receptor-related protein (LRP). J Lipid Res 37: 926-936.

24. Ji, Z. S., S. J. Lauer, S. Fazio, A. Bensadoun, J. M. Taylor, and R. W. Mahley. 1994. Enhanced binding and uptake of remnant lipoproteins by hepatic lipase-secreting hepatoma cells in culture. J Biol Chem 269: 13429-13436.

25. Ji, Z. S., H. L. Dichek, R. D. Miranda, and R. W. Mahley. 1997. Heparan sulfate proteoglycans participate in hepatic lipaseand apolipoprotein E-mediated binding and uptake of plasma lipoproteins, including high density lipoproteins. J Biol Chem 272: 31285-31292.

26. Stahl, A., R. E. Gimeno, L. A. Tartaglia, and H. F. Lodish. 2001. Fatty acid transport proteins: a current view of a growing family. Trends Endocrinol Metab 12: 266-273.

27. Stremmel, W. 1989. Mechanism of hepatic fatty acid uptake. J Hepatol 9: 374-382. 
28. Fulgencio, J. P., C. Kohl, J. Girard, and J. P. Pegorier. 1996. Troglitazone inhibits fatty acid oxidation and esterification, and gluconeogenesis in isolated hepatocytes from starved rats. Diabetes 45: 1556-1562.

29. Coleman, R. A., T. M. Lewin, and D. M. Muoio. 2000. Physiological and nutritional regulation of enzymes of triacylglycerol synthesis. Annu Rev Nutr 20: 77-103.

30. Muoio, D. M., T. M. Lewin, P. Wiedmer, and R. A. Coleman. 2000. Acyl-CoAs are functionally channeled in liver: potential role of acyl-CoA synthetase. Am J Physiol Endocrinol Metab 279: E1366-1373.

31. Doege, H., R. A. Baillie, A. M. Ortegon, B. Tsang, Q. Wu, S. Punreddy, D. Hirsch, N. Watson, R. E. Gimeno, and A. Stahl. 2006. Targeted deletion of FATP5 reveals multiple functions in liver metabolism: alterations in hepatic lipid homeostasis. Gastroenterology 130: $1245-1258$.

32. Seglen, P. O. 1973. Preparation of rat liver cells. 3. Enzymatic requirements for tissue dispersion. Exp Cell Res 82: 391-398.

33. Stabile, L. P., S. A. Klautky, S. M. Minor, and L. M. Salati. 1998. Polyunsaturated fatty acids inhibit the expression of the glucose-6-phosphate dehydrogenase gene in primary rat hepatocytes by a nuclear posttranscriptional mechanism. J Lipid Res 39: 1951-1963.

34. Hansmannel, F., S. Mordier, and P. B. Iynedjian. 2006. Insulin induction of glucokinase and fatty acid synthase in hepatocytes: analysis of the roles of sterol-regulatory-element-binding protein-1c and liver X receptor. Biochem J 399: 275-283.

35. Tso, P., M. D. Karlstad, B. R. Bistrian, and S. J. DeMichele. 1995. Intestinal digestion, absorption, and transport of structured triglycerides and cholesterol in rats. Am J Physiol 268: G568-577. 
36. Floren, C. H., and A. Nilsson. 1977. Degradation of chylomicron remnant cholesteryl ester by rat hepatocyte monolayers. Inhibition by chloroquine and colchicine. Biochem Biophys Res Commun 74: 520-528.

37. Lowenstein, J. M., H. Brunengraber, and M. Wadke. 1975. Measurement of rates of lipogenesis with deuterated and tritiated water. Methods Enzymol 35: 279-287.

38. Vigne, J. L., and R. J. Havel. 1981. Metabolism of apolipoprotein A-I of chylomicrons in rats and humans. Can J Biochem 59: 613-618.

39. Mortimer, B. C., P. Tso, C. T. Phan, D. J. Beveridge, J. Wen, and T. G. Redgrave. 1995. Features of cholesterol structure that regulate the clearance of chylomicron-like lipid emulsions. J Lipid Res 36: 2038-2053.

40. Ziegler, E., E. and L.J. Filer, Jr., editor. 1996. Present Knowledge in Nutrition. 7th ed. ILSI Press, Washington, D.C.

41. Kawaguchi, T., K. Osatomi, H. Yamashita, T. Kabashima, and K. Uyeda. 2002. Mechanism for fatty acid "sparing" effect on glucose-induced transcription: regulation of carbohydrate-responsive element-binding protein by AMP-activated protein kinase. J Biol Chem 277: 3829-3835.

42. Suchankova, G., M. Tekle, A. K. Saha, N. B. Ruderman, S. D. Clarke, and T. W. Gettys. 2005. Dietary polyunsaturated fatty acids enhance hepatic AMP-activated protein kinase activity in rats. Biochem Biophys Res Commun 326: 851-858.

43. Xiong, Y., Q. F. Collins, J. An, E. Lupo, Jr., H. Y. Liu, D. Liu, J. Robidoux, Z. Liu, and W. Cao. 2007. p38 mitogen-activated protein kinase plays an inhibitory role in hepatic lipogenesis. J Biol Chem 282: 4975-4982. 
44. Talukdar, I., W. Szeszel-Fedorowicz, and L. M. Salati. 2005. Arachidonic acid inhibits the insulin induction of glucose-6-phosphate dehydrogenase via p38 MAP kinase. J Biol Chem 280: 40660-40667.

45. Botolin, D., Y. Wang, B. Christian, and D. B. Jump. 2006. Docosahexaneoic acid (22:6,n-3) regulates rat hepatocyte SREBP-1 nuclear abundance by Erk- and 26S proteasomedependent pathways. J Lipid Res 47: 181-192.

46. Stabile, L. P., D. L. Hodge, S. A. Klautky, and L. M. Salati. 1996. Posttranscriptional regulation of glucose-6-phosphate dehydrogenase by dietary polyunsaturated fat. Arch Biochem Biophys 332: 269-279.

47. Saltiel, A. R., and C. R. Kahn. 2001. Insulin signalling and the regulation of glucose and lipid metabolism. Nature 414: 799-806.

48. Aguirre, V., T. Uchida, L. Yenush, R. Davis, and M. F. White. 2000. The c-Jun NH(2)terminal kinase promotes insulin resistance during association with insulin receptor substrate-1 and phosphorylation of Ser(307). J Biol Chem 275: 9047-9054.

49. Mothe, I., and E. Van Obberghen. 1996. Phosphorylation of insulin receptor substrate-1 on multiple serine residues, 612, 632, 662, and 731, modulates insulin action. J Biol Chem 271: $11222-11227$.

50. Pederson, T. M., D. L. Kramer, and C. M. Rondinone. 2001. Serine/threonine phosphorylation of IRS-1 triggers its degradation: possible regulation by tyrosine phosphorylation. Diabetes 50: 24-31.

51. Redgrave, T. G. 1983. Formation and metabolism of chylomicrons. Int Rev Physiol 28: $103-130$. 
52. Xu, J., M. T. Nakamura, H. P. Cho, and S. D. Clarke. 1999. Sterol regulatory element binding protein-1 expression is suppressed by dietary polyunsaturated fatty acids. A mechanism for the coordinate suppression of lipogenic genes by polyunsaturated fats. $J$ Biol Chem 274: $23577-23583$.

53. Mater, M. K., A. P. Thelen, D. A. Pan, and D. B. Jump. 1999. Sterol response elementbinding protein 1c (SREBP1c) is involved in the polyunsaturated fatty acid suppression of hepatic S14 gene transcription. J Biol Chem 274: 32725-32732.

54. DeBose-Boyd, R. A., M. S. Brown, W. P. Li, A. Nohturfft, J. L. Goldstein, and P. J. Espenshade. 1999. Transport-dependent proteolysis of SREBP: relocation of site-1 protease from Golgi to ER obviates the need for SREBP transport to Golgi. Cell 99: 703-712.

55. Hannah, V. C., J. Ou, A. Luong, J. L. Goldstein, and M. S. Brown. 2001. Unsaturated fatty acids down-regulate srebp isoforms 1a and 1c by two mechanisms in HEK-293 cells. J Biol Chem 276: 4365-4372.

56. Worgall, T. S., S. L. Sturley, T. Seo, T. F. Osborne, and R. J. Deckelbaum. 1998. Polyunsaturated fatty acids decrease expression of promoters with sterol regulatory elements by decreasing levels of mature sterol regulatory element-binding protein. J Biol Chem 273: 2553725540 .

57. Stoeckman, A. K., and H. C. Towle. 2002. The role of SREBP-1c in nutritional regulation of lipogenic enzyme gene expression. J Biol Chem 277: 27029-27035.

58. Dozin, B., J. E. Rall, and V. M. Nikodem. 1986. Tissue-specific control of rat malic enzyme activity and messenger RNA levels by a high carbohydrate diet. Proc Natl Acad Sci U S A 83: 4705-4709. 
59. Nomura, T., E. A. Irving, and R. A. Harris. 1981. Comparison of the metabolic effects of chylomicrons and their remnants on isolated hepatocytes. Arch Biochem Biophys 211: 211-221. 60. Jump, D. B., D. Botolin, Y. Wang, J. Xu, B. Christian, and O. Demeure. 2005. Fatty acid regulation of hepatic gene transcription. J Nutr 135: 2503-2506.

61. Sampath, H., and J. M. Ntambi. 2005. Polyunsaturated fatty acid regulation of genes of lipid metabolism. Annu Rev Nutr 25: 317-340.

62. Hillgartner, F. B., L. M. Salati, and A. G. Goodridge. 1995. Physiological and molecular mechanisms involved in nutritional regulation of fatty acid synthesis. Physiol Rev 75: 47-76.

63. Thompson, K. S., and H. C. Towle. 1991. Localization of the carbohydrate response element of the rat L-type pyruvate kinase gene. J Biol Chem 266: 8679-8682.

64. Cao, W., Q. F. Collins, T. C. Becker, J. Robidoux, E. G. Lupo, Jr., Y. Xiong, K. W. Daniel, L. Floering, and S. Collins. 2005. p38 Mitogen-activated protein kinase plays a stimulatory role in hepatic gluconeogenesis. J Biol Chem 280: 42731-42737.

65. Willnow, T. E., Z. Sheng, S. Ishibashi, and J. Herz. 1994. Inhibition of hepatic chylomicron remnant uptake by gene transfer of a receptor antagonist. Science 264: 1471-1474. 66. Yu, K. C., and A. D. Cooper. 2001. Postprandial lipoproteins and atherosclerosis. Front Biosci 6: D332-354.

67. Brown, M. S., and J. L. Goldstein. 1986. A receptor-mediated pathway for cholesterol homeostasis. Science 232: 34-47.

68. Herz, J., U. Hamann, S. Rogne, O. Myklebost, H. Gausepohl, and K. K. Stanley. 1988. Surface location and high affinity for calcium of a 500-kd liver membrane protein closely related to the LDL-receptor suggest a physiological role as lipoprotein receptor. Embo J 7: 4119-4127. 
69. Ellsworth, J. L., L. G. Fong, F. B. Kraemer, and A. D. Cooper. 1990. Differences in the processing of chylomicron remnants and beta-VLDL by macrophages. J Lipid Res 31: 13991411.

70. Abumrad, N., C. Harmon, and A. Ibrahimi. 1998. Membrane transport of long-chain fatty acids: evidence for a facilitated process. J Lipid Res 39: 2309-2318.

71. Lewin, T. M., J. H. Kim, D. A. Granger, J. E. Vance, and R. A. Coleman. 2001. AcylCoA synthetase isoforms 1,4 , and 5 are present in different subcellular membranes in rat liver and can be inhibited independently. J Biol Chem 276: 24674-24679.

72. Lewin, T. M., C. G. Van Horn, S. K. Krisans, and R. A. Coleman. 2002. Rat liver acylCoA synthetase 4 is a peripheral-membrane protein located in two distinct subcellular organelles, peroxisomes, and mitochondrial-associated membrane. Arch Biochem Biophys 404: 263-270. 73. Rusinol, A. E., Z. Cui, M. H. Chen, and J. E. Vance. 1994. A unique mitochondriaassociated membrane fraction from rat liver has a high capacity for lipid synthesis and contains pre-Golgi secretory proteins including nascent lipoproteins. J Biol Chem 269: 27494-27502. 74. Lambert, M. S., M. A. Avella, K. M. Botham, and P. A. Mayes. 1998. Comparison of short- and long-term effects of different dietary fats on the hepatic uptake and metabolism of chylomicron remnants in rats. Br J Nutr 79: 203-211.

75. Sapiro, J. M., M. T. Mashek, A. S. Greenberg, and D. G. Mashek. 2009. Hepatic triacylglycerol hydrolysis regulates PPAR-alpha activity. J Lipid Res. 


\section{FIGURE LEGENDS:}

Figure 1. Chylomicron remnants from rats intubated with safflower oil are enriched in polyunsaturated fatty acid. Total lipid analysis was performed by Lipomics Technologies (Sacramento, CA) to determine the fatty acid composition of the prepared chylomicron remnants. Data is expressed as the percent of the total triacylglycerol content of the chylomicron remnants. A. Gray bars represent chylomicron remnants derived from safflower oil-intubated rats; black bars represent chylomicron remnants derived from lard-intubated rats. B. The polyunsaturated fatty acid species making up the total chylomicron remnant triacylglycerol were determined as in A. n3, n6, n7, n9 refers to the position of the double bond from the methyl end of the fatty acid. SFA, saturated fatty acid; MUFA, monounsaturated fatty acid; PUFA, polyunsaturated fatty acid; CR, chylomicron remnants; TAG, triacylglycerol.

Figure 2. Polyunsaturated fatty acid-enriched chylomicron remnants and non-esterified polyunsaturated fatty acids result in different patterns of cellular signaling. Primary rat hepatocytes were plated on collagen coated dishes and incubated in $\mathrm{Hi} / \mathrm{Wo} / \mathrm{Ba}$ medium. After 20 $\mathrm{h}$ in culture, the medium was replaced with $\mathrm{Hi} / \mathrm{Wo} / \mathrm{Ba}$ with or without insulin $(80 \mathrm{nM}$; I), albumin-bound arachidonic acid (175 $\mu \mathrm{M}$; AA), or polyunsaturated fatty acid-enriched chylomicron remnants (100 $\mu \mathrm{g}$ triacylglycerol; PUFA CR). For measurement of AMPK and p38 MAPK, the cells (2 plates/treatment) were harvested and total cell lysates prepared at 5, 10 and 30 min after treatment. AKT and ERK were measured in cells (2 plates/treatment) incubated with or without albumin-bound arachidonic acid $(175 \mu \mathrm{M})$, or polyunsaturated fatty acidenriched chylomicron remnants (100 $\mu \mathrm{g}$ triacylglycerol) for $24 \mathrm{~h}$ and then treated with insulin $(80 \mathrm{nM})$ for 5, 10 and $30 \mathrm{~min}$. A. Western analysis was performed using antibodies against 
phosphorylated $\mathrm{Thr}^{180} / \mathrm{Tyr}^{182}$ of p38 MAPK, $\mathrm{Thr}^{202} / \mathrm{Tyr}^{204}$ of ERK, $\mathrm{Thr}^{172}$ of AMPK, and $\mathrm{Ser}^{473}$ of AKT, as well as against the total amount of each protein. Representative blots are shown. B. Quantitative representation of the fold increase in phosphorylated protein as compared to no addition (NA) at each time point. Densitometry was performed with ImageQuant software (Molecular Dynamics). Values were calculated as arbitrary densitometric units of phosphorylated protein divided by total protein and are expressed as the fold-increase over no addition (NA). Each bar represents the mean and SE of $\mathrm{n}=4$ separate hepatocyte isolations. $\left.{ }^{*}\right)$ $\mathrm{p}<0.05$ compared to cells treated with insulin. C. For measurement of IRS-1, the cells ( 3 plates/treatment) were harvested and total cell lysates prepared 60 min after treatment. For phosphorylated IRS-1, immunoprecipitation was performed using an antibody against total IRS1 followed by western analysis using an antibody against $\operatorname{Ser}^{307}$ of IRS-1 (right graph) or phosho-tyrosine (left graph). Total IRS-1 was measured by western analysis using an antibody against total IRS-1. Densitometry is expressed at arbitrary densitometric units and is a measure of phosphorylated protein divided by total protein. Each bar represents the mean and SE of $n=4$ separate hepatocyte isolations. $(*) \mathrm{p}<0.05$ compared to cells treated with insulin, NS, not significant.

\section{Figure 3. Polyunsaturated fatty acid-enriched chylomicron remnants inhibit the rate of}

fatty acid synthesis. Primary rat hepatocytes were plated on collagen coated dishes and incubated in $\mathrm{Hi} / \mathrm{Wo} / \mathrm{Ba}$ medium. After $20 \mathrm{~h}$ in culture, the medium was replaced with $\mathrm{Hi} / \mathrm{Wo} / \mathrm{Ba}$ with or without insulin $(80 \mathrm{nM}$; I), albumin-bound arachidonic acid (175 $\mu \mathrm{M}$; AA), or chylomicron remnants (100 $\mu \mathrm{g}$ triacylglycerol; CR). Media was replaced every $12 \mathrm{~h}$ with one of identical composition, and fatty acid synthesis was measured after $24 \mathrm{~h}$ of treatment as described 
in the methods ( 3 plates/treatment). Values are expressed as the fold-increase over no addition (NA). Each bar represents the mean \pm SE of $n=3$ independent primary hepatocyte isolations. $(*)$ $\mathrm{p}<0.05$ compared to cells treated with insulin, NS, not significant. NA, no addition; I, insulin; AA, arachidonic acid; PUFA CR, polyunsaturated fatty acid-enriched chylomicron remnants; LARD CR, saturated fatty acid-enriched chylomicron remnants.

\section{Figure 4. G6PD expression is inhibited by both polyunsaturated fatty acid-enriched} chylomicron remnants and non-esterified polyunsaturated fatty acids. Primary rat hepatocytes were plated on collagen coated dishes and incubated in $\mathrm{Hi} / \mathrm{Wo} / \mathrm{Ba}$ medium. A. After $20 \mathrm{~h}$ in culture, the medium was replaced with $\mathrm{Hi} / \mathrm{Wo} / \mathrm{Ba}$ with insulin $(80 \mathrm{nM}$; I) for $24 \mathrm{~h}$. Albumin-bound arachidonic acid (175 $\mu \mathrm{M}$; AA-solid line), or polyunsaturated fatty acidenriched chylomicron remnants (100 $\mu$ g triacylglycerol; PUFA CR-dashed line) were then added to the media and RNA was isolated after $0,2,4,8$, and $24 \mathrm{~h}$ (2 plates/treatment). RNA expression was determined by quantitative real-time RT-PCR relative to rat cyclophilin B. Values are expressed compared to cells treated with insulin. Each bar represents the mean $\pm \mathrm{SE}$ of $n=3$ independent primary hepatocyte isolations. B. Primary rat hepatocytes were incubated with $\mathrm{Hi} / \mathrm{Wo} / \mathrm{Ba}$ with or without insulin $(80 \mathrm{nM}$; I), albumin-bound fatty acid (175 $\mu \mathrm{M}$; AA, EPA, LIN), chylomicron remnants (100 $\mu \mathrm{g}$ triacylglycerol; CR), or chylomicrons (100 $\mu \mathrm{g}$ triacylglycerol; CM). Media was replaced every $12 \mathrm{~h}$ with one of identical composition, and RNA was isolated after $24 \mathrm{~h}$ with treatment ( 2 plates/treatment). RNA expression was determined by quantitative real-time RT-PCR relative to rat cyclophilin B. Values are expressed as the fold-increase over no addition (NA). $\left(^{*}\right) \mathrm{p}<0.05$, compared to cells treated with insulin, NS, not significant. Each bar represents the mean $\pm \mathrm{SE}$ of the indicated number of independent 
primary hepatocyte isolations: NA, INS, AA, $\mathrm{n}=8$; EPA, LIN, $\mathrm{n}=5$; PUFA CR, LARD CR, PUFA CM, LARD CM, n=8. G6PD, glucose-6-phosphate dehydrogenase; NA, no addition; I, insulin; AA, arachidonic acid; EPA, eicosapentaenoic acid; LIN, linoleic acid; PUFA CR, polyunsaturated fatty acid-enriched chylomicron remnants; LARD CR, saturated fatty acidenriched chylomicron remnants; PUFA CM, polyunsaturated fatty acid-enriched chylomicrons; LARD CM, saturated fatty acid-enriched chylomicrons.

\section{Figure 5. SREBP-1c is inhibited by polyunsaturated fatty acid-enriched chylomicron}

remnants. Primary rat hepatocytes were plated on collagen coated dishes and incubated in $\mathrm{Hi} / \mathrm{Wo} / \mathrm{Ba}$ medium. After $20 \mathrm{~h}$ in culture, the medium was replaced with $\mathrm{Hi} / \mathrm{Wo} / \mathrm{Ba}$ with or without insulin ( $80 \mathrm{nM}$; I), albumin-bound fatty acid (175 $\mu \mathrm{M}$; AA, EPA, LIN), chylomicron remnants (100 $\mu \mathrm{g}$ triacylglycerol; CR), or chylomicrons (100 $\mu \mathrm{g}$ triacylglycerol; CM). Media was replaced every $12 \mathrm{~h}$ with one of identical composition. A. RNA was isolated after $24 \mathrm{~h}$ in culture ( 2 plates/treatment). RNA expression was determined by quantitative real-time RT-PCR relative to rat cyclophilin B. Values are expressed as the fold-increase over no addition (NA). $\left(^{*}\right)$ $\mathrm{p}<0.05$, compared to cells treated with insulin, NS, not significant. Each bar represents the mean \pm SE of the indicated number of independent primary hepatocyte isolations: NA, INS, AA, $\mathrm{n}=8$; EPA, LIN, n=3; PUFA CR, n=6; LARD CR, PUFA CM, LARD CM, n=3. B. For measurement of mature SREBP-1c, cells were harvested and total cell lysates prepared 30 min after treatment (2 plates/treatment). Western analysis was performed using an antibody against total SREBP-1c (Santa Cruz). A representative blot is shown. Densitometry was performed with ImageQuant software (Molecular Dynamics), and values were calculated as arbitrary densitometric units of mature protein. $\left({ }^{*}\right) \mathrm{p}<0.05$ compared to cells treated with insulin. Each bar represents the mean \pm 
$\mathrm{SE}$ of $\mathrm{n}=3$ independent primary hepatocyte isolations. SREBP-1c, sterol regulatory element binding protein-1c; NA, no addition; AA, arachidonic acid; EPA, eicosapentaenoic acid; LIN, linoleic acid; PUFA CR, polyunsaturated fatty acid-enriched chylomicron remnants; LARD CR, saturated fatty acid-enriched chylomicron remnants; PUFA CM, polyunsaturated fatty acidenriched chylomicrons; LARD CM, saturated fatty acid-enriched chylomicrons.

\section{Figure 6. Polyunsaturated fatty acid-enriched chylomicron remnants inhibit the expression} of SREBP-1c dependent genes. Primary rat hepatocytes were plated on collagen coated dishes and incubated in $\mathrm{Hi} / \mathrm{Wo} / \mathrm{Ba}$ medium. After $20 \mathrm{~h}$ in culture, the medium was replaced with $\mathrm{Hi} / \mathrm{Wo} / \mathrm{Ba}$ with or without insulin (80 nM; I), albumin-bound fatty acid (175 $\mu \mathrm{M}$; AA, EPA, LIN), chylomicron remnants (100 $\mu \mathrm{g}$ triacylglycerol; CR), or chylomicrons (100 $\mu \mathrm{g}$ triacylglycerol; CM). Media was replaced every $12 \mathrm{~h}$ with one of identical composition, and RNA was isolated after $24 \mathrm{~h}$ of treatment (2 plates/treatment). RNA expression was determined by quantitative real-time RT-PCR relative to rat cyclophilin B. Values are expressed as the foldincrease over no addition (NA). $\left(^{*}\right) \mathrm{p}<0.05$, compared to cells treated with insulin, NS, not significant. Each bar represents the mean $\pm \mathrm{SE}$ of the indicated number of independent primary hepatocyte isolations: NA, INS, AA, n=8; EPA, LIN, n=5; PUFA CR, LARD CR, $n=8$; PUFA CM, LARD CM, n=6. FAS, fatty acid synthase; ACC-1, acetyl-CoA carboxylase-1; ATP-CL, ATP-citrate lyase; SCD, stearoyl -CoA desaturase 1; S14, spot 14; NA, no addition; AA, arachidonic acid; EPA, eicosapentaenoic acid; LIN, linoleic acid; PUFA CR, polyunsaturated fatty acid-enriched chylomicron remnants; LARD CR, saturated fatty acid-enriched chylomicron remnants; PUFA CM, polyunsaturated fatty acid-enriched chylomicrons; LARD CM, saturated fatty acid-enriched chylomicrons. 


\section{Figure 7. PUFA-enriched chylomicron remnants do not inhibit the expression of SREBP-1c}

independent genes. Primary rat hepatocytes were plated on collagen coated dishes and incubated in $\mathrm{Hi} / \mathrm{Wo} / \mathrm{Ba}$ medium. After $20 \mathrm{~h}$ in culture, the medium was replaced with $\mathrm{Hi} / \mathrm{Wo} / \mathrm{Ba}$ with or without insulin (80 nM; I), albumin-bound fatty acid (175 $\mu \mathrm{M}$; AA, EPA, LIN), chylomicron remnants (100 $\mu$ g triacylglycerol; CR), or chylomicrons (100 $\mu \mathrm{g}$ triacylglycerol; $\mathrm{CM})$. Media was replaced every $12 \mathrm{~h}$ with one of identical composition, and RNA was isolated after $24 \mathrm{~h}$ with treatment ( 2 plates/treatment). RNA expression was determined by quantitative real-time RT-PCR relative to rat cyclophilin B. Values are expressed as the fold-increase over no addition (NA). $\left(^{*}\right) \mathrm{p}<0.05$, compared to cells treated with insulin, NS, not significant. Each bar represents the mean $\pm \mathrm{SE}$ of the indicated number of independent primary hepatocyte isolations: NA, INS, AA, n=8; EPA, LIN, n=5; PUFA CR, LARD CR, n=8; PUFA CM, LARD CM, n=6. GK, glucokinase; Cyp-7 $\alpha$, cytochrome p450-7a; ME, malic enzyme; L-PK, liver pyruvate kinase; NA, no addition; AA, arachidonic acid; EPA, eicosapentaenoic acid; LIN, linoleic acid; PUFA CR, polyunsaturated fatty acid-enriched chylomicron remnants; LARD CR, saturated fatty acid-enriched chylomicron remnants; PUFA CM, polyunsaturated fatty acid-enriched chylomicrons; LARD CM, saturated fatty acid-enriched chylomicrons.

Supplemental Figure S1. Primary rat hepatocytes were plated on collagen coated dishes and incubated in $\mathrm{Hi} / \mathrm{Wo} / \mathrm{Ba}$ medium. After $20 \mathrm{~h}$ in culture, the medium was replaced with $\mathrm{Hi} / \mathrm{Wo} / \mathrm{Ba}$ with insulin (80 nM; I) and polyunsaturated fatty acid-enriched chylomicron remnants (25-100 $\mu \mathrm{g}$ triacylglycerol; PUFA CR). Media was replaced every $12 \mathrm{~h}$ with one of identical composition, and RNA was isolated after $24 \mathrm{~h}$ with treatment ( 2 plates/treatment). RNA 
expression was determined by quantitative real-time RT-PCR relative to rat cyclophilin B. Values are expressed compared to treatment with insulin. Each bar represents the mean $\pm \mathrm{SE}$ of $\mathrm{n}=3$ independent primary hepatocyte isolations. G6PD, glucose-6-phosphate dehydrogenase. 
Figure 1A.

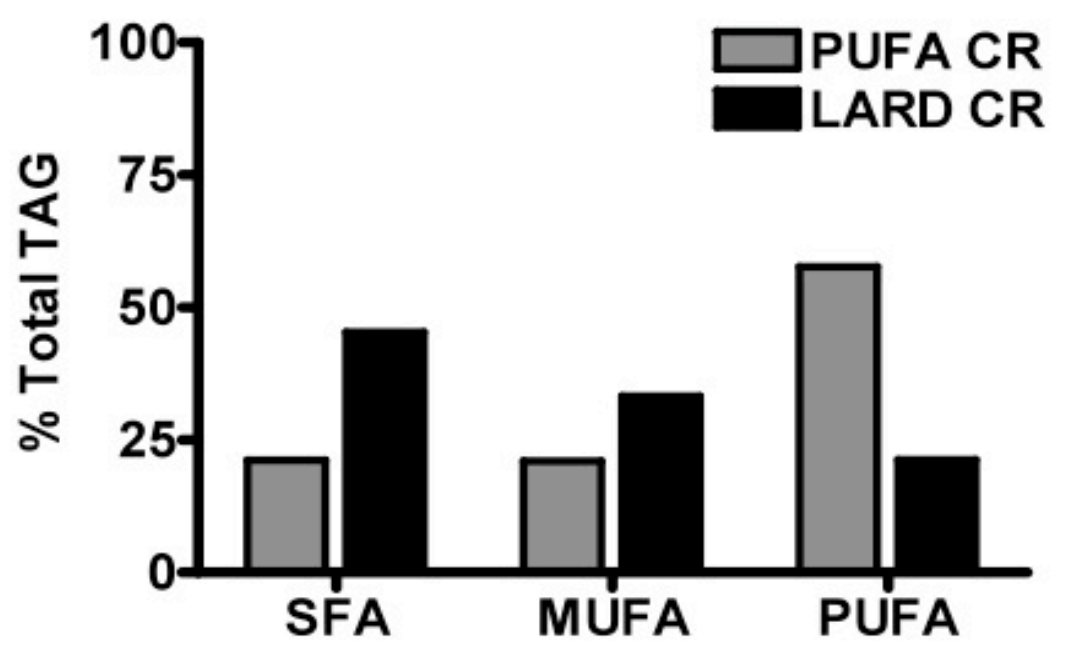

Figure 1B.

\begin{tabular}{|l|c|c|}
\hline \multirow{2}{*}{$\begin{array}{c}\text { TYPE OF } \\
\text { PUFA }\end{array}$} & PUFA CR & LARD CR \\
\cline { 2 - 3 } & \multicolumn{2}{|c|}{$\%$ total triacylglycerol } \\
\hline n-3 & 1.9 & 1.2 \\
\hline n-6 & 55.9 & 20.1 \\
\hline n-7 & 1.4 & 3.5 \\
\hline n-9 & 19.5 & 29.8 \\
\hline
\end{tabular}


Figure 2A.

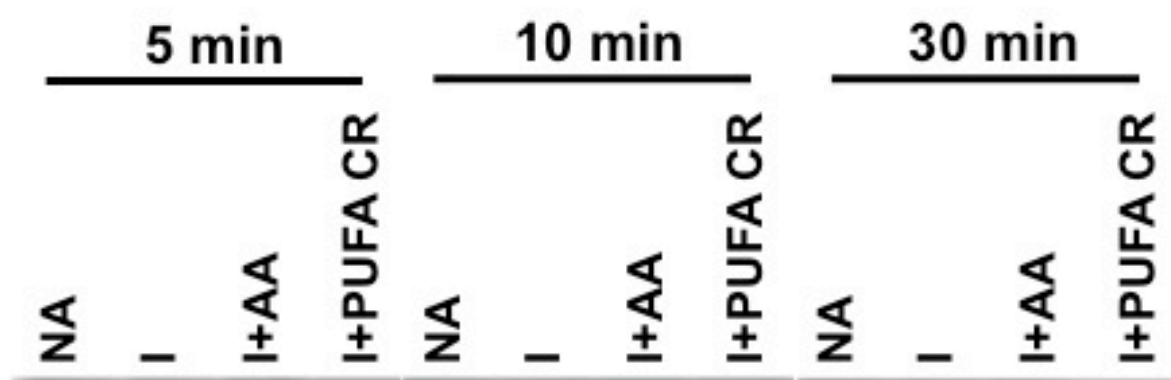

P-p38

p38

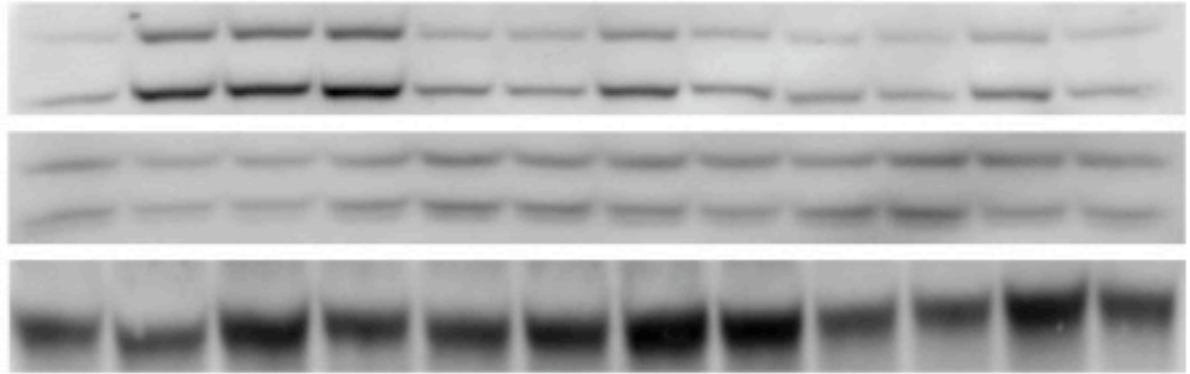

P-ERK

ERK

P-AMPK

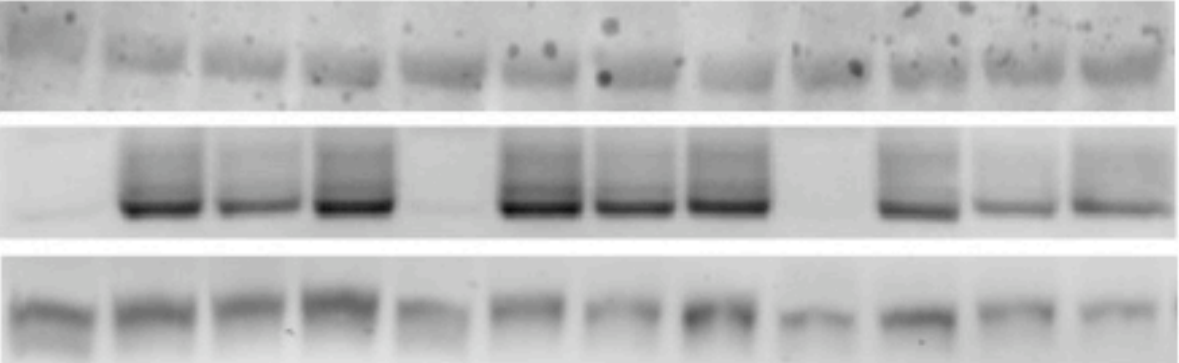

AMPK

P-AKT

AKT 
Figure 2B.
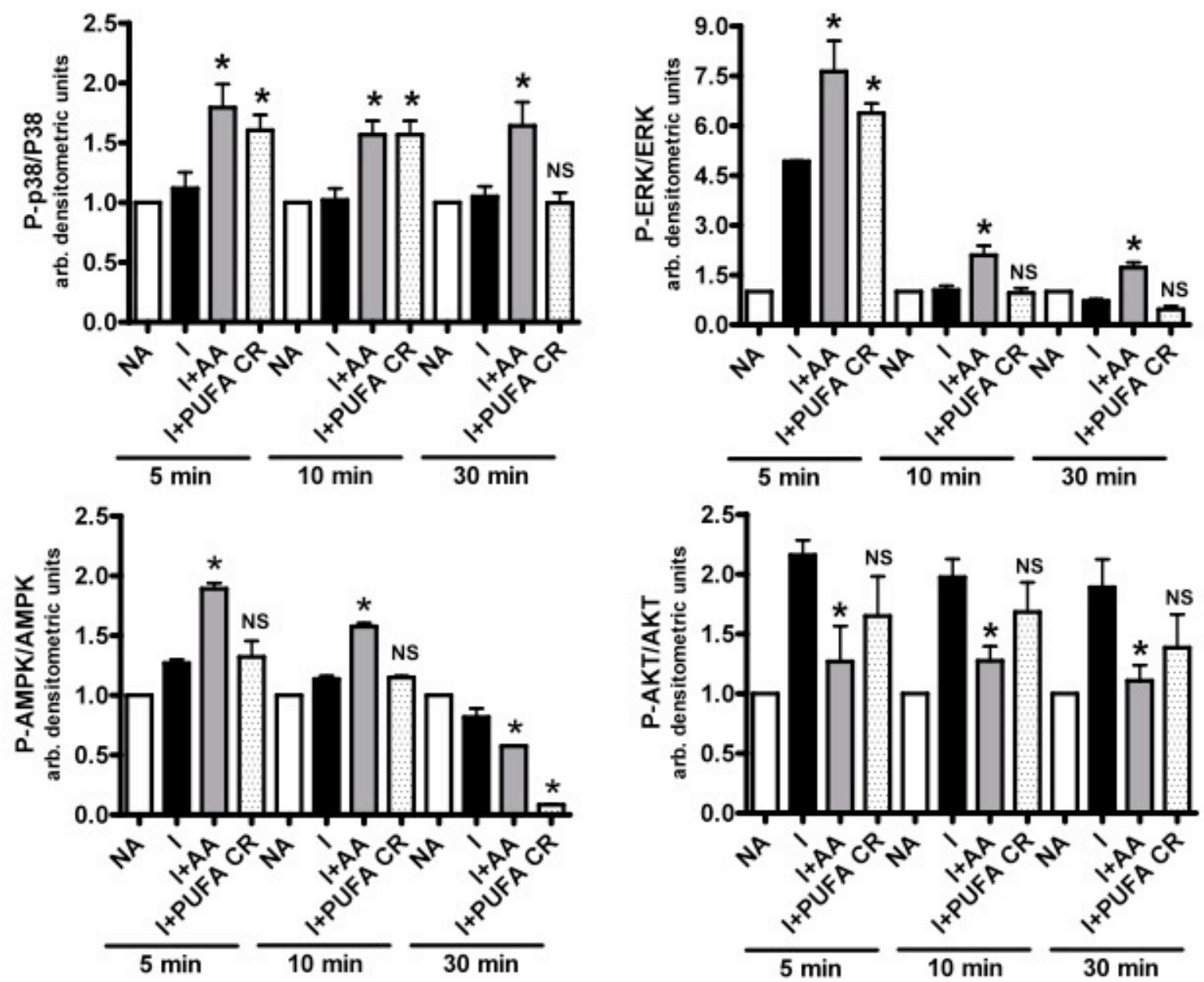

Figure 2C.
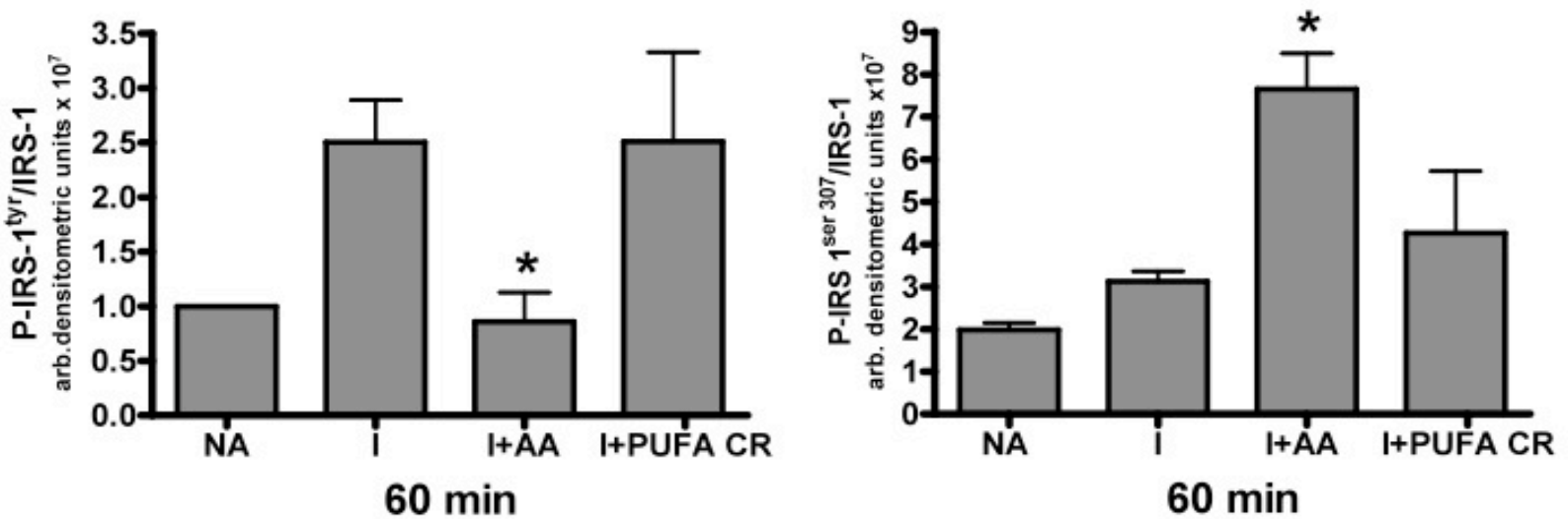
Figure 3.

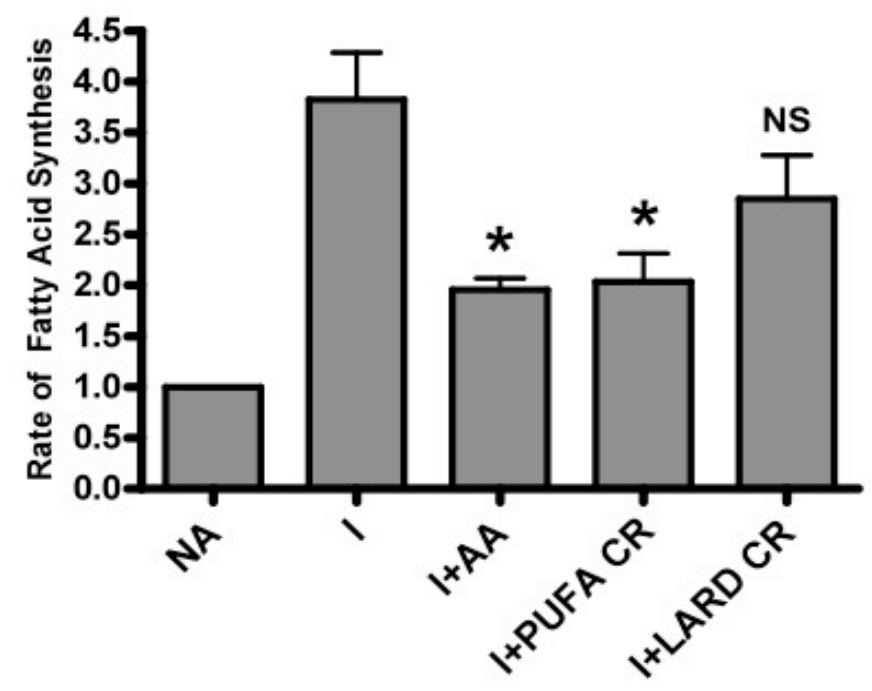


Figure 4A.

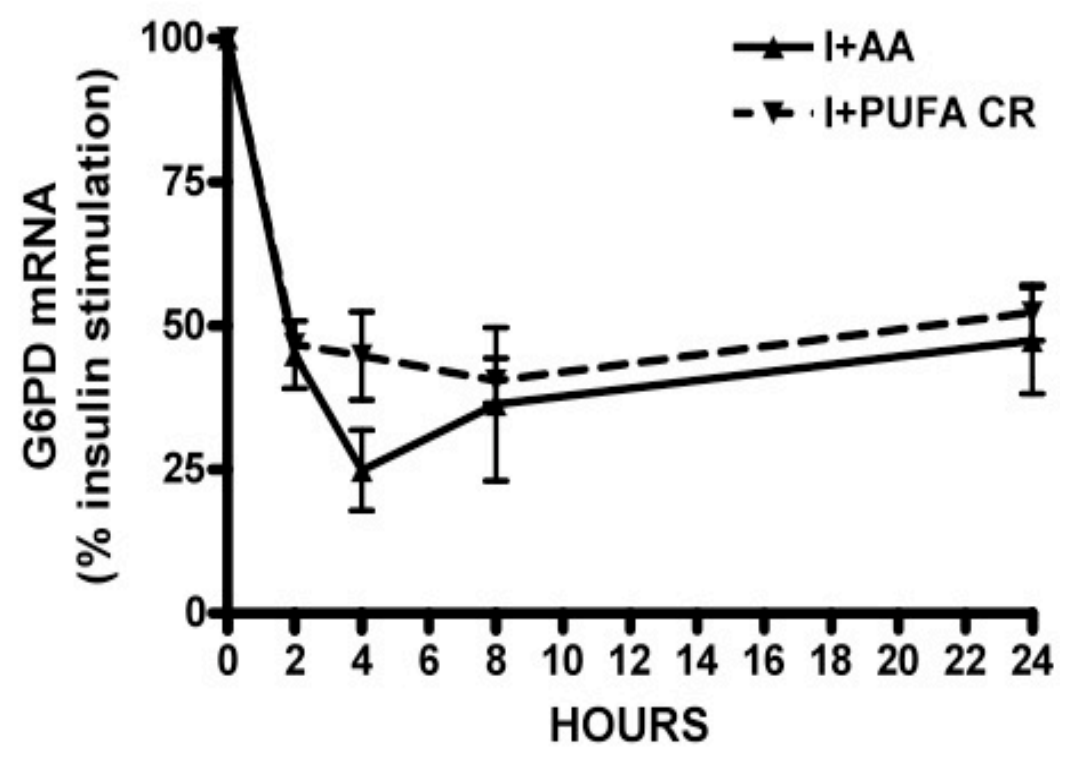

Figure 4B.

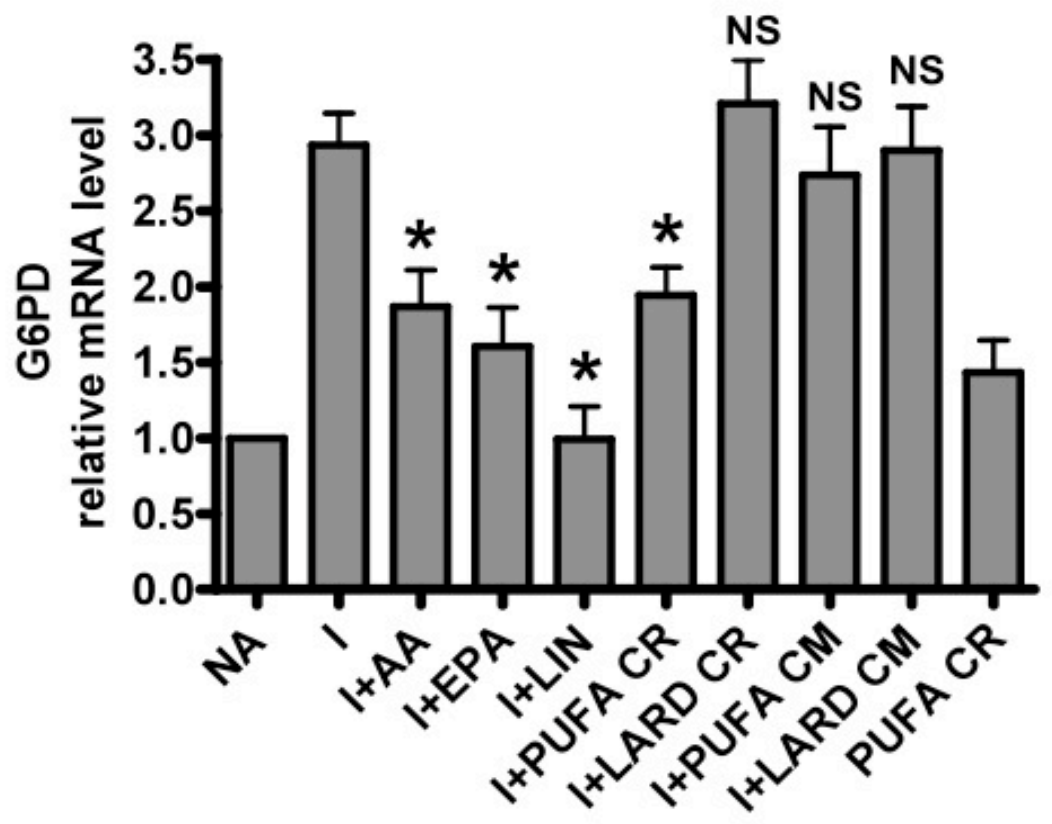


Figure 5A.

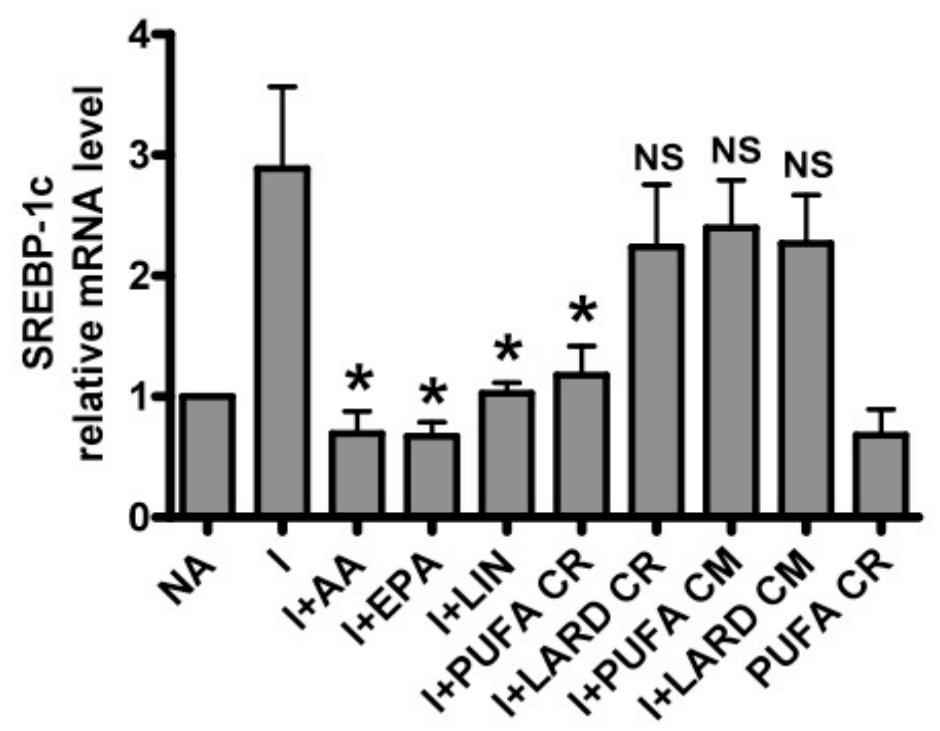

Figure 5B.

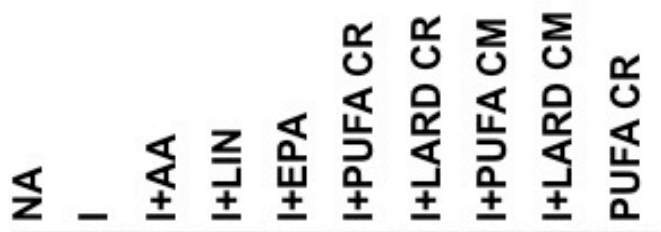

mSREBP-1c

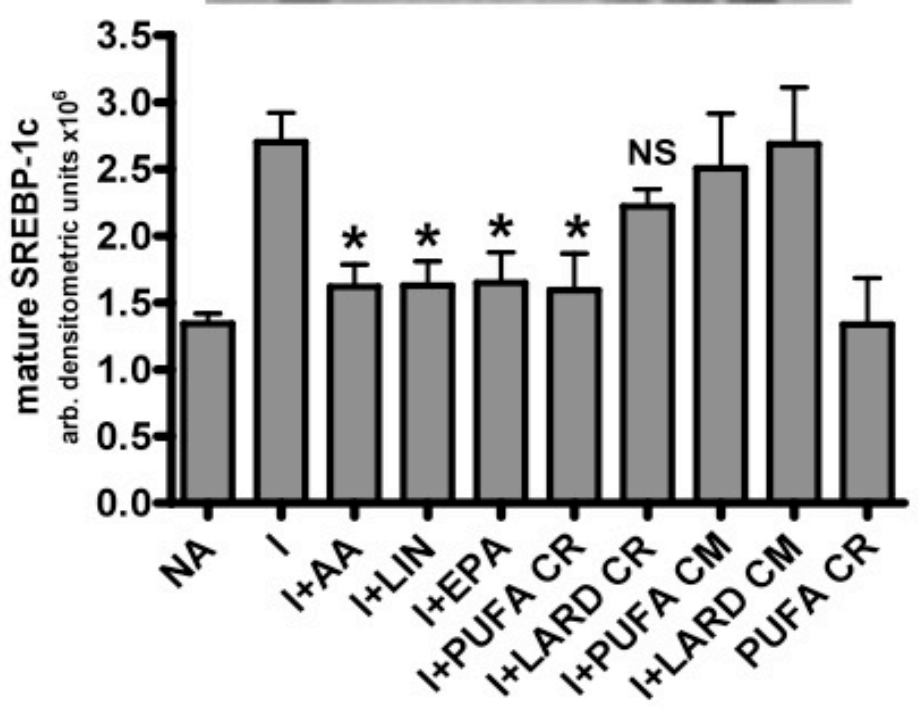


Figure 6.
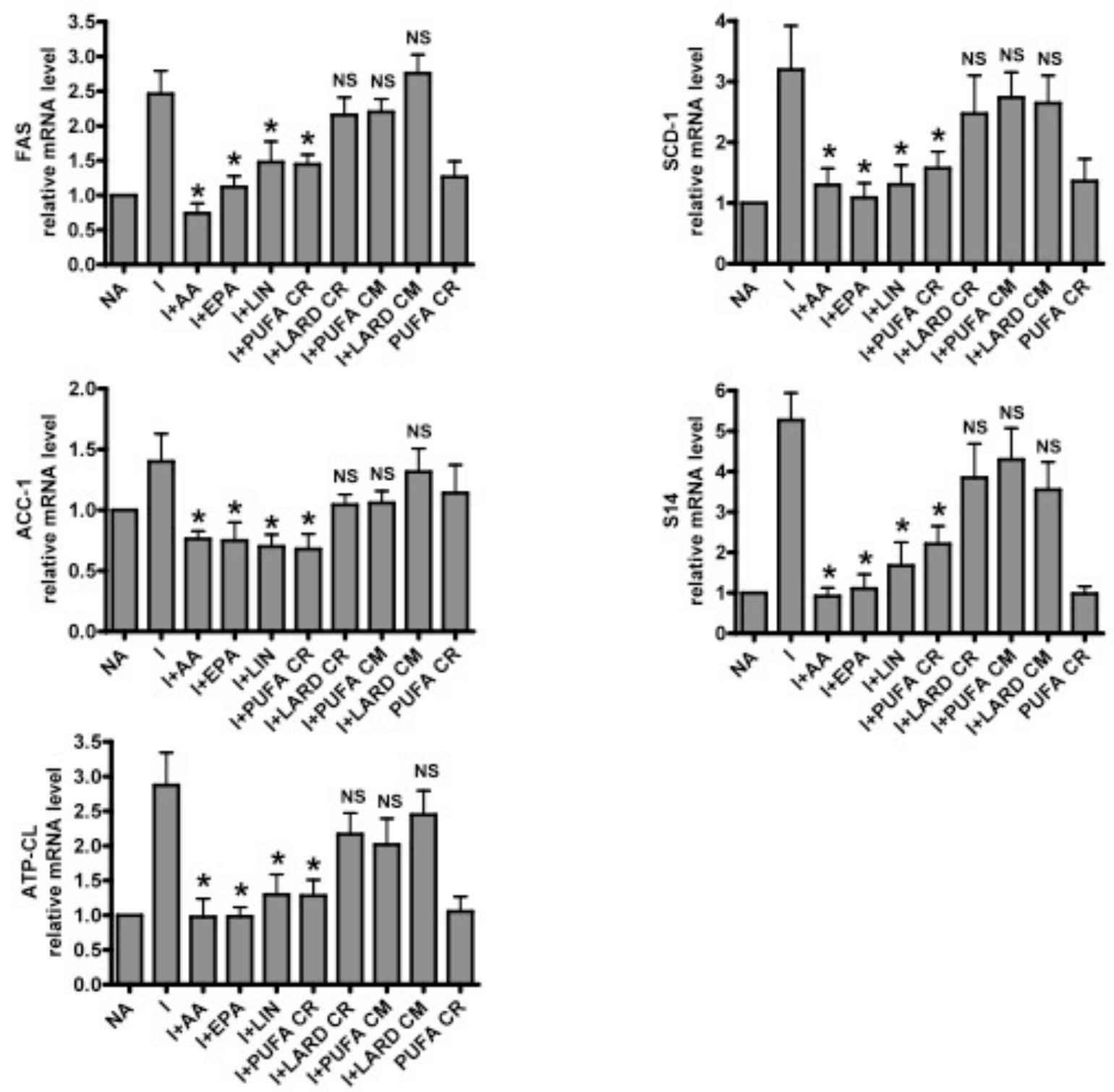
Figure 7.
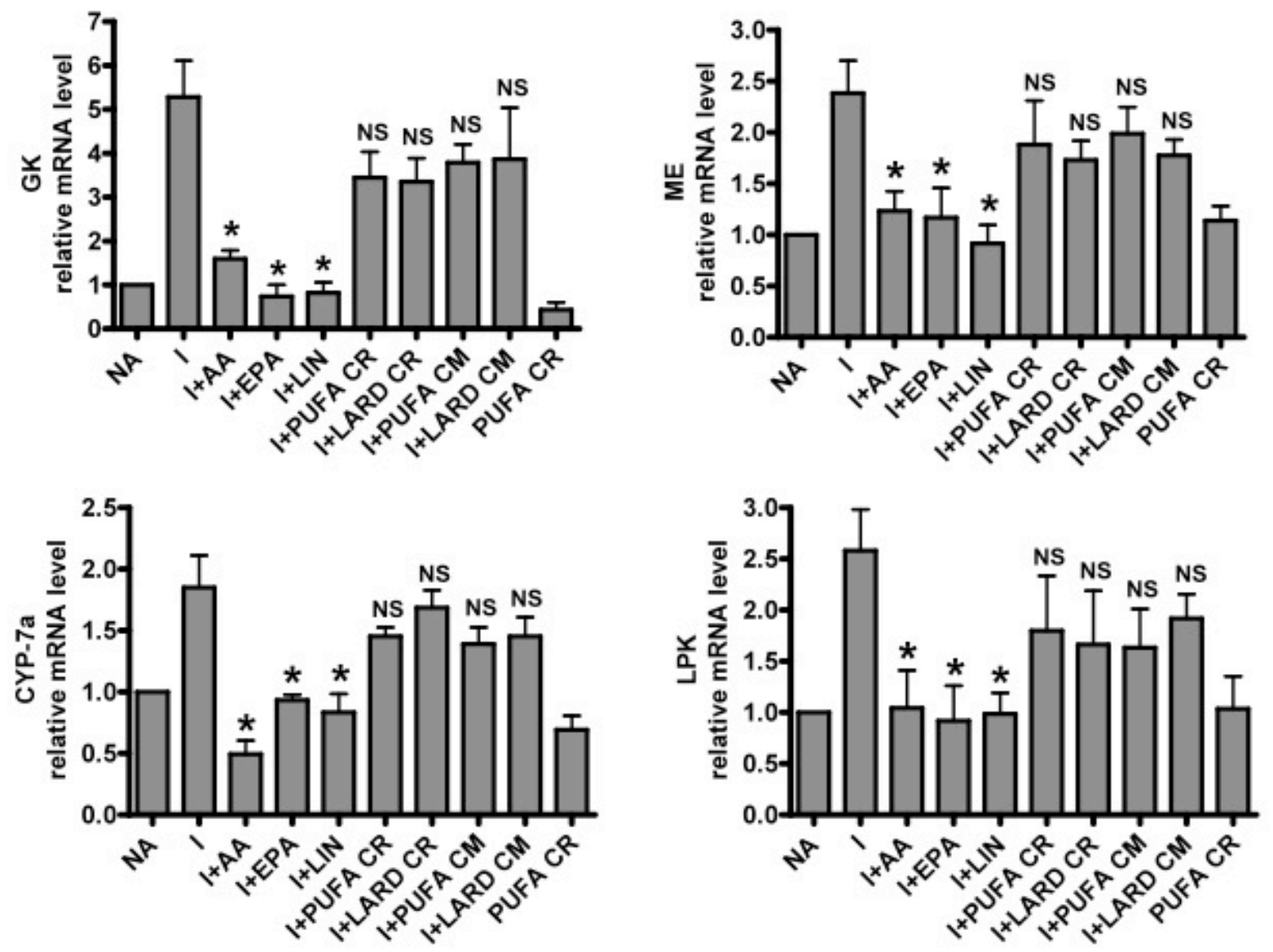


\section{Supplemental Figure S1.}

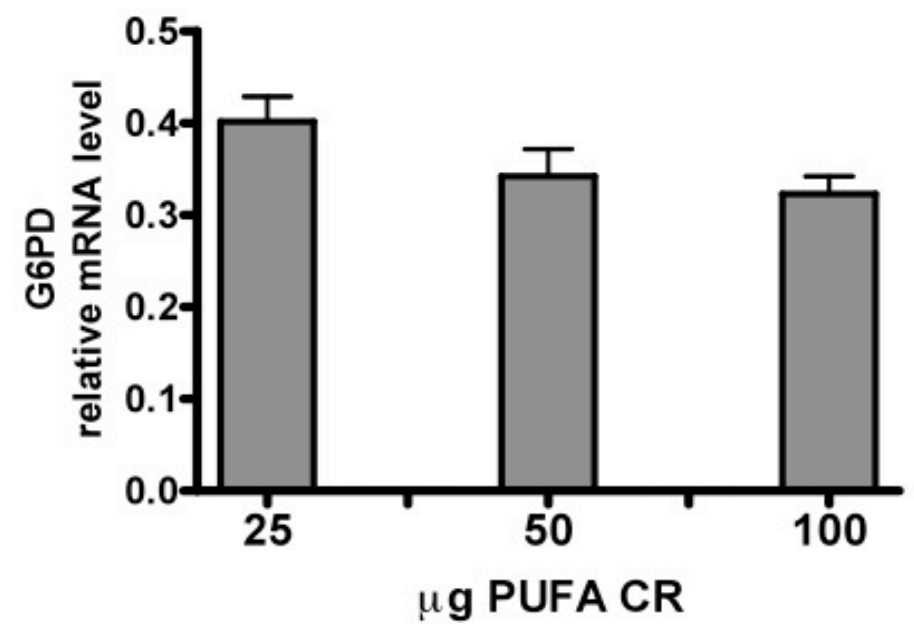


Supplemental Table S1. Primers Used in Quantitative RT-PCR Analysis. Primers to rat mRNA sequences were designed and synthesized using PrimerQuest (Integrated DNA Technologies). The specificity of primers was verified by BLAST analysis, visualization of RTPCR products by ethidium bromide staining after agarose gel electrophoresis, and by melt curve analysis of PCR products.

mRNA

Acetyl-CoA carboxylase-1

ATP-citrate lyase

Cyclophilin B

Cyp7a

Fatty acid synthase

Glucokinase

Glucose 6-phosphate

dehydrogenase

Malic enzyme

Pyruvate kinase, liver

Spot-14

Stearoyl-CoA desaturase-1

Sterol regulatory element binding protein-1c

\section{Primers}

sense, 5'-AGGGCAAAGGGACTGGTGTTCAGAT-3' antisense, 5'-GCCAACGGAGATGGTTCATCCATTA-3'

sense, 5'-TGGTTTCATCGGCGTTGCGTTT -3'

antisense, 5'-TTGGCTTTCCATGCCTGCACAT-3'

sense, 5'-CGTGGGCTCCGTTGTCTT-3'

antisense, 5'-TGACTTTAGGTCCCTTCTTCTTATC

sense, 5'-CCTTTGGAGAACGGGTTGATT-3'

antisense, 5'-CAGGGAGTTTGTGATGAAATGG-3'

sense, 5'-TGCAACTGTGCGTTAGCCACC-3' antisense, 5'-TGTTTCAGGGGAGAAGAGACC-3'

sense, 5'-GGAGACTTTCTCTCCTTAAGAC-3' antisense, 5'-ATTGGCGGTCTTCATAGTAGC-3'

sense, 5'-TATGTCTATGGCAGCCGAGGT-3' antisense, 5'- GCAGAGTGCAGATGGTGTAAG -3'

sense, 5'-TTGTTGCCACCCTGCATTGTCA-3' antisense, 5'-ACAACATCTTCTGGCCATGCGT-3'

sense, 5'-GATGAAATTCTAGAAG-3'

antisense, 5'-GCTTCGTCAGCACGATG-3'

sense, 5'-CAGGAGGTGACGCAGAAATAC-3' antisense, 5'-GTGAGGTAAATACAGCGTCCC-3'

sense, 5'-AGCTCAGCCAAATGCTGTGTTGTC-3' antisense, 5'-TGCCTTGATCAGTCACAGACACCT-3'

sense, 5'-ACGACGGAGCCATGGATTGCAC-3' antisense, 5'-CCGGAAGGCAGGCTTGAGTACC-3' 
Supplemental Table S2. Fatty acid composition of safflower oil and lard. Approximate composition of these dietary fats are reproduced here from a published source (40).

\begin{tabular}{lll}
\hline Fatty Acid & Safflower Oil & Lard \\
\hline \multicolumn{3}{c}{ \% of total fatty acids } \\
\hline 12:10:0 & & 0.1 \\
$14: 0$ & 0.1 & 0.1 \\
$16: 0$ & 6.5 & 1.5 \\
$16: 1$ & & 24.8 \\
$18: 0$ & 2.4 & 3.1 \\
$18: 1$ & 13.1 & 12.3 \\
$18: 2$ & 77.7 & 45.1 \\
$18: 3$ & & 9.9 \\
other & 0.2 & 1.1 \\
\hline
\end{tabular}




\section{APPENDIX.}

Figure 1. Effect of chylomicron remnants on potential PPAR-a target genes. Primary rat hepatocytes were plated on collagen-coated plates in $\mathrm{Hi} / \mathrm{Wo} / \mathrm{Ba}$ medium supplemented with $5 \%$ newborn calf serum. $2 \mathrm{~h}$ later, the medium was removed and hepatocytes received Matrigel $\AA^{\text {in }}$ serum-free $\mathrm{Hi} / \mathrm{Wo} / \mathrm{Ba}$ medium. $20 \mathrm{~h}$ after plating, medium was replaced (without Matrigel) and hepatocytes were treated with or without $80 \mathrm{nM}$ insulin, $175 \mathrm{mM}$ arachidonic acid, eicosapentaenoic acid (EPA), linoleic acid (LIN), or $100 \mu \mathrm{g}$ chylomicron remnants (CR) or chylomicrons (CM). Media was replaced every $12 \mathrm{~h}$ complete with treatments, and RNA was isolated after $24 \mathrm{~h}$ in culture. RNA expression was determined by quantitative Real Time RT$\mathrm{PCR}$, and is expressed relative to rat cyclophilin B. Each bar represents the mean $\pm \operatorname{SE}$ of $n=4$ independent primary hepatocyte isolations, with the exception of eicosapentaenoic and linoleic acid treatments, where $\mathrm{n}=2$.
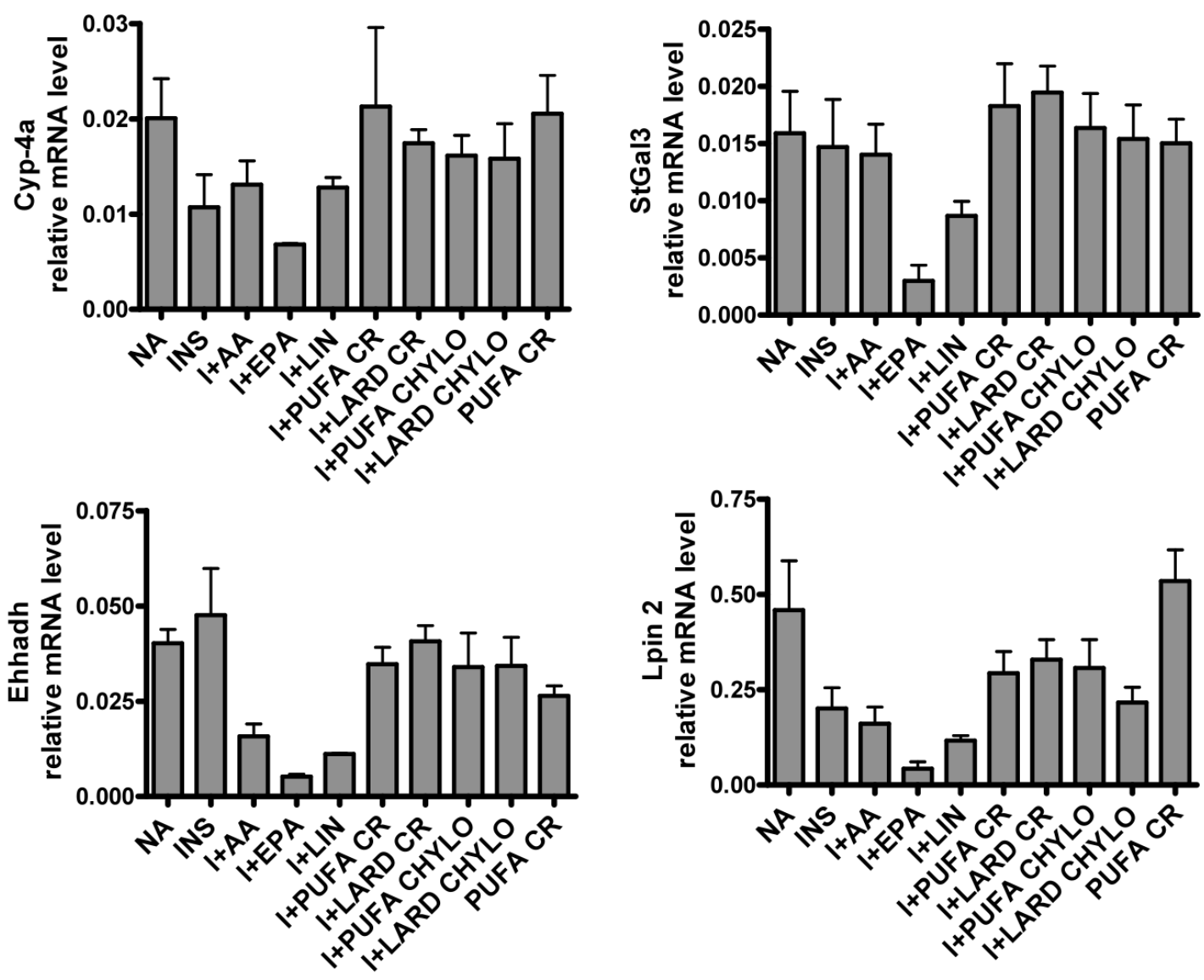
Figure 2. Effect of chylomicron remnants on PPAR-a target genes. Primary rat hepatocytes were plated on collagen-coated plates in $\mathrm{Hi} / \mathrm{Wo} / \mathrm{Ba}$ medium supplemented with $5 \%$ newborn calf serum. $2 \mathrm{~h}$ later, the medium was removed and hepatocytes received Matrigel $\AA^{\circledR}$ in serum-free $\mathrm{Hi} / \mathrm{Wo} / \mathrm{Ba}$ medium. $20 \mathrm{~h}$ after plating, medium was replaced (without Matrigel) and hepatocytes were treated with or without $80 \mathrm{nM}$ insulin, $175 \mathrm{mM}$ arachidonic acid, eicosapentaenoic acid (EPA), linoleic acid (LIN), or $100 \mu \mathrm{g}$ chylomicron remnants (CR) or chylomicrons (CM). Media was replaced every $12 \mathrm{~h}$ complete with treatments, and RNA was isolated after $24 \mathrm{~h}$ in culture. RNA expression was determined by quantitative Real Time RT-PCR, and is expressed relative to rat cyclophilin B. Each bar represents the mean $\pm \mathrm{SE}$ of $n=4$ independent primary hepatocyte isolations.
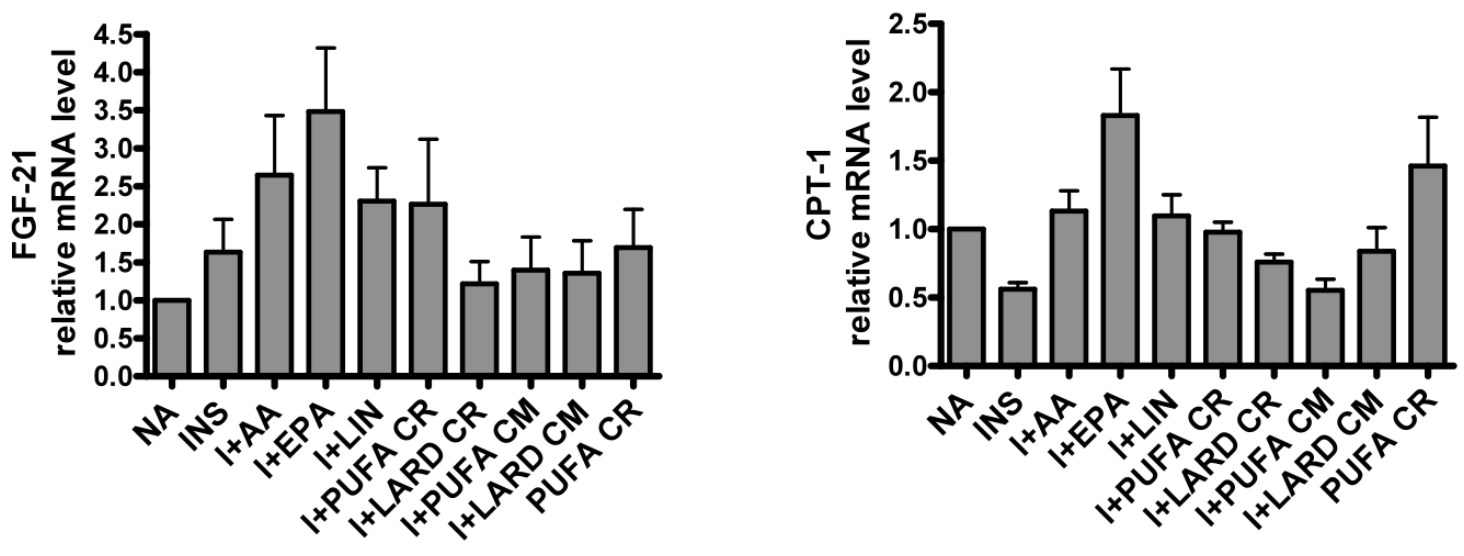
Figure 3. Effect of constitutively-active AKT on lipogenic mRNA. Primary rat hepatocytes were plated on collagen coated dishes and incubated in $\mathrm{Hi} / \mathrm{Wo} / \mathrm{Ba}$ medium. After $2 \mathrm{~h}$ in culture, hepatocytes were infected with 1,5 , and 10 infectious units/cell of either constitutively-active AKT expressing adenovirus (CA-AKT) or control adenovirus expressing GFP. After $2 \mathrm{~h}$, cells were washed twice, and media was replaced with one containing Matrigel. After $20 \mathrm{~h}$ in culture, the medium was replaced with $\mathrm{Hi} / \mathrm{Wo} / \mathrm{Ba}$ with or without insulin $(40 \mathrm{nM}$; I) and arachidonic acid $(175 \mu \mathrm{M} ; \mathrm{AA})$. For isolation of mRNA, media was replaced every $12 \mathrm{~h}$ with one of identical composition, and RNA was isolated after $24 \mathrm{~h}$ of treatment (2 plates/treatment). G6PD mRNA abundance is calculated relative to rat cyclophilin B. Values are expressed as the fold-increase over no addition (NA). Each bar represents the mean $\pm S E$ of $n=3$ independent primary hepatocyte isolations.
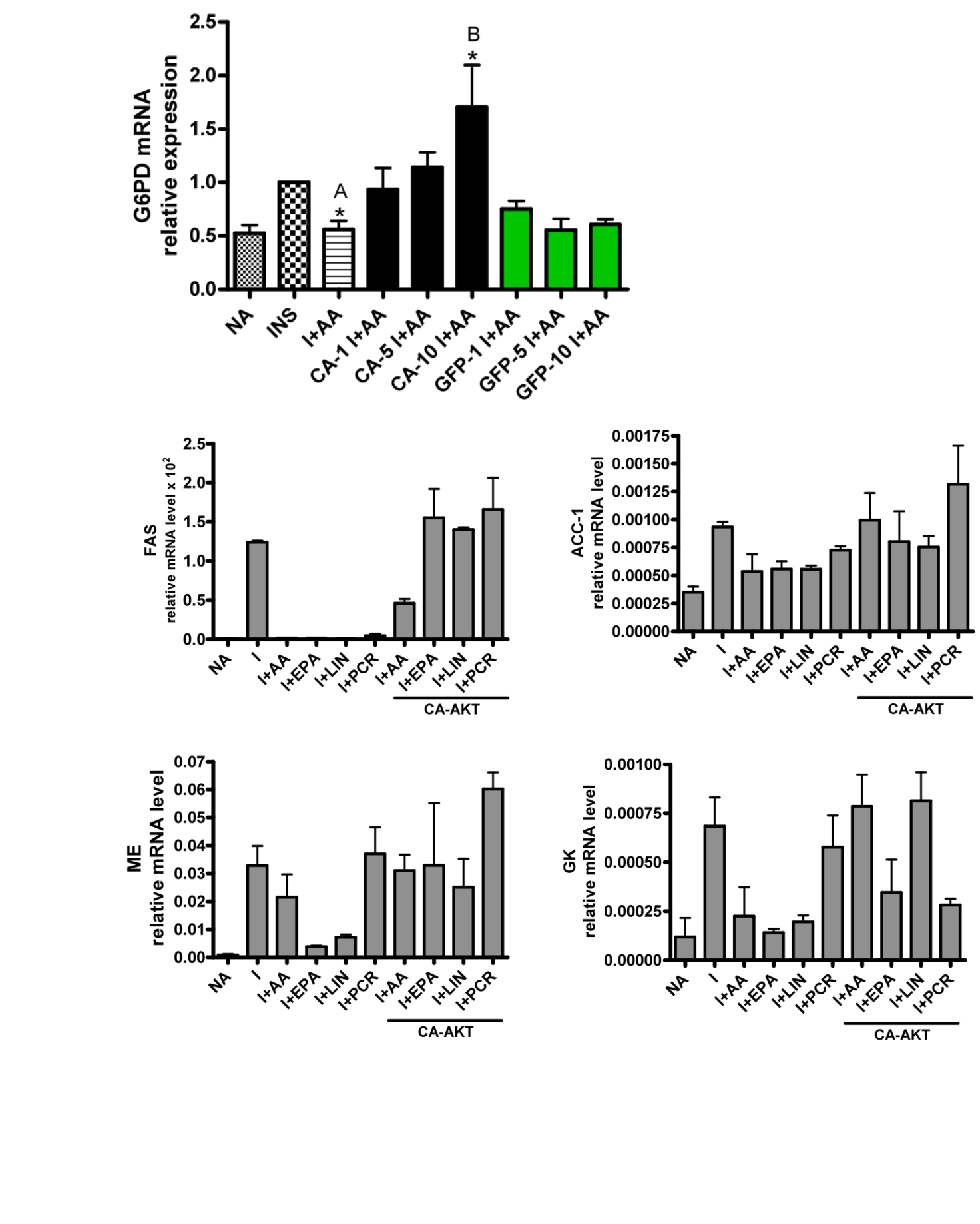